Florida International University FIU Digital Commons

$10-21-2013$

\title{
Comprehensive Forensic Toxicological Analysis of Designer Drugs
}

Madeleine Jean Swortwood

Florida International University, swortwoodm@gmail.com

DOI: $10.25148 /$ etd.FI13120611

Follow this and additional works at: https://digitalcommons.fiu.edu/etd

Part of the Analytical Chemistry Commons, and the Toxicology Commons

\section{Recommended Citation}

Swortwood, Madeleine Jean, "Comprehensive Forensic Toxicological Analysis of Designer Drugs" (2013). FIU Electronic Theses and Dissertations. 997.

https://digitalcommons.fiu.edu/etd/997

This work is brought to you for free and open access by the University Graduate School at FIU Digital Commons. It has been accepted for inclusion in FIU Electronic Theses and Dissertations by an authorized administrator of FIU Digital Commons. For more information, please contact dcc@fiu.edu. 


\section{FLORIDA INTERNATIONAL UNIVERSITY \\ Miami, Florida}

COMPREHENSIVE FORENSIC TOXICOLOGICAL ANALYSIS OF DESIGNER DRUGS

A dissertation submitted in partial fulfillment of

the requirements for the degree of

DOCTOR OF PHILOSOPHY

in

CHEMISTRY

by

Madeleine Jean Swortwood 
To: $\quad$ Dean Kenneth Furton

College of Arts and Sciences

This dissertation, written by Madeleine Jean Swortwood, and entitled Comprehensive Forensic Toxicological Analysis of Designer Drugs, having been approved in respect to style and intellectual content, is referred to you for judgment.

We have read this dissertation and recommend that it be approved.

$\begin{array}{r}\hline \text { Piero Gardinali } \\ \hline \text { W. Lee Hearn } \\ \hline \text { Jaroslava Mikšovská } \\ \hline \text { Georg Petroianu } \\ \hline \text { Anthony DeCaprio, Major Professor }\end{array}$

Date of Defense: October 21, 2013

The dissertation of Madeleine Jean Swortwood is approved.

$\begin{array}{r}\hline \begin{array}{r}\text { Dean Kenneth Furton } \\ \text { College of Arts and Sciences }\end{array} \\ \hline \begin{array}{r}\text { Dean Lakshmi N. Reddi } \\ \text { University Graduate School }\end{array}\end{array}$

Florida International University, 2013 
Copyright (C) 2013 by Madeleine Jean Swortwood Copyright (C) 2013 John Wiley \& Sons, Ltd.

Swortwood, M. J., Hearn, W. L., DeCaprio, A. P. (2013) Cross-reactivity of designer drugs, including cathinone derivatives, in commercial enzyme-linked immunosorbent assays. Drug Test. Anal. DOI 10.1002/dta.1489

Copyright (C) 2012 Springer-Verlag Berlin Heidelberg

Swortwood, M. J., Boland, D. M., DeCaprio, A. P. (2012) Determination of 32 cathinone derivatives and other designer drugs in serum by comprehensive LC-QQQ-MS/MS analysis. Anal. Bioanal. Chem. 405, 1383. DOI 10.1007/s00216-012-6548-8

All rights reserved. 


\section{ACKNOWLEDGMENTS}

I would first like to thank my friends, family, and lab-mates (especially V\$ and K) for their support and encouragement during my time at FIU. I would also like to extend my gratitude to Dr. Piero Gardinali, Dr. Lee Hearn, Dr. Jaroslava Mikšovská, and Dr. Georg Petroianu for sharing their knowledge and expertise with me while serving on my dissertation committee. In addition, I want to thank Dr. Anthony DeCaprio for allowing me to pursue my research goals in his lab and providing me the opportunities to succeed. I also want to personally thank Dr. Mark Witkowski for encouraging me to not only enroll in a $\mathrm{PhD}$ program but to stick with it when the going got tough. I want to express thanks to Agilent Technologies for the opportunities to utilize their instrumentation for research purposes and to take my new-found expertise to conferences both nationally and internationally. I would like to acknowledge the National Institute of Justice in awarding a grant, 2011-DN-BX-K559, to fund my research efforts. I also want to show my appreciation for Dr. Hearn, Dr. Boland, Buzz Hime, and all of the toxicologists at the Miami-Dade Medical Examiner Laboratory for their continued guidance, support, teaching, and friendship throughout my internship and employment with their department. 


\section{ABSTRACT OF THE DISSERTATION \\ COMPREHENSIVE FORENSIC TOXICOLOGICAL ANALYSIS OF DESIGNER \\ DRUGS \\ by \\ Madeleine Jean Swortwood}

Florida International University, 2013

Miami, Florida

\section{Professor Anthony DeCaprio, Major Professor}

New designer drugs are constantly emerging onto the illicit drug market and it is often difficult to validate and maintain comprehensive analytical methods for accurate detection of these compounds. Generally, toxicology laboratories utilize a screening method, such as immunoassay, for the presumptive identification of drugs of abuse. When a positive result occurs, confirmatory methods, such as gas chromatography (GC) or liquid chromatography (LC) coupled with mass spectrometry (MS), are required for more sensitive and specific analyses. In recent years, the need to study the activities of these compounds in screening assays as well as to develop confirmatory techniques to detect them in biological specimens has been recognized. Severe intoxications and fatalities have been encountered with emerging designer drugs, presenting analytical challenges for detection and identification of such novel compounds. The first major task of this research was to evaluate the performance of commercially available immunoassays to determine if designer drugs were cross-reactive. The second major task was to develop and validate a confirmatory method, using LC-MS, to identify and quantify these designer drugs in biological specimens. 
Cross-reactivity towards the cathinone derivatives was found to be minimal. Several other phenethylamines demonstrated cross-reactivity at low concentrations, but results were consistent with those published by the assay manufacturer or as reported in the literature. Current immunoassay-based screening methods may not be ideal for presumptively identifying most designer drugs, including the "bath salts." For this reason, an LC-MS based confirmatory method was developed for 32 compounds, including eight cathinone derivatives, with limits of quantification in the range of 1-10 $\mathrm{ng} / \mathrm{mL}$. The method was fully validated for selectivity, matrix effects, stability, recovery, precision, and accuracy. In order to compare the screening and confirmatory techniques, several human specimens were analyzed to demonstrate the importance of using a specific analytical method, such as LC-MS, to detect designer drugs in serum as immunoassays lack cross-reactivity with the novel compounds. Overall, minimal crossreactivity was observed, highlighting the conclusion that these presumptive screens cannot detect many of the designer drugs and that a confirmatory technique, such as the LC-MS, is required for the comprehensive forensic toxicological analysis of designer drugs. 


\section{TABLE OF CONTENTS}

CHAPTER

PAGE

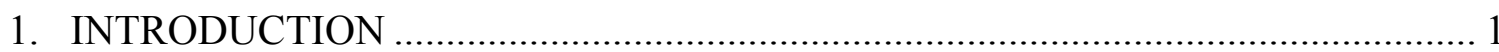

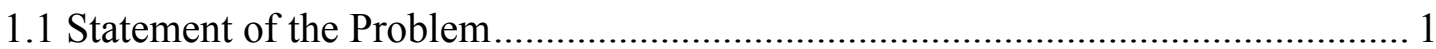

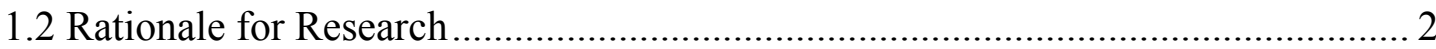

1.3 Significance of Study .................................................................................... 3

1.3.1 Task 1 - Determination of cross-reactivity of designer drugs ................... 6

1.3.2 Task 2 - Development of a comprehensive LC-MS method...................... 6

1.3.3 Task 3 - Application of the developed techniques to forensic samples .... 6

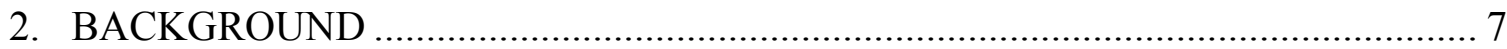

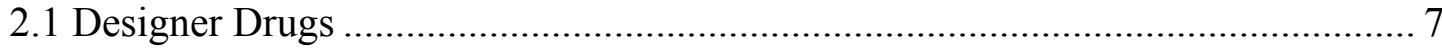

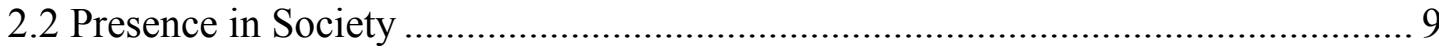

2.3 Analysis of Drugs of Abuse in Biological Specimens......................................... 11

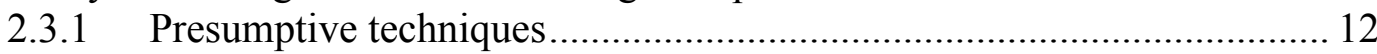

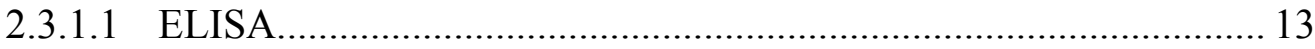

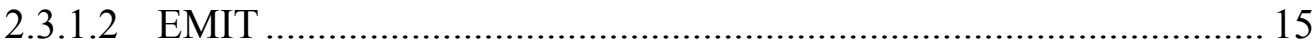

2.3.2 Confirmatory techniques ...................................................................... 16

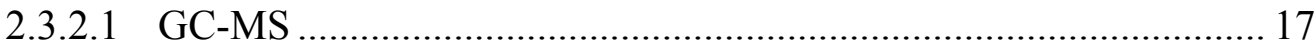

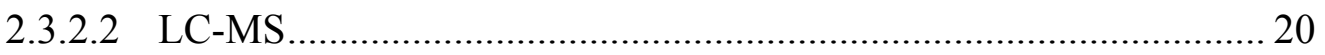

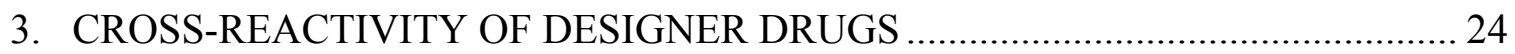

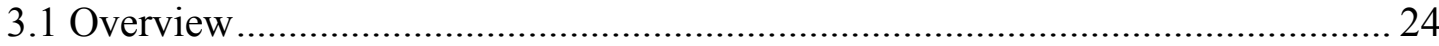

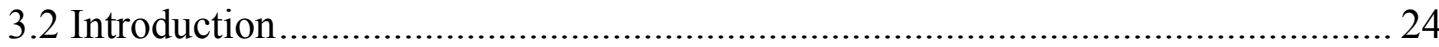

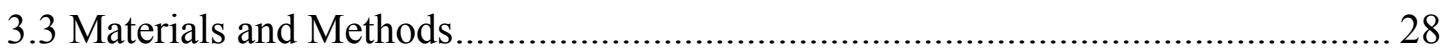

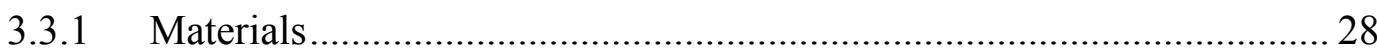

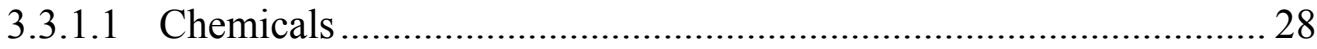

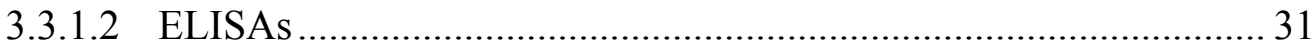

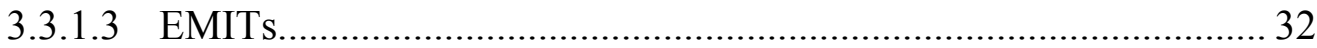

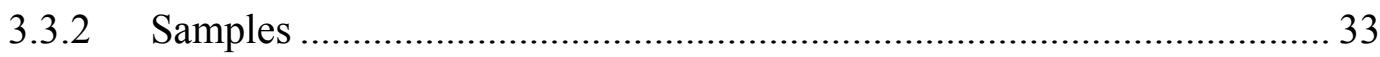

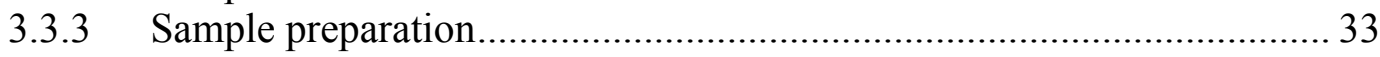

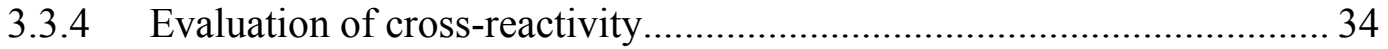

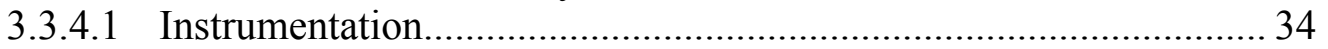

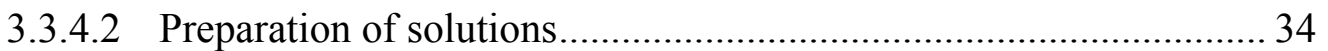

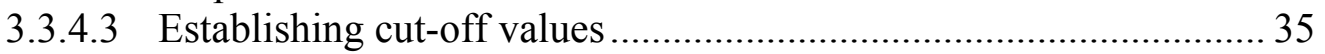

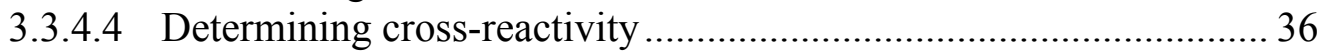

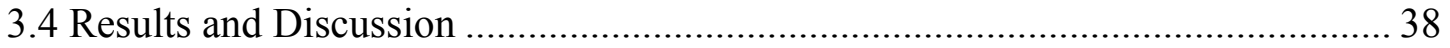

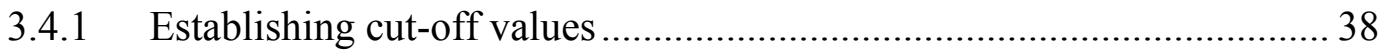

3.4.2 Determining cross-reactivity ............................................................. 40

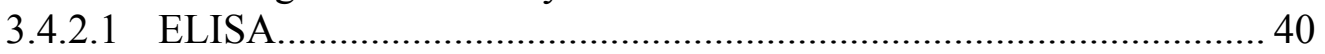

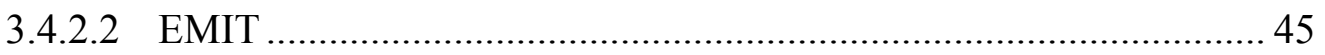

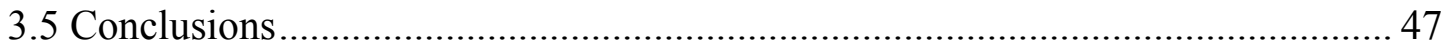




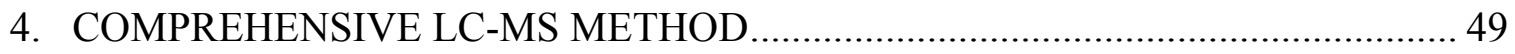

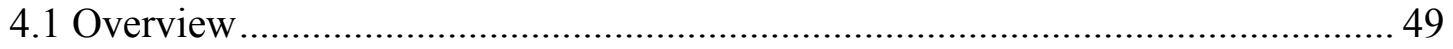

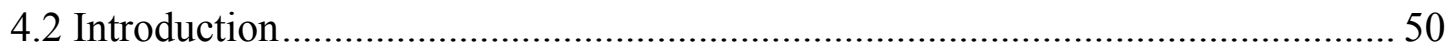

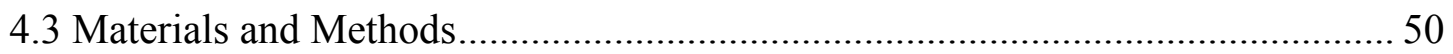

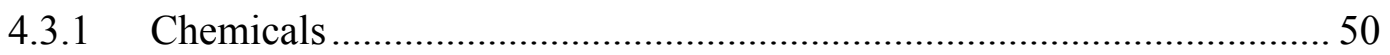

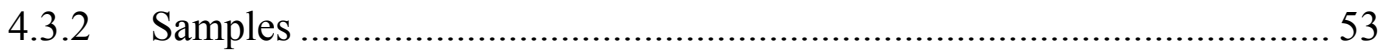

4.3.3 Sample Preparation .................................................................... 53

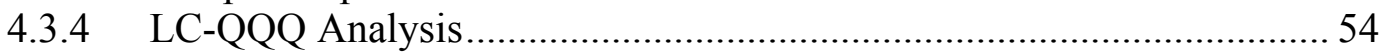

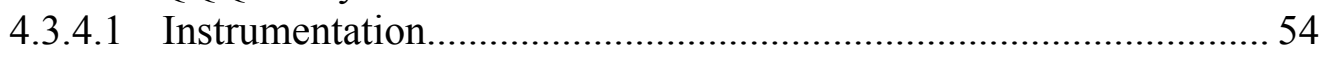

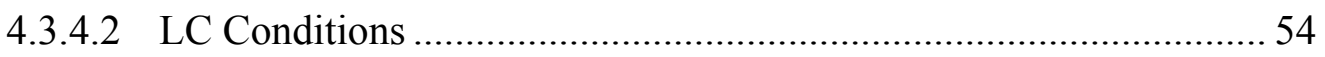

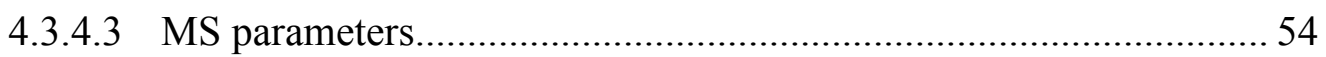

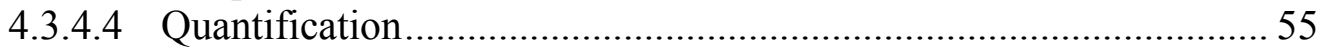

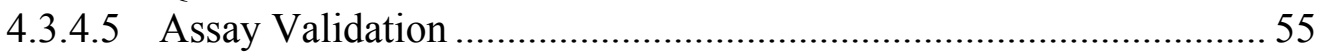

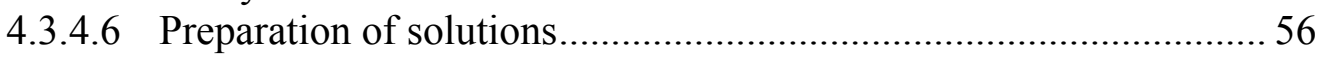

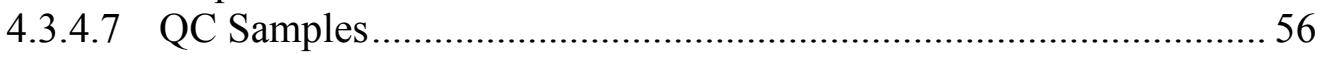

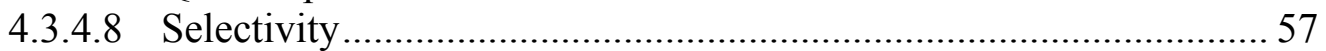

4.3.4.9 Matrix effects, recovery, and process efficiency.............................. 57

4.3.4.10 Processed sample stability ………………….............................. 58

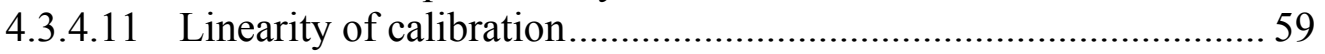

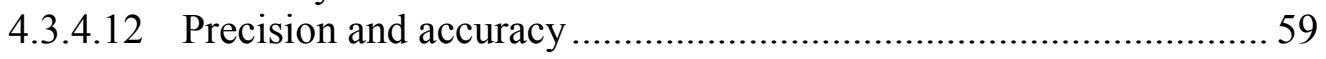

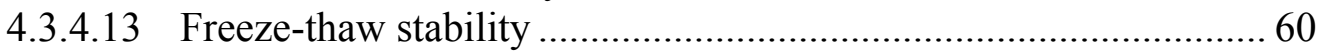

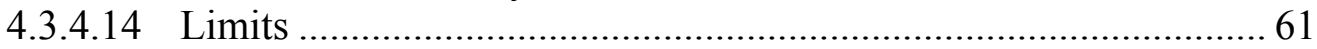

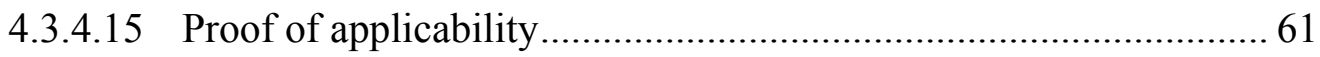

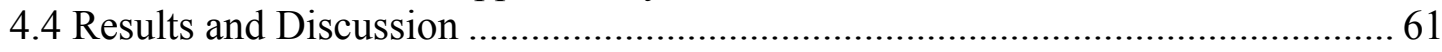

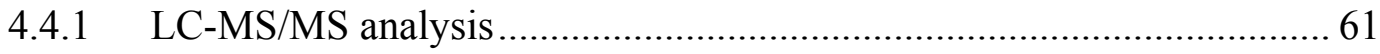

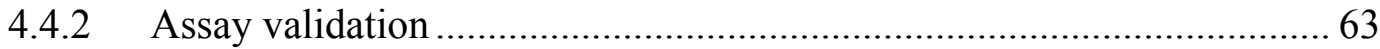

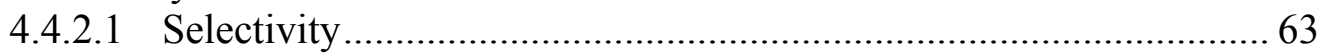

4.4.2.2 Matrix effects, recovery, and process efficiency............................... 63

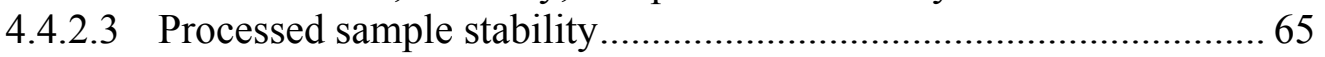

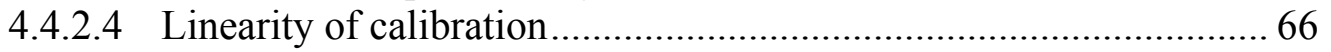

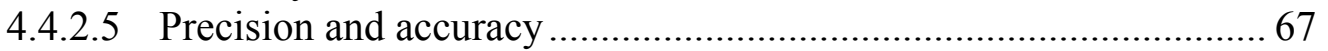

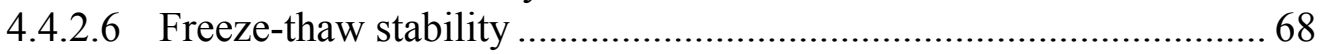

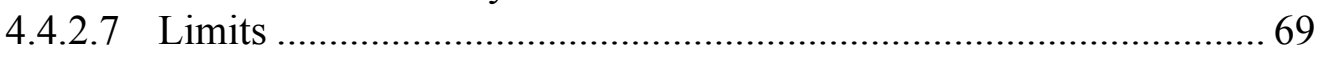

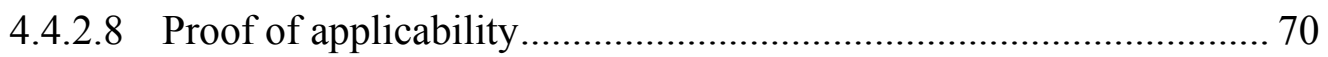

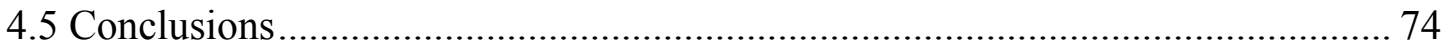

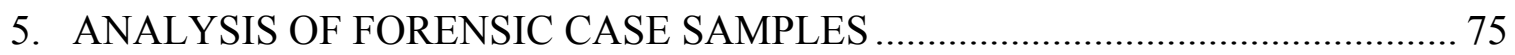

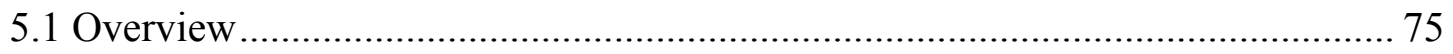

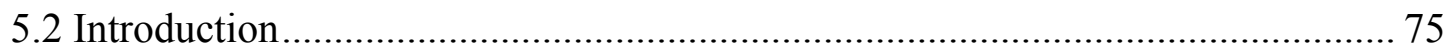

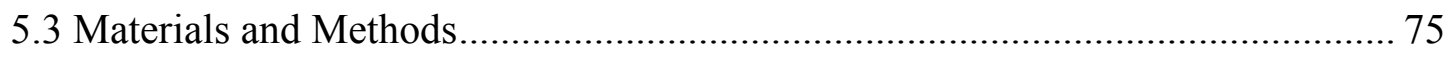

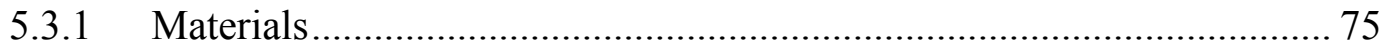

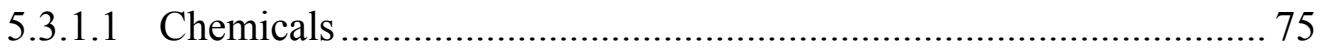

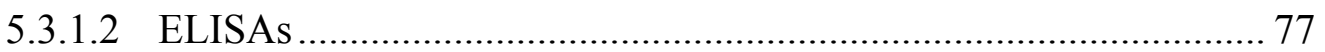

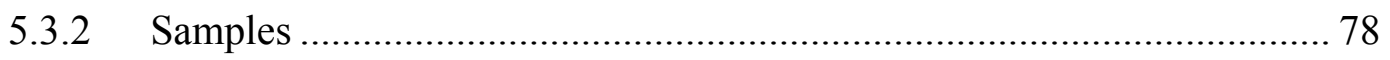

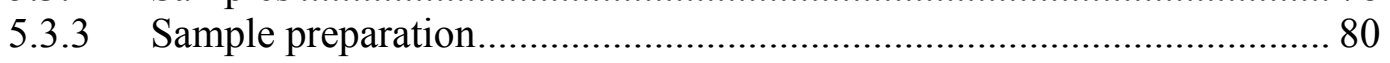




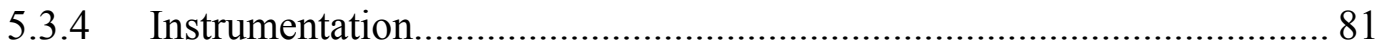

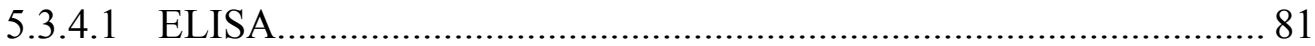

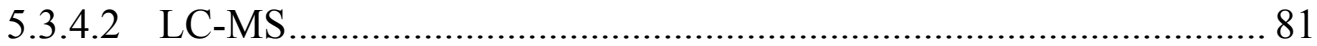

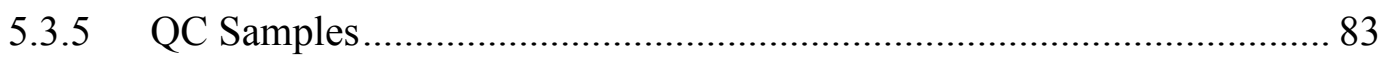

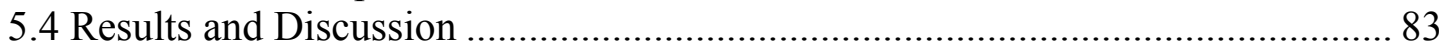

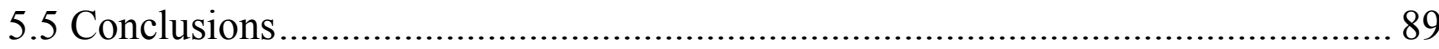

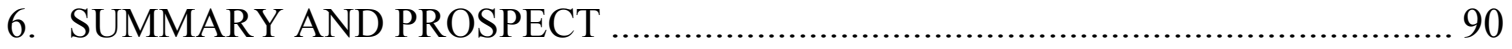

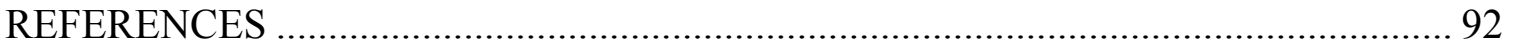

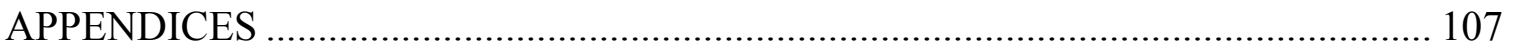

VITA 


\section{LIST OF TABLES}

TABLE

PAGE

Table 1: Designer Drug Abbreviations and Chemical Names ........................................ 5

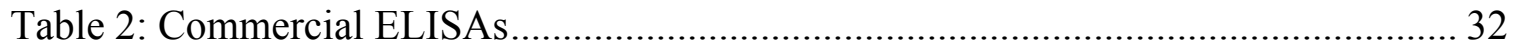

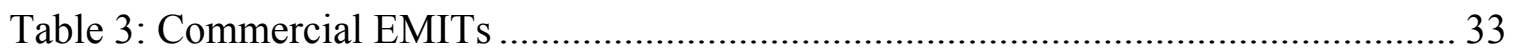

Table 4: Summary of Cross-Reactivity Data by Assay …....................................... 42

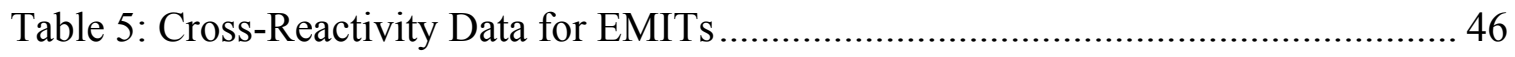

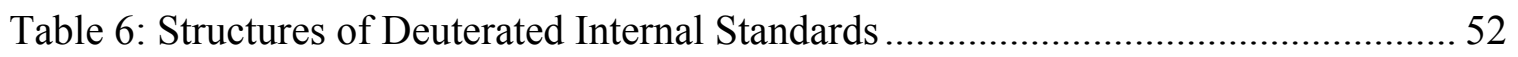

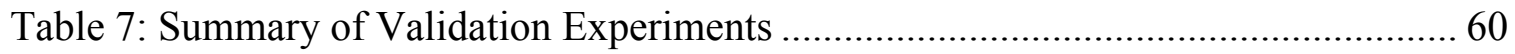

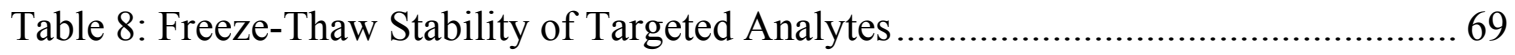

Table 9: Summary of Quantitative Results for Case Samples...................................... 71

Table 10: Composition of Serum Samples Spiked in Blind Study …............................ 79

Table 11: LC-QTOF Data for Blind Spiked Samples................................................ 86

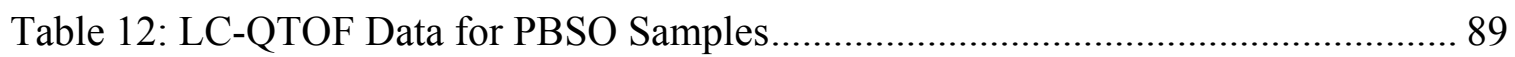




\section{LIST OF FIGURES}

FIGURE

PAGE

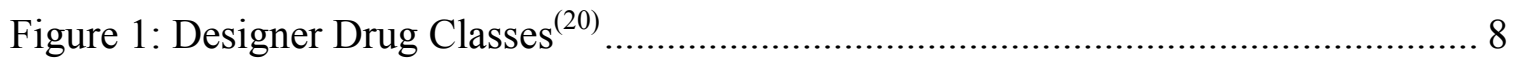

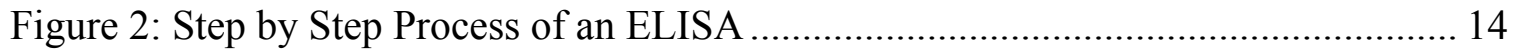

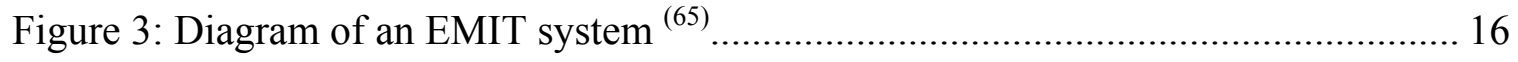

Figure 4: Structures of Target Compounds for ELISAs .......................................... 30

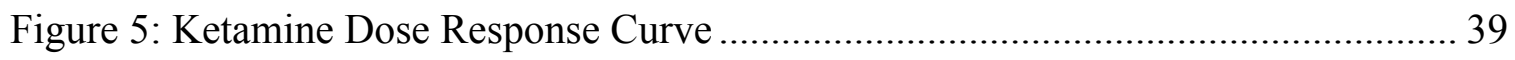

Figure 6: Chromatogram of Primary MRM Transitions for 32 Analytes ......................... 62

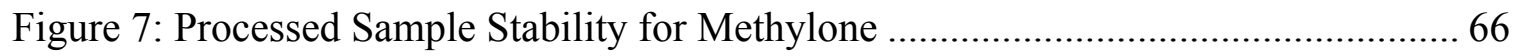

Figure 8: Chromatogram of Case 1 (counts vs. acquisition time) ............................... 72

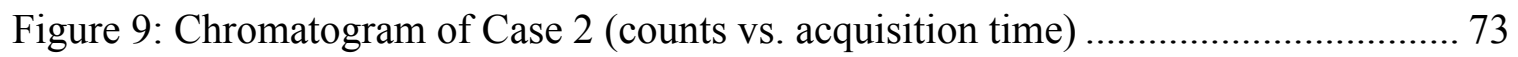

Figure 10: Extracted Ion Chromatogram and Library Match for Sample 1 ................... 85 


\section{LIST OF APPENDICES}

APPENDIX

PAGE

Appendix 1: Designer Drugs by Class and Sub-class................................................. 107

Appendix 2: Designer Drugs of Interest by Structure ............................................. 110

Appendix 3: Test Procedures for ELISA Analysis ................................................ 112

Appendix 4: Cross-Reactivity Data for ELISAs....................................................... 113

Appendix 5: Dynamic MRM MS Parameters......................................................... 118

Appendix 6: Matrix Effects, Recovery, and Process Efficiency .................................. 120

Appendix 7: Processed Sample Stability at Two Concentrations............................... 122

Appendix 8: Summary of Precision and Accuracy Data for at Four Concentrations ..... 124

Appendix 9: Blind Spiked Sample Analysis by ELISA .......................................... 125

Appendix 10: PBSO Sample Analysis by ELISA ….................................................. 126 


\section{LIST OF ABBREVIATIONS, ACRONYMS, AND SYMBOLS}

$\Delta \mathrm{t} \quad$ Retention time window

AA Acetic anhydride

AAPCC American Association of Poison Control Centers

ANOVA Analysis of variance

DAD Diode array detection

DEA Drug Enforcement Agency

DI Deionized

DUI Driving under the influence

DUID Driving under the influence of drugs

$\mathrm{EC}_{50} \quad$ Half-maximal effective concentration

EI Electron impact ionization

ELISA Enzyme-linked immunosorbent assay

EMIT Enzyme multiplied immunoassay technique

ESI Electrospray ionization

G6PDH Glucose-6-phosphate dehydrogenase

GC Gas chromatography

HFBA Heptafluorobutyric anhydride

HRP Horseradish peroxidase

IPA Isopropanol, 2-propanol

IS Internal standard

LC Liquid chromatography

LLE Liquid-liquid extraction

LOD Limit of detection 
LOQ Limit of quantification

MBTFA N-methyl-bis(trifluoroacetamide)

MDMA 3,4-methylenedioxymethamphetamine, Ecstasy

ME Matrix effect

MRM Multiple reaction monitoring

MS Mass spectrometry

MS/MS Tandem mass spectrometry

MSD Mass selective detector

NAD $+\quad$ Oxidized nicotinamide adenine dinucleotide

$\mathrm{NADH} \quad$ Reduced nicotinamide adenine dinucleotide

NCSL National Conference of State Legislatures

PBS Phosphate buffered saline

PBSO Palm Beach County Sheriff's Office

PE Process efficiency

PFPA Pentafluoropropionic anhydride

QC Quality control

QQQ Triple-quadrupole mass spectrometer

QTOF Quadrupole time-of-flight mass spectrometer

RE Extraction recovery

RSD Relative standard deviation

SIM Single ion monitoring

SPE Solid-phase extraction

SPME Solid-phase microextraction

TFAA Trifluoroacetic anhydride 
TMB 3,3',5,5' -tetramethylbenzidine

TOF Time-of-flight mass spectrometer

UPLC Ultra-performance liquid chromatography 


\section{INTRODUCTION}

\subsection{Statement of the Problem}

The "designer drugs" are analogs or derivatives of controlled substances that are sold on the street in an attempt to circumvent the legal restrictions placed on scheduled drugs (www.dea.gov). New designer drugs are constantly emerging onto the illicit drug market and it is difficult to validate and maintain comprehensive analytical methods for accurate detection of these compounds. Chemical modifications in these substances can be very subtle, leading to virtually unlimited structural variation. As a consequence, there are many hundreds of such entities that have been identified to date. Generally, forensic toxicology laboratories utilize a screening method, such as immunoassay, for the presumptive identification of drugs of abuse. When a positive result occurs, confirmatory methods, such as gas chromatography (GC) or liquid chromatography (LC) coupled with mass spectrometry (MS), are required for more sensitive and specific qualitative and quantitative analyses. In recent years, the need to study the activities of these compounds in screening assays as well as to develop confirmatory techniques to detect them in biological specimens has been recognized. ${ }^{(1)}$

Designer drugs have been a major topic of concern in Europe for some time and this issue has also become increasingly important in the United States. The United States Drug Enforcement Agency (DEA) has scheduled, emergency scheduled, and even unscheduled a number of these compounds (www.dea.gov). For example, DEA recently scheduled 26 designer drugs in the cathinone, phenethylamine, and synthetic cannabinoid classes under the Synthetic Drug Abuse Prevention Act of 2012. In addition to the federal legislation, 43 states and Puerto Rico have outlawed synthetic cathinones as of 
November 2012, according to the National Conference of State Legislatures (NCSL). Many of the states have enacted laws more stringent than those in place at the federal level, with some states banning cathinones as a general class of compounds. Most recently, severe intoxications and fatalities have been reported with new and emerging designer drugs, presenting challenges for toxicologists involved with the detection and identification of such novel compounds..$^{(1-19)}$

\subsection{Rationale for Research}

On the basis of the above data, there is a critical need in the field of forensic toxicology for reliable screening assays for multiple designer drugs, in addition to analytical methods optimized for comprehensive screening and confirmation of such drugs in a variety of human specimens for both ante- and post-mortem investigation. A major goal of the research presented here was to evaluate the performance of commercially available screening immunoassays for detecting a wide range of designer drugs. Since each manufacturer is likely to employ different antibodies, specificity for individual drugs cannot always be predicted or compared among other types of immunoassays (e.g., EMIT), different matrices (i.e., meconium, whole blood, oral fluid), or different manufacturers. Regardless of any cross-reactivity that may occur, it is crucial that the forensic analytical toxicology community be made aware of the results, as screening techniques are currently limited for designer drugs, particularly the cathinone derivatives.

In addition, it was also imperative to develop a MS confirmatory assay capable of rapid analysis of multiple designer drugs in a single run with high specificity at trace (i.e., parts per trillion to low parts per billion) levels. In order to achieve this goal and confirm 
cross-reactivity findings, a rapid, sensitive, and specific LC-MS analytical method was also developed. It is anticipated that successful achievement of these goals will provide working forensic toxicology laboratories with important new data and tools for analysis of this class of drugs.

Two primary hypotheses were tested in this project: 1) Some amphetamine-like designer compounds would not be detected using conventional assays, even when multiple immunoassay platforms were utilized (i.e., false negatives) and 2) some designer compounds would be detected in assays that theoretically target only amphetamine and methamphetamine (i.e., false positives). In a working toxicology laboratory, a negative result as in (1) would generally not be further analyzed or confirmed with other methods, with the result that the drugs may be overlooked. In contrast, a positive result as in (2) would trigger a confirmatory analysis, although an unknown designer drug would generally not be identified without proper reference standards or a comprehensive chromatographic method. A focus was placed on amphetamine or methamphetamine/MDMA assays, as one or both of these types of assays are used in routine drug screens by a majority of laboratories. Since presumptive methods, like ELISA and EMIT, are the first line of screening methods for detecting drugs of abuse, it was necessary to understand how these important drugs can be detected, if at all, by currently available immunoassays, even where cross-reactivity is not expected.

\subsection{Significance of Study}

The comprehensive study has applicability to forensic science, toxicology, law enforcement, and clinical medicine. The research addresses issues of ultra-trace analysis, multiple-analyte samples, detection of novel drugs of abuse across different classes, and 
cross-reactivities of such drugs in widely used immunoassays. A comprehensive confirmatory analytical method for the identification of at least 30 designer drug entities in a short analysis period was developed.

For the completion of the research, drugs were chosen based on prevalence in literature reports, DEA schedule, and availability as standards. Focus was placed on cathinone derivatives, or "bath salts," as their occurrence in society has been on the rise. Table 1 details the names and abbreviations for the 32 analytes chosen for inclusion in the study. Additional information, including class and structure, can be found in Appendix 1. 
Table 1: Designer Drug Abbreviations and Chemical Names

\begin{tabular}{|l|l|}
\hline Abbreviation or Common Name & \multicolumn{1}{c|}{ Chemical Name } \\
\hline 2C-B & 2,5-dimethoxy-4-bromophenethylamine \\
\hline 2C-E & 2,5-dimethoxy-4-ethylphenethylamine \\
\hline 2C-I & 2,5-dimethoxy-4-iodophenethylamine \\
\hline 2C-T-4 & 2,5-dimethoxy-4-(i)-propylthiophenethylamine \\
\hline 2C-T-7 & 2,5-dimethoxy-4-(n)-propylthiophenethylamine \\
\hline 4-FMC, Flephedrone & 4-fluoromethcathinone \\
\hline 4-MEC & 4-methylethcathinone \\
\hline 4-MMC, Mephedrone & 4-methylmethcathinone \\
\hline 5-MeO-DiPT & 5-methoxy-diisopropyltryptamine \\
\hline 5-MeO-DMT & 5-methoxy-dimethyltryptamine \\
\hline AMT & $\alpha$-methyltryptamine \\
\hline bk-MBDB, Butylone & 3,4-methylenedioxyethcathinone \\
\hline bk-MDMA, Methylone & 3,4 -methylenedioxymethcathinone \\
\hline bk-PMMA, PMMC, Methedrone, & 4-methoxymethcathinone \\
\hline BZP & benzylpiperazine \\
\hline Cathinone & $\alpha$-aminopropiophenone \\
\hline DBZP & dibenzylpiperazine \\
\hline DMT & dimethyltryptamine \\
\hline DOB & 2,5-dimethoxy-4-bromoamphetamine \\
\hline DOET & 2,5-dimethoxy-4-ethylamphetamine \\
\hline DOM & 2,5-dimethoxy-4-methylamphetamine \\
\hline mCPP & 3-chlorophenylpiperazine \\
\hline MDA & 3,4-methylenedioxyamphetamine \\
\hline MDEA & 3,4-methylenedioxyethylamphetamine \\
\hline MDMA, Ecstasy & 3,4-methylenedioxymethamphetamine \\
\hline MDPV & 3,4 -methylenedioxypyrovalerone \\
\hline Methcathinone & 2-methylaminopropiophenone \\
\hline TFMPP & 3 -trifluoromethylphenylpiperazine \\
\hline TMA & 3,4,5-trimethoxyamphetamine \\
\hline
\end{tabular}


In order to fully test the proposed hypotheses, the research was divided into three major tasks.

\subsubsection{Task 1 - Determination of cross-reactivity of designer drugs}

In order to determine if structural analogs of drugs of abuse can be detected by immunoassays, cross-reactivity must be determined to examine if false positives or false negatives occur. The current report details the design and results of a comprehensive study to examine cross-reactivity of thirty designer drugs in both serum and urine amongst 18 commercial immunoassays.

\subsubsection{Task 2 - Development of a comprehensive LC-MS method}

Since immunoassays are employed as presumptive, screening methods, a comprehensive analytical method was developed to confirm and quantify any drugs present in the samples. In addition, the method was fully validated according to accepted analytical method development practices.

\subsubsection{Task 3 - Application of the developed techniques to forensic samples}

In forensic science, one of the most important tasks in regard to method development is the application. In Task 3, forensic specimens were analyzed by both immunoassays and the confirmatory LC-MS method. The dual-analysis allowed for true comparison of the two techniques (immunoassay and LC-MS) as well as assessment of the comprehensive LC-MS method when applied towards forensic case samples. 


\section{BACKGROUND}

\subsection{Designer Drugs}

A designer drug is a compound which is psychotropic in nature and can be a synthetically altered natural compound, a structural modification of an existing xenobiotic, or a new chemical entirely. ${ }^{(20)}$ The term "designer drug" was first coined by Dr. Gary Henderson in the 1980s when fentanyl analogs began creeping into the drug market as "China White" heroin after passage of the Comprehensive Drug Abuse Prevention and Control Act of 1970. ${ }^{(21)}$ In general, designer drugs are structural analogs of Drug Enforcement Agency (DEA) Schedule I and II substances that are synthesized to mimic the effects of scheduled compounds and to avoid the provisions of drug laws. ${ }^{(22)}$ Over the past decade, hundreds of such compounds have flooded the illicit drug market under the terms "designer drugs" or "research chemicals." In addition to the legal issues, these structurally related drugs often carry unknown safety profiles, a high potential for abuse, high potency, and serious potential health consequences, especially when ingested unknowingly. Easy access via the internet has made such "designer drugs" more available to the general public. 


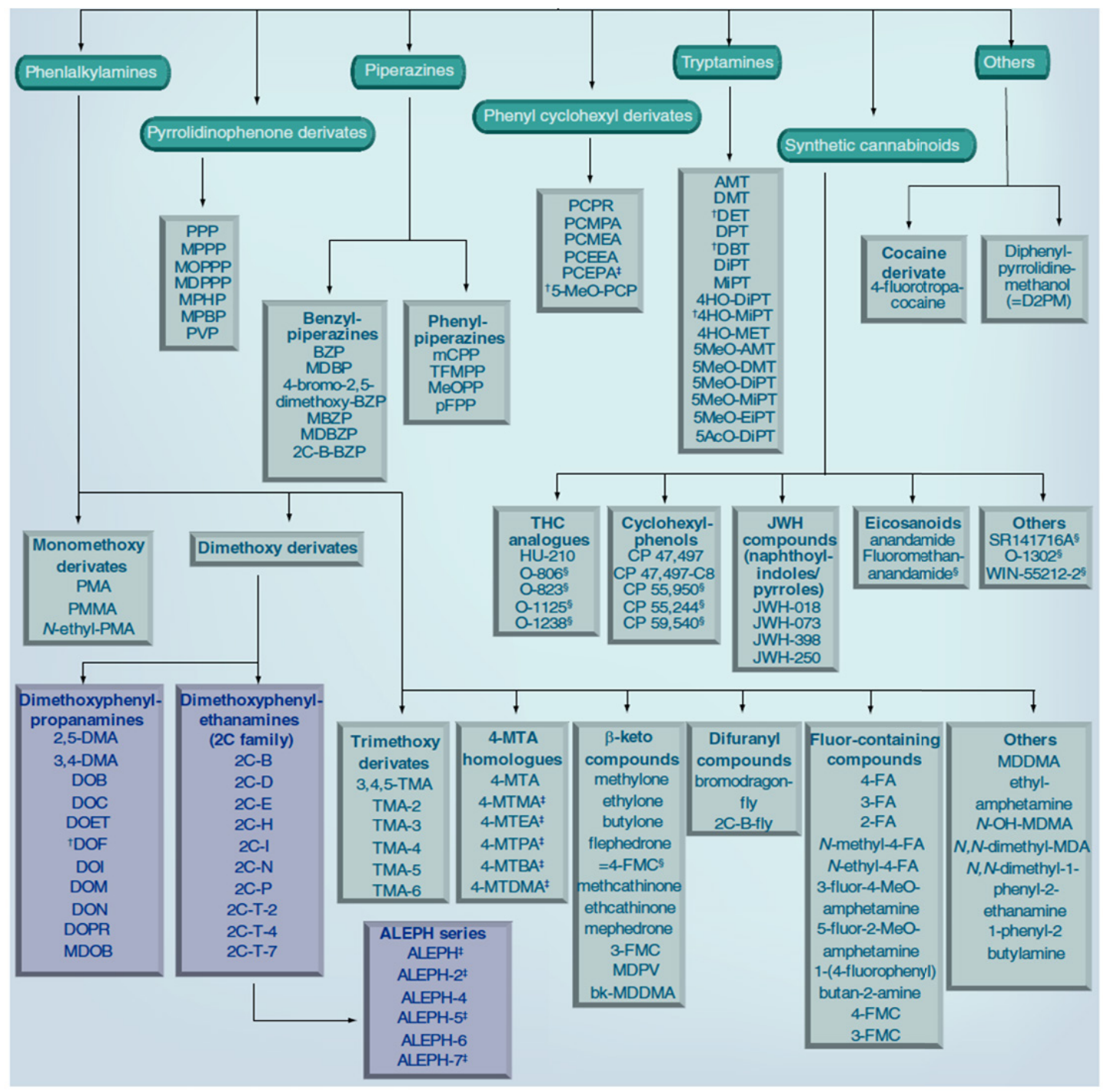

Figure 1: Designer Drug Classes ${ }^{(20)}$

Structures of most of the designer stimulant compounds fall into three major classes: phenethylamines, tryptamines, and piperazines, as seen in Figure $1 .^{(20)}$ The $\beta$ keto-phenethylamine derivatives, analogs of cathinone, have been on the rise in the last few years, often sold as "bath salts" or "plant food" over the internet or in head shops. ${ }^{(23,24)}$ Cathinone itself is a Schedule I drug occurring naturally in the leaves of the khat bush. Another popular group of emerging designer drugs includes synthetic 
cannabinoids, originally sold as "K2" or "Spice" as "legal" alternatives to marijuana. In addition, previously available tryptamines such as $\alpha$-methyltryptamine and 5methoxydiisopropyltryptamine ("Foxy") have enjoyed resurgence and have been linked to several deaths in recent years. ${ }^{(6,25)}$ Trifluoromethylphenylpiperazine, once banned by the DEA, and benzylpiperazine, often found in combination with each other, have also been cited in several cases. ${ }^{(2)}$ While severe intoxications and even fatalities are not uncommon with abuse of these substances, they can be difficult to identify from a forensic analytical standpoint because of the large number of potential structures, the constant introduction of novel compounds, inadequate accessibility to standards, and the generally limited frequency of occurrences. ${ }^{(26)}$ Most importantly, there is a lack of comprehensive analytical methods available for detection of these compounds, either as screening techniques or for quantification purposes.

\subsection{Presence in Society}

During the 1990s, detailed user reports and steps for manufacturing hundreds of designer drugs were published by a former DEA-licensed chemist, Dr. Alexander Shulgin. "Phenethylamines I Have Known and Loved" (PiHKAL) and "Tryptamines I Have Known and Loved" (TiHKAL) allowed drug users and manufacturers to have formulas at their fingertips. As the use of the internet grew, additional resources, such as the website Erowid.org, offered similar forums.

The American Association of Poison Control Centers (AAPCC) was the first to ring the alarm about "bath salts." In 2011 alone, their 57 call centers received over 6,000 calls about exposures to these compounds, followed by almost 3,000 calls in 2012 (aapcc.org). The AAPCC has noted that the average users are in their twenties, but they 
have received calls for children as young as 6 years old and adults as old as 59 years of age. The merchandise, disguised as household products, was sold under brand names such as "Bliss", "Cloud Nine", "Ivory Wave", and "Vanilla Sky" as powders in small foil packages (globaldrugpolicy.org). In addition to these formulations, cathinone derivatives have also appeared in Ecstasy tablets after a worldwide shortage of MDMA precursors transpired in early $2008 .^{(27)}$

In October 2011, the DEA placed three of the most common compounds (methylone, mephedrone, and MDPV) into Schedule I as an emergency action. In July of 2012, President Obama signed the Synthetic Drug Abuse Prevention Act into law, permanently scheduling mephedrone, MDPV, and the $2 \mathrm{C}$ series of analogs, among other compounds, as Schedule I drugs.

Although the street products are clearly labeled "not for human consumption," the most common routes of administration are snorting, smoking, injecting, or swallowing (dea.gov). With possible high potencies, the number of intoxications and lethal overdoses is rather large, especially when users also ingest their typical dose of another drug, such as Ecstasy. The physiological and psychological effects of many of these substances somewhat mimic those of amphetamine, methamphetamine, and Ecstasy: increased energy, empathy, and extroversion. ${ }^{(24)}$ In addition, users may also experience multiple adverse effects, including hyperthermia, palpitations, agitation, headache, nausea, and vomiting. ${ }^{(24)}$ Furthermore, chronic users in online drug forums often discuss adding additional drugs, such as ibuprofen or Xanax (alprazolam) to combat these undesirable effects. Many individuals have presented to emergency departments and hospitals with severe intoxications. Reports have characterized the more dangerous 
effects, including suicidal and homicidal ideations ${ }^{(12)}$, psychosis $^{(4,16)}$, acute kidney injury $^{(13,28)}$, multi-organ failure ${ }^{(29)}$, seizures ${ }^{(18)}$, and Serotonin Syndrome ${ }^{(18)}$. With regard to fatal intoxications, case reports include cause of death such as disseminated

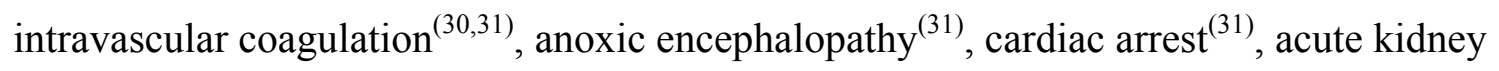
failure $^{(32)}$, and lethal Serotonin Syndrome. ${ }^{(11)}$

\subsection{Analysis of Drugs of Abuse in Biological Specimens}

Currently, there are established approaches for the detection of drugs of abuse in forensic toxicological specimens. In the analysis of drugs of abuse, blood and urine have become the most commonly used human sample matrices ${ }^{(33)}$, while only a few groups incorporate hair ${ }^{(34-36)}$ or oral fluid. ${ }^{(37,38)}$ Blood is often the matrix of choice because it is easy to obtain and because of its applicability to both ante- and post-mortem samples. Blood (plasma, serum, or whole) has been utilized in various studies for the detection of amphetamines, tryptamines, piperazines, and major metabolites for purposes of drug screening, confirming driving under the influence of drugs (DUID), and examining road fatalities. ${ }^{(39,40,41,42)}$ Alternatively, hair, oral fluid, and exhaled breath have been examined but are less commonly encountered because of extraction complications, difficulty in obtaining samples, or lack of validation. ${ }^{(43-45)}$ In cases of DUI, blood is often the matrix of choice as it may correlate with impairment as well. ${ }^{(42,46)}$ The disadvantages of blood include the applicability to only short-term or recent drug use, a limited window of detection, and legal difficulties in obtaining blood from people suspected of drug abuse. $^{(47)}$ 
As a way of sample clean-up and preparation, solid-phase extraction (SPE) is commonly used. Solid-phase extraction is advantageous over liquid-liquid extraction because it is less costly, smaller amounts of solvent are used, and because it can be fully automated. ${ }^{(48-50)}$ Proper extraction is vital for limited sample sizes as well as for the analysis of multiple, chemically diverse analytes within one specimen. ${ }^{(51)}$ Preconcentration utilizing SPE allows for enhanced method sensitivity. ${ }^{(52)}$ However, matrix effects may hinder solid-phase extractions if incompatible cartridge chemistry is selected. $^{(53)}$

In routine toxicology casework, a screening technique, usually presumptive such as an immunological screen, is employed to identify specific analytes or a class of analytes. Additional, more specific methods, including chromatographic separation, are employed to confirm positive findings. Ultimately, quantitative results may also be necessary.

\subsubsection{Presumptive techniques}

Historically, color tests and thin-layer chromatography may have been used to presumptively identify drugs of abuse after simple extraction. ${ }^{(54)}$ Currently, in terms of drug screens, immunoassays are the gold standard for presumptively detecting drugs of abuse in biological specimens. ${ }^{(55)}$ These screens work well with blood but are not ideal for unclassified substances as each kit is designed only for a class of structures based on antigen-antibody interactions. ${ }^{(56)}$ Commercial assays are advantageous due to their general availability, quick analysis time, ease of automation, and sensitivity. However, disadvantages include deficits in cross-reactivity data, a lack of specificity for some tests, 
and labor intensiveness. ${ }^{(57-60)}$ While different assays are useful for detecting different types of drugs in forensic toxicology, false positives may occur. In addition, positives still require confirmation by a chromatographic technique, and multiple classes of drugs cannot be detected and identified by one single test. ${ }^{(61)}$

\subsubsection{ELISA}

Enzyme-linked immunosorbent assays can be designed for a variety of biochemistry-related applications depending on the targeted antigen. The technology is based on antibodies produced to bind to specific antigens. The most popular type of ELISA, the direct competitive assay design, uses a plastic microtiter plate (96-well plates) coated with antibodies. ${ }^{(62)}$ The antibodies can be mono- or polyclonal in nature. Generally, monoclonal antibodies are more specific to a single antigen while polyclonal antibodies are capable of binding to a broader range of antigens. These heterogeneous assays can be applied to a variety of liquid biological specimens, including whole blood, serum, oral fluid, or urine.

In the analysis of drugs of abuse in biological specimens, several commercial manufacturers have designed antibodies and reagents for the detection of the most common classes of compounds, including amphetamines, barbiturates, benzodiazepines, benzoylecgonine (a cocaine metabolite), opiates, THC, and synthetic cannabinoids. Very few kits have, as of yet, been targeted towards synthetic cathinone derivatives. In general, these kits are packaged with all of the materials necessary, including a 96-well plate pre-coated with the antibodies. In a typical ELISA, the sample is added to the well, followed by a drug-enzyme conjugate and a short incubation time. Usually, horseradish 
peroxidase (HRP) is the enzyme utilized in these assays for the color generating reaction. A wash step removes any materials (drug or drug-enzyme conjugate) that did not bind to the antibodies. A substrate, usually TMB (3,3',5,5'-tetramethylbenzidine), is added and reacts with the drug-enzyme conjugate to produce a colored product. The absorbance is measured at a specified wavelength. The more drug that is present in the sample, the less of the conjugate that will bind, leading to less color produced. The absorbance values are then compared to positive and negative controls to determine positivity. The ELISA process is represented graphically in Figure 2.

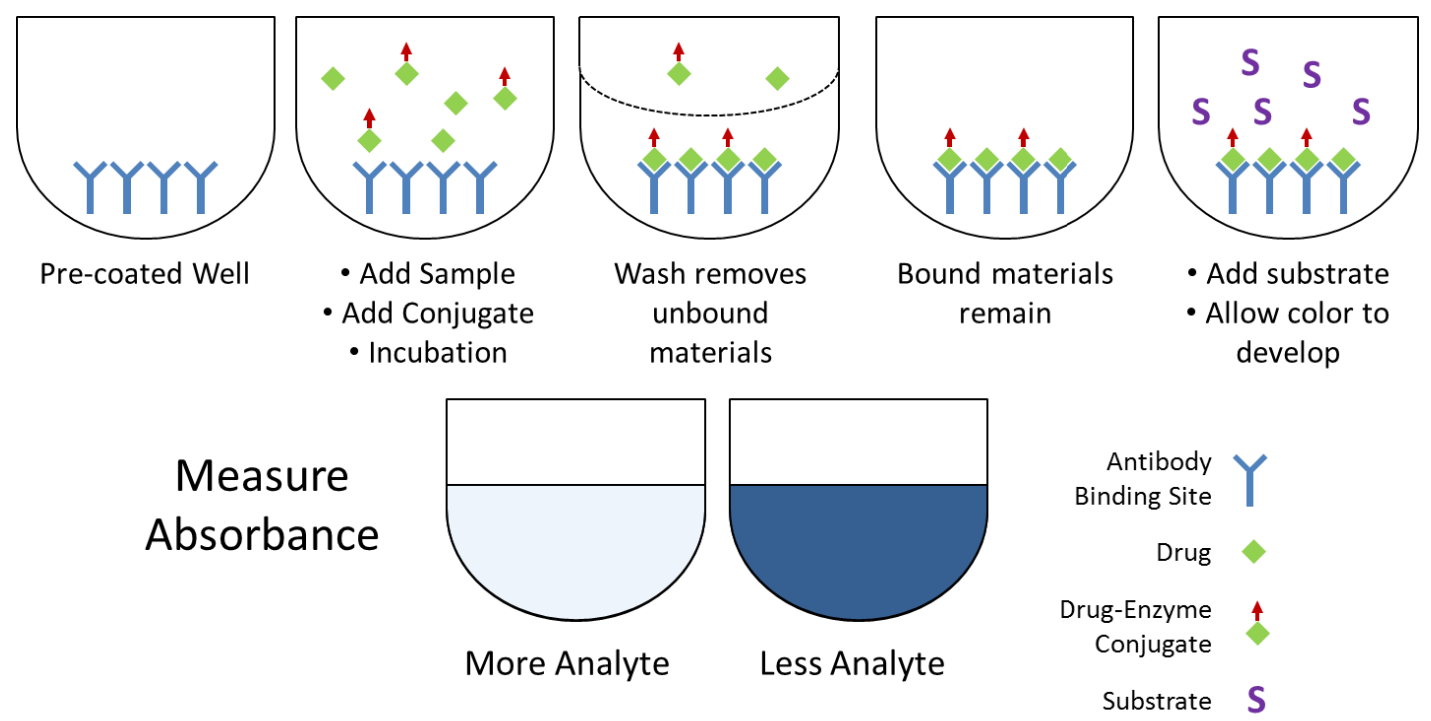

Figure 2: Step by Step Process of an ELISA Adapted from neogen.com 
Since the development of antibodies is a lengthy process, it is difficult for manufacturers of immunoassays to constantly develop assays to target the ever-changing designer drugs on the market today. For this reason, it is important to understand the extent of cross-reactivity of designer drugs in current immunoassays, as will be discussed in Chapter 3.

\subsubsection{EMIT}

Enzyme multiplied immunoassay technique (EMIT) is a screening technique applied to the analysis of drugs in serum or metabolites in urine. ${ }^{(63)}$ This homogeneous assay is based on the ability of antibodies to inhibit the activity of a drug-enzyme conjugate. ${ }^{(64)}$ The enzyme employed is Glucose-6-phosphate dehydrogenase (G6PDH). If drug is present in the sample, it will bind to the antibodies and displace the drugenzyme conjugate, leading to increased enzyme activity, as seen in Figure 3. The reaction rate, dependent on drug concentration in the sample, is monitored at $340 \mathrm{~nm}$ to detect the formation of NADH (reduced nicotinamide adenine dinucleotide). ${ }^{(64)}$ Glucose6-phosphate dehydrogenase G6PDH converts NAD+ (oxidized nicotinamide adenine dinucleotide) to NADH, resulting in an absorbance change. ${ }^{(64)}$ The EMIT technology is a simplified protocol and easily adapted to automation. Enzyme multiplied immunoassays also offer significant sensitivity increases over heterogeneous assays like ELISA. ${ }^{(64)}$ However, like ELISA, lengthy research is required to develop antibodies that not only offer specificity and affinity to the target but also inhibition of the drug-enzyme conjugate. Today, Syva, a division of Siemens, offers the most popular assays of this nature for the detection of drug metabolites in urine. 

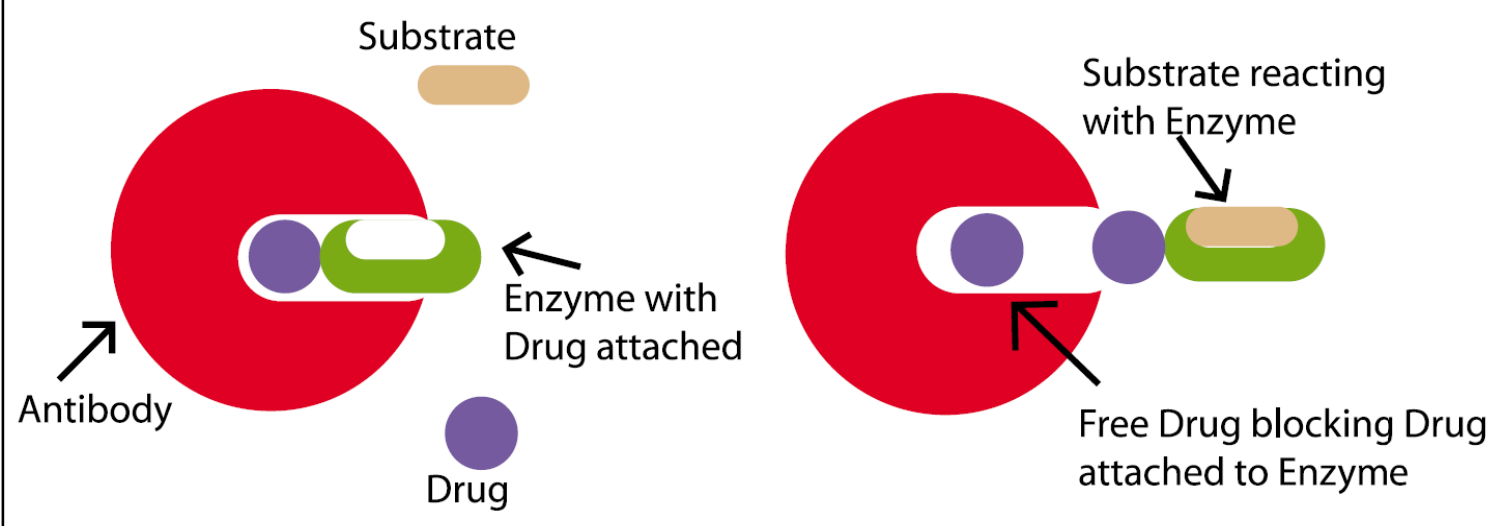

Figure 3: Diagram of an EMIT system ${ }^{(65)}$

Like ELISA, assays have been developed by Syva for common drugs of abuse, including amphetamines, barbiturates, benzodiazepines, benzoylecgonine, Ecstasy, opiates, and THC. There are no assays yet available for synthetic cathinones. For EMITs, it is also important to understand cross-reactivity using the current platforms, as specific assays for such designer drugs is not yet available, as will be discussed further in Chapter 3.

\subsubsection{Confirmatory techniques}

After presumptive screens are employed, positive results are confirmed, generally by chromatographic techniques such as GC-MS or LC-MS, in order to accurately identify and, if necessary, quantify the compounds present. Since many of the designer drugs may not be detected by immunoassay screens, confirmatory techniques are necessary to fully characterize biological specimens when screening for these drugs. Even when using MS-based screening techniques, some of the newer designer drugs may be overlooked, either because reference spectra are not available or because single ion monitoring (SIM) 
or multiple reaction monitoring (MRM) methods may miss the typical fragments of certain compounds. ${ }^{(66)}$ For these reasons, it is important to expand and improve upon current analytical methods for comprehensive screening and confirmation of designer drugs.

\subsubsection{GC-MS}

Gas chromatography-mass spectrometry is a widely used analytical technique for the detection and quantification of a vast range of drugs in forensic toxicology. Gas chromatography-mass spectrometry requires relatively volatile analytes, giving rise to the need for the selective extraction of the drugs from the biological matrix of choice and, often, subsequent derivatization prior to GC analysis. Although several GC-MS methods have been published for the simultaneous analysis of a number of designer drugs belonging to different structural classes ${ }^{(67-69)}$ most of the published literature focuses on the detection of single drugs and their associated metabolites. ${ }^{(70-74)}$ The drug-specific method approach is a consequence of the continuing appearance of novel drug analogs on the illicit market. Some research groups have developed methods for simultaneous detection of a small number of the most frequently encountered designer drugs, ${ }^{(75-79)}$ while others have focused on creating GC-MS databases of designer and other drugs of abuse. ${ }^{(80,81)}$ A two-dimensional GC-MS method for the achievement of higher chromatographic resolution and selectivity has also been reported. ${ }^{(82)}$ Aside from detection of designer drugs in biological specimens, GC-MS can also be applied as an analytical technique in studies exploring the metabolism of these drugs. ${ }^{(83)}$ Several reviews on the analysis of phenethylamine, tryptamine, piperazine and cathinone-related 
designer drug analogs have been published in recent years, ${ }^{(42,84)}$ but comprehensive GCMS screening methods spanning all of these drug classes are rare.

The three most commonly encountered biological matrices used for GC-MS based ante-mortem confirmatory drug analysis are whole blood or plasma/serum and urine. Urine is a generally preferred matrix due to the non-invasive nature of its collection, but it contains mostly conjugated metabolites, requiring a hydrolysis step prior to further analysis by gas chromatography. ${ }^{(85)}$ Blood is the biological matrix of choice in postmortem analysis, as it provides good quantitative information that can be compared to ancillary data from other sources to assist with assigning lethal drug concentrations at the time of death. ${ }^{(9)}$

Extraction methods for GC analysis of designer drugs depend on the specimen matrix of choice, but liquid-liquid extraction (LLE) with a variety of organic solvents is widely used, along with SPE and mixed-mode cartridges containing hydrophobic C18 residues and a cation-exchange resin. Solid-phase microextraction (SPME) is not as widely employed, as it has not been shown to be very efficient for this class of drugs. Headspace analysis is also less common, due to the relatively non-volatile nature of the analytes, unless a derivatization step can be introduced. ${ }^{(86)}$ All phenethylamine, tryptamine, piperazine and cathinone derivatives contain an amine functional group. Such compounds tend to adsorb onto the capillary column and the glass inserts of the GC, causing poor peak shapes, excessive peak tailing, and poor resolution. ${ }^{(84)}$ These characteristics, together with the low volatility of the designer drugs, give rise to the need for derivatization of the analytes prior to the GC-MS analysis. 
The amine functional group is very amenable to acylation, which is the preferred derivatization technique employed in designer drug analysis, although other approaches such as alkylation and silylation have also been successfully employed, especially with hydroxylated metabolites. ${ }^{(70)}$ Acetic anhydride (AA) with pyridine, trifluoroacetic anhydride (TFAA), and N-methyl-bis(trifluoroacetamide) (MBTFA) are the most convenient acylating reagents. These introduce an acetyl or a trifluoroacetyl group onto the free amine moiety, resulting in more volatile analyte derivatives and a better separation on the GC column. The reagents are relatively inexpensive and easy to use, but the derivatives are prone to hydrolysis by exposure to atmospheric moisture, and some are only stable for a few hours. ${ }^{(84)}$ Although certain alternative reagents, such as pentafluoropropionic anhydride (PFPA) and heptafluorobutyric anhydride (HFBA), produce more stable derivatives, the reagents themselves are less volatile than AA or TFAA and thus require longer evaporation procedures before GC analysis. The evaporation step can lead to variable co-evaporation of the designer drug derivatives, resulting in analyte loss and introducing error into quantitative analysis. ${ }^{(87)}$

The capillary columns typically used in the gas chromatographic analysis employ non-polar (e.g., 100\% dimethyl polysiloxane) or slightly polar (e.g., 5\% diphenyl, 95\% dimethyl polysiloxane) stationary phases, often made of modified polydimethylsiloxane polymers (MS-type columns) to reduce bleeding and improve MS analysis. The most commonly used ionization source in the GC-MS analysis of designer drugs is electron impact ionization (EI), although many techniques also use chemical ionization in either positive or negative mode. The vast majority of analyses have been performed on a single quadrupole mass analyzer, with a few examples available using ion trap MS. ${ }^{(75)}$ 
Analysis of amphetamines and other designer drugs by GC-MS/MS has only been done as a part of a screening method for different drugs of abuse in hair, ${ }^{(88)}$ and no comprehensive study of this class of drugs using GC-triple quadrupole MS/MS has been published to date.

The most popular combination of GC and a mass analyzer reported in recent literature is that supplied by Agilent Technologies, Inc., which couples a model 6890/7890 GC to a model 5973 mass selective detector, or MSD..$^{(9,67,68,69,76,77,80,89)}$ Limits of detection of the various published GC-MS methods vary depending on the specific compound, the matrix and the ionization source, but the numbers for blood and urine mostly lie in the low ppb range, with the best techniques reporting $1-50 \mathrm{ng} / \mathrm{mL}$. Detection limits in hair are on the order of $100 \mathrm{ppb}(0.1-0.5 \mathrm{ng} / \mathrm{mg})$. The linear ranges of the various methods, when reported, are also comparable, and are on the order of $10^{2}$, typically ranging between 10 and $2000 \mathrm{ppb} .^{(84)}$

\subsubsection{LC-MS}

While GC-MS has been the gold standard for detecting drugs of abuse, ${ }^{(90)}$ liquidchromatography coupled with mass spectrometry (LC-MS) has become more popular for detection and analysis of polar compounds such as amphetamines while offering higher sample throughput, easier sample preparation, structural elucidation, and increased sensitivity over GC-based methods that often require complex sample preparation and derivatization schemes. ${ }^{(41,91-92)}$ Additionally, LC-MS is not limited to non-polar or volatile compounds. ${ }^{(39,93-95)}$ Ultra-fast methods can be used when applying high-pressure to the chromatographic system, as is the case with UPLC, or ultra-performance liquid 
chromatography. More importantly, fragmentation patterns can positively identify compounds when $\mathrm{MS}^{\mathrm{n}}$ is used. ${ }^{(91)}$

Liquid chromatography has been combined with diode array detection (DAD), single stage MS, or tandem MS for the analysis of designer drugs in biological materials. Diode array detection spectra may assist in the differentiation between certain isomers of some compounds, like mCPP. ${ }^{(2)}$ Several LC-MS based methods have been published that allow for the screening of different drug substance classes simultaneously. ${ }^{(53,96-99)}$ Of note, Wohlfarth et al. described a method for the detection of amphetamines, tryptamines, piperazines, and a few cathinone derivatives in human serum by LC-MS/MS, with limits of detection in the 1.0 to $5.0 \mathrm{ng} / \mathrm{mL}$ range. ${ }^{(53)}$ Other research has focused solely on LCMS analysis of single compounds and metabolites ${ }^{(25,40,100-102)}$ or on a small subset of a single drug class. ${ }^{(79,94,103-106)}$ Recently, cathinone derivatives have appeared on the illicit designer drug market and are increasing in popularity among users. Until a couple of years ago, no published methods were available for comprehensive confirmatory analysis of these compounds. Now, several methods have been developed with the focus on designer drugs, particularly the cathinone derivatives. ${ }^{(107-110)}$ However, as drug regulations intensify, substitution of new analogs continues, leaving laboratory methods one step behind the current compounds available on the market. With the continuing expansion of LC-MS based methods, authors have also applied the technique to understanding designer drug metabolism.

Confirmatory methods using GC rely heavily on comprehensive GC-MS libraries for analyte identification, which are generated using standardized instrumentation and ionization parameters. However, such libraries are not as common for LC-MS based 
drug analysis, due primarily to variations in instrumental operating parameters among different instruments and laboratories. A few groups have created LC-MS databases of multiple designer drugs ${ }^{(53,81,95,111)}$ or have published information about structural elucidation and fragmentation patterns of such drugs that can be helpful in identifying unknowns. ${ }^{(91,112)}$

In addition to commonly employed biological matrices like blood, hair, and urine, several other matrices have been introduced to LC-MS techniques, including oral fluid, ${ }^{(45,61,93,113)}$ vitreous humor (post-mortem), ${ }^{(114)}$ and exhaled breath. ${ }^{(44)}$ Depending on desired sample matrix available, varying extraction methods are available for LC-MS sample preparation; unlike GC-MS, derivatization of analytes is generally not required. While LLE has been utilized it requires significant amounts of solvent and is not amenable to automation. ${ }^{(51,92)}$ More frequently, samples for LC-MS analysis are applied to SPE cartridges for clean-up and pre-concentration of target compounds. Solid phase extraction has several advantages, including lower cost, ease of automation, and increased sensitivity, especially if proper cartridge chemistry is chosen to extract multiple, structurally diverse analytes free from matrix effects. ${ }^{(48-50)}$ Often, reversedphase extraction is carried out on mixed-mode C18 sorbent beds with hydrophobic residues and cation-exchange resins. ${ }^{(115)}$ Liquid chromatography-mass spectrometry methods for designer drugs also usually employ C18 reversed-phase columns for the chromatographic separations along with mobile phases modified with ammonium formate/formic acid. ${ }^{(40,53,113)}$

Traditionally, LC-MS methods utilize deuterated compounds as internal standards. ${ }^{(116)}$ When unavailable, as is often the case for new designer drugs, 
investigators attempt to choose compounds that are similar in structure to the targeted analyte. For example, Boland et al. chose 5-MeO-AMT as the internal standard for the analysis of $\mathrm{AMT}^{(25)}$ while Pichini et al. chose MDPA as the internal standard for a variety of "hallucinogenic designer drugs". ${ }^{(99)}$ When analyzing different drugs or multiple classes, it is important to select appropriate internal standards to represent the range of analytes being targeted in order to ensure accurate quantification. The use of internal standards containing stable isotope labeled carbon or nitrogen may introduce unwanted bias or ion suppression with co-eluting peaks and is rarely used in forensic toxicological analysis. ${ }^{(117)}$

Limits of detection of the various LC-MS methods depend on a variety of factors but are typically in the range of $0.1-5 \mathrm{ng} / \mathrm{mL} .^{(20,39,53,96,104,118,119)}$ Commonly, data acquisition is performed in MRM mode with positive electrospray ionization. ${ }^{(53)}$ Usually, two transitions are sufficient for qualitatively identifying a compound; however many of the designer drugs yield similar fragments so differentiation among positional isomers may be challenging. Even with the advent of ion trap mass spectrometers, some compounds are still indistinguishable even at the $\mathrm{MS}^{6}$ level. ${ }^{(91)}$ 


\section{CROSS-REACTIVITY OF DESIGNER DRUGS}

Copyright (C) 2013 John Wiley \& Sons, Ltd.

Swortwood, M. J., Hearn, W. L., DeCaprio, A. P. (2013) Cross-reactivity of designer drugs, including cathinone derivatives, in commercial enzyme-linked immunosorbent assays. Drug Testing and Analysis DOI 10.1002/dta.1489

\subsection{Overview}

Immunoassays are designed to indicate the presence (above a certain cut-off concentration) of a particular class or type of substance, such as amphetamines. For example, a typical toxicology laboratory may perform a drug screen with individual assays targeting barbiturates, benzodiazepines, cocaine, opiates, and oxycodone. Depending on the nature of the immunoassay (i.e., monoclonal vs. polyclonal), the concentration of the drugs, or the structures of the analogs, some compounds may not be detected. Consequently, while these screens may perform well for known derivatives, they are not ideal for unclassified substances because of the likelihood of unconfirmed positives. In addition, multiple classes of drugs generally cannot be detected and

identified in a single test. ${ }^{(60,61)}$ In regulated workplace drug testing, only a few drugs are targeted and high specificity is a desirable characteristic for antibodies used in that field. However, for postmortem and human performance drug testing, broad selectivity is desirable.

\subsection{Introduction}

The structures of many of the stimulant-type designer drugs closely resemble those of amphetamine, methamphetamine, and MDMA. Simply in terms of structural similarities, it is not unreasonable to expect that the antibodies used in the commercial 
immunoassays may also recognize these drugs. ${ }^{(20)}$ However, cross-reactivity is not based on structural similarity alone, but also involves antibody and hapten/conjugate design. Consequently, it is difficult to accurately predict cross-reactivity since the latter parameters are typically proprietary information. Specific immunoassays are not yet widely available for new designer drugs of this class, although some limited research has been performed to characterize the performance of pre-existing immunoassays for such compounds. However, one commercial provider (Randox Laboratories) recently released two kits for the presumptive identification of 'bath salts', one targeting MDPV and another targeting mephedrone/methcathinone. To date, very few investigations of the cross-reactivity of new designer drugs in standard immunoassays have been reported. Consequently, cross-reactivities still remain unknown for many drugs, particularly the newest compounds such as the cathinone derivatives.

There have been several studies that have reported cross-reactivity values for numerous compounds with a variety of assays using spiked specimens. Park et al. described the cross-reactivity of several amphetamine analogs in human urine using Abbott TDx (amphetamine cut-off $300 \mathrm{ng} / \mathrm{mL}$ ), Vitalab Selectra (methamphetamine cutoff $1000 \mathrm{ng} / \mathrm{mL}$ ), Accusign MET (on-site test kit, methamphetamine cut-off 1000 $\mathrm{ng} / \mathrm{mL}$ ), and SD Bioline MET (on-site test kit, methamphetamine cut-off $1000 \mathrm{ng} / \mathrm{mL}$ ). ${ }^{(57)}$ They demonstrated high cross-reactivities for MDA, MDMA, and MDEA for all of the kits, with confirmation by GC-MS. Crooks et al. investigated an alternative matrix, oral fluid, in order to assess screening assays for amphetamines and methamphetamines. ${ }^{(59)}$ Roche DAT assays (amphetamines cut-off $40 \mathrm{ng} / \mathrm{mL}$; methamphetamines cut-off 40 ng/mL) were evaluated with MDA, MDMA, MDEA, MBDB (N-methyl-1,3- 
benzodioxolylbutanamine), PMA (paramethoxyamphetamine), and BDB (3,4-

methylenedioxy- $\alpha$-ethylphenethylamine). Cross-reactivity was reported for PMA, MDA, and $\mathrm{BDB}$ for the amphetamine assay while MDMA, MDEA, and MBDB showed significant reactivity using the methamphetamine assay.

Cody et al. used fluorescence polarization immunoassays to detect a group of designer drug analogs and metabolites in urine with two Abbott TDx assays (Amphetamine class; Amphetamine/ Methamphetamine II). ${ }^{(120)}$ High cross-reactivity was reported for MDA, MDMA, MDEA, and 4-hydroxymethamphetamine for both assays but many compounds still were either undetected or detected as positives with only one set of assays, indicating that a negative immunoassay result does not mean an amphetamine analog is not present. Apollonio et al. also completed a study examining the cross-reactivities of amphetamine-type drugs using two BioQuant Direct ELISA assays (Amphetamine; Methamphetamine) ${ }^{(55)}$ Using a PBS (phosphate buffered saline) matrix, high cross-reactivity at $50 \mathrm{ng} / \mathrm{mL}$ was reported for MDA, PMA, 4methylthioamphetamine, and phentermine with the amphetamine assay. They concluded that the assays are useful for the examination of blood, urine, and saliva at drug concentrations as low as $6 \mathrm{ng} / \mathrm{mL}$ without interferences from putrefactive amines. Recently, Kerrigan et al. published a more comprehensive evaluation of psychedelic phenethylamines (i.e., 2C-B, 2C-I, DOB, DOI), ${ }^{(121)}$ while Nakanishi et al. reported crossreactivities for additional phenethylamines. ${ }^{(63)}$ However, these studies have incorporated relatively few designer drug compounds or synthetic cathinones, and some drugs only demonstrate minimal cross-reactivity, indicating that abuse of these substances may not be detected. 
Several authors have also reported cross-reactivities of designer drugs when performing drug screens in case work for intoxications or deaths using a variety of types of immunoassays. Both BZP and TFMPP have been reported to cross-react in urine at varying concentrations with EMIT d.a.u. (drug abuse assay) Amphetamine/ Methamphetamine II, Roche AbuScreen for Amphetamines, Syva EMIT II Plus for Amphetamines, and EMIT II Ecstasy. ${ }^{(122-124)}$ Cross-reactivity has also been reported for phentermine in meconium ( $89 \%$ at $25 \mathrm{ng} / \mathrm{g}$ using Immunalysis ELISA for amphetamine), AMT in urine and gastric contents (using Syva EMIT for amphetamines), and mCPP in urine (positive at $5000-7500 \mathrm{ng} / \mathrm{mL}$ using EMIT II Ecstasy). ${ }^{(25,58,124)}$ Others have reported that drugs such as $\mathrm{DOB}, 5-\mathrm{MeO}-\mathrm{DiPT}, 2 \mathrm{C}-\mathrm{T}-4$, and mephedrone test negative on screens for amphetamine, methamphetamine, or MDMA. ${ }^{(96,125-127)}$ Most recently, Torrance et al. reported cross-reactivity of mephedrone with a methamphetamine-based Immunalysis ELISA assay when investigating four fatalities. ${ }^{(7)}$ The cross-reactivities ranged from $1-3 \%$ in urine and blood, yet no cross-reactivity was demonstrated with the amphetamine assay up to $5000 \mathrm{ng} / \mathrm{mL}$. With regard to bath salts, cross-reactivity has been observed with butylone on the Microgenics CEDIA amphetamines/ecstasy immunoassay ${ }^{(128)}$ and well as with MDPV towards the PCP (phencyclidine) assay. ${ }^{(129)}$

Based on these data, there is a critical need in the field of forensic toxicology for reliable screening assays for multiple designer drugs, in addition to analytical methods optimized for comprehensive screening and confirmation of such drugs in a variety of human specimens for both ante- and post-mortem investigation. The major goal of the present study was to evaluate the performance of commercially available screening immunoassays for detecting a wide range of designer drugs. Since each manufacturer 
likely uses different antibodies, the specificity cannot always be predicted or compared to other types of immunoassays (e.g., EMIT), different matrices (i.e., meconium, whole blood, oral fluid), or different manufacturers. Regardless of the cross-reactivity that may occur, it is imperative that the forensic analytical toxicology community be made aware of the results, as screening techniques are limited for designer drugs, particularly the cathinone derivatives. The present study was, in part, conducted to determine if preexisting immunoassays are capable of reliably detecting these compounds. A focus was placed on amphetamine and methamphetamine/MDMA kits, as these types of assays are typically used in routine drug screens by a majority of laboratories. Since presumptive methods, like ELISA, are the first line of screening methods for detecting drugs of abuse, it is necessary to understand how the compounds can be detected by currently available immunoassays, even if cross-reactivity is not expected.

\subsection{Materials and Methods}

\subsubsection{Materials}

\subsubsection{Chemicals}

The following drugs were obtained from LipoMed (Cambridge, MA, USA) as 1 $\mathrm{mg} / \mathrm{mL}$ calibrated reference standards in solvent: 2C-B, $( \pm)-3,4,5-\mathrm{TMA},( \pm)-4-$ methylethcathinone, $( \pm)$-butylone, $( \pm)$-cathinone, DMT, $( \pm)$-DOB, $( \pm)$-DOET, $( \pm)$-DOM, ( \pm )-flephedrone, mCPP, $( \pm)$-MDPV, $( \pm)$-mephedrone, $( \pm)$-methcathinone, $( \pm)$ methedrone, $( \pm)$-methylone, $( \pm)$-N-ethylamphetamine, and TFMPP. The following drugs were obtained from Cerilliant (Round Rock, TX) as $1 \mathrm{mg} / \mathrm{mL}$ calibrated reference standards in solvent: $(+)$-amphetamine, $(+)$-methamphetamine, ketamine, methylphenidate, $( \pm)$-amphetamine, $( \pm)$-MDA, $( \pm)$-MDEA, $( \pm)$-MDMA, and $( \pm)$ - 
methamphetamine. The following drugs were obtained from Grace Davison Discovery Sciences (Deerfield, IL, USA) as $1 \mathrm{mg} / \mathrm{mL}$ calibrated reference standards in solvent: 2CT-4, 2C-T-7, 2C-E, 2C-I, 5-MeO-DiPT, AMT, and BZP. An in-house standard of mephentermine, from powder, was available at a concentration of $1.02 \mathrm{mg} / \mathrm{mL}$ in methanol. The structures for each of the assay-targeted analytes and each of the analytes under investigation can be found in Figure 4 and Appendix 2, respectively. The drug name abbreviations can be found in Table 1. Methanol $\left(\mathrm{GC}^{2} \mathbb{\circledR}\right)$ was obtained from Honeywell Burdick \& Jackson (Muskegon, MI, USA). Dilution buffer (EIA buffer) and wash buffer (Wash Buffer Concentrate 10X) were obtained from Neogen Corporation (Lexington, KY, USA). All other materials and solutions were included in the individual immunoassays listed below. 


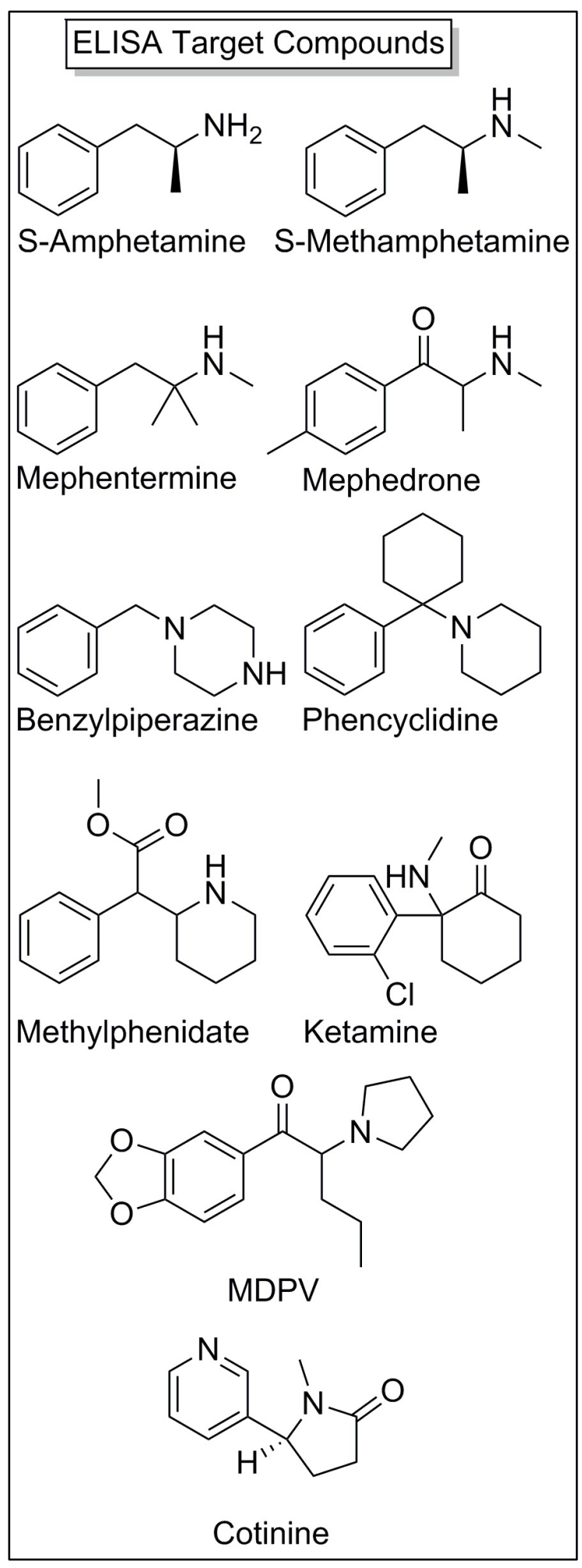

Figure 4: Structures of Target Compounds for ELISAs 


\subsubsection{ELISAs}

Sixteen immunoassay kits were obtained from four commercial manufacturers: Immunalysis Amphetamine Direct ELISA and Methamphetamine Direct ELISA (Pomona, CA); Neogen Amphetamine ELISA, Amphetamine Specific Forensic ELISA, Amphetamine Ultra Forensic ELISA, Benzylpiperazine Forensic ELISA, Ketamine Forensic ELISA, Methylphenidate Forensic ELISA, Methamphetamine/ MDMA Forensic ELISA, and Mephentermine Forensic ELISA (Lexington, KY, USA); Randox MDPV ELISA and Mephedrone/Methcathinone ELISA (Co. Antrim, UK); and OraSure Technologies PCP Intercept ${ }^{\circledR}$ Micro-Plate EIA, Cotinine Serum Micro-Plate EIA, Amphetamine-Specific Serum Micro-Plate EIA, and Methamphetamine Intercept ${ }^{\circledR}$ Micro-Plate EIA (Bethlehem, PA, USA). All of the antibodies were polyclonal in nature, with the exception of the PCP and Amphetamine-Specific assays from OraSure. Each kit consisted of 96-well microtiter plates coated with antibody for the targeted analyte, enzyme conjugate, TMB, and an acid stop solution. A summary of the commercial immunoassays tested in this study can be found in Table 2 . 
Table 2: Commercial ELISAs

\begin{tabular}{|c|c|c|c|c|}
\hline Company & Assay & Targeted Analyte $^{\mathrm{a}}$ & \begin{tabular}{|c|} 
Type of \\
Antibody
\end{tabular} & $\begin{array}{l}\text { Cut-Off }^{\text {b }} \\
\text { (ng/mL) }\end{array}$ \\
\hline \multirow{2}{*}{ Immunalysis } & Amphetamine Direct ELISA & d-Amphetamine & Polyclonal & 25 \\
\hline & Methamphetamine Direct ELISA & d-Methamphetamine & Polyclonal & 25 \\
\hline \multirow{8}{*}{ Neogen } & Amphetamine ELISA & d-Amphetamine & Polyclonal & 50 \\
\hline & Amphetamine Specific Forensic ELISA & d-Amphetamine & Polyclonal & 50 \\
\hline & Amphetamine Ultra Forensic ELISA & d-Amphetamine & Polyclonal & 50 \\
\hline & Benzylpiperazine Forensic ELISA & Benzylpiperazine & Polyclonal & 25 \\
\hline & Ketamine Forensic ELISA & Ketamine & Polyclonal & 50 \\
\hline & Methylphenidate Forensic ELISA & Methylphenidate & Polyclonal & 10 \\
\hline & Methamphetamine/MDMA Forensic ELISA & d-Methamphetamine & Polyclonal & 25 \\
\hline & Mephentermine Forensic ELISA & Mephentermine & Polyclonal & 10 \\
\hline \multirow{2}{*}{ Randox } & MDPV ELISA & MDPV & Polyclonal & 10 \\
\hline & Mephedrone/Methcathinone ELISA & Mephedrone & Polyclonal & 1.25 \\
\hline \multirow{4}{*}{ OraSure } & PCP Intercept ${ }^{\circledR}$ Micro-Plate EIA & Phencyclidine & Monoclonal & 20 \\
\hline & Cotinine Serum Micro-Plate EIA & Cotinine & Polyclonal & 100 \\
\hline & Amphetamine-Specific Serum Micro-Plate EIA & d-Amphetamine & Monoclonal & 50 \\
\hline & Methamphetamine Intercept ${ }^{\circledR}$ Micro-Plate EIA & d-Methamphetamine & Polyclonal & 10 \\
\hline
\end{tabular}

${ }^{a}$ Assay's targeted analyte used for controls.

${ }^{\mathbf{b}}$ Experimentally determined. See Materials and Methods.

\subsubsection{EMITs}

Two EMIT assays were obtained from Syva ${ }^{\circledR}$ (Siemens Healthcare Diagnostics; Newark, DE): EMIT® II Plus Ecstasy Assay and EMIT® ${ }^{\circledR}$ II Plus Amphetamines Assay. The antibodies for the Ecstasy assay were polyclonal while those for the Amphetamines assay were monoclonal. Each kit supplied antibodies, drug-enzyme conjugate and all other necessary solutions. The EMIT ${ }^{\circledR}$ and EMIT ${ }^{\circledR}$ II Plus Ecstasy calibrators and controls were also purchased from Syva ${ }^{\circledR}$. A summary of these assays can be found in Table 3. 
Table 3: Commercial EMITs

\begin{tabular}{|c|c|c|c|}
\hline Company & Assay & $\begin{array}{c}\text { Type of } \\
\text { Antibody }\end{array}$ & $\begin{array}{c}\text { Cut-Off } \\
\text { (ng/mL) }\end{array}$ \\
\hline \multirow{2}{*}{ Syva } & $\begin{array}{c}\text { EMIT II Plus } \\
\text { Amphetamines }\end{array}$ & Monoclonal & 300 \\
\cline { 2 - 4 } & EMIT II Plus Ecstasy & Polyclonal & 300 \\
\hline
\end{tabular}

${ }^{\mathrm{a}}$ Chosen from Manufacturer. See Materials and Methods (3.3.4.3).

\subsubsection{Samples}

Drug-free frozen serum, pooled from nine donors, was obtained from Utak Laboratories (Valencia, CA, USA) and screened negative by ELISA for amphetamine, benzoylecgonine, ethanol, methamphetamine, morphine, oxazepam, phencyclidine, secobarbital, and 11-nor-9-carboxy-THC. This blank matrix was used for the preparation of controls as well as spiked samples. After thawing, it was stored at $4{ }^{\circ} \mathrm{C}$.

Drug-free urine was obtained from a volunteer and used for the preparation of spiked samples. After collection, it was stored at $4^{\circ} \mathrm{C}$.

\subsubsection{Sample preparation}

For determination of cross-reactivity by ELISA, samples of drug-free serum $(0.5$ $\mathrm{mL}$ ) were fortified with $50 \mu \mathrm{L}$ of a methanolic spiking solution for analysis (see below). All calibrators, controls, and samples were subjected to a 1:4 (i.e., 5-fold) dilution with buffer (EIA buffer) using a Hamilton Microlab ${ }^{\circledR} 500$ Dual Syringe Diluter (Reno, NV). The dilution factor chosen was recommended by the manufacturer for forensic blood specimens. This helped to achieve uniformity and consistency between assays. For analysis by EMIT, samples of drug-free urine $(1 \mathrm{~mL})$ were fortified with $100 \mu \mathrm{L}$ of a 
methanolic spiking solution for analysis (see section 3.3.4.2 below). The urine samples were not diluted prior to analysis, per manufacturer instructions.

\subsubsection{Evaluation of cross-reactivity}

\subsubsection{Instrumentation}

The ELISAs were performed using a DSX $®$ Four-Plate Automated ELISA processing System (Dynex Technologies; Chantilly, VA, USA) operating Revelation version 6.15 software. The plates were read using a $450 \mathrm{~nm}$ filter. Test procedures were carried out according to manufacturers' instructions listed in the package inserts, as summarized in Appendix 3. All incubations were performed at ambient temperature. Wash buffer was diluted 10X with deionized (DI) water for use in the wash step (unless

otherwise noted). Conjugates that were not 'ready-to-use' were diluted according to the package inserts with the appropriate diluents provided from the manufacturer.

EMIT was performed using a V-Twin ${ }^{\circledR}$ analyzer (Siemens). The methods for qualitative analyses were downloaded from the manufacturer and carried out according to instructions. Daily calibrations were performed by running the appropriate calibrators for a $300 \mathrm{ng} / \mathrm{mL}$ cut-off. The calibration was validated by running negative and positive controls at the appropriate levels, per the kit inserts. Once the calibration was validated, urine specimens were analyzed.

\subsubsection{Preparation of solutions}

For 'targeted analytes' (Figure 4), $1 \mathrm{mg} / \mathrm{mL}$ methanolic reference standards were diluted with methanol for a final concentration of $100,000 \mathrm{ng} / \mathrm{mL}$ working stock. These were diluted further to create spiking standards at concentrations of 2,000, 1,000, 500, 
$250,100,50,25$, and $10 \mathrm{ng} / \mathrm{mL}$ in methanol. For the analytes under investigation, 'analytes of interest' (Appendix 2), $1 \mathrm{mg} / \mathrm{mL}$ reference standards were diluted with methanol (or appropriate solvent) for a final concentration of $100,000 \mathrm{ng} / \mathrm{mL}$ working stock. These were diluted further to create spiking standards at concentrations of 50,000, $25,000,12,500,6,250,3,125,1,562,781.2,390.6,195.3,97.6 \mathrm{ng} / \mathrm{mL}$ in methanol (or solvent).

\subsubsection{Establishing cut-off values}

The optimal range for cut-off values is typically provided by the kit's manufacturer for enzyme-linked immunosorbent assays. However, due to instrumental variation and varying matrices, it is important to determine the cut-off concentration from a dose response curve. There should be a displacement between 30 and $60 \%$ of $\mathrm{B} / \mathrm{B}_{0}$, where $\mathrm{B}=$ raw absorbance and $\mathrm{B}_{0}=$ raw absorbance of the blank matrix, in order to demonstrate the greatest discrimination between positives and negatives. This level of displacement is consistent with the manufacturers' kit inserts and was used for determining the matrix-matched serum controls for the study. For each assay, the cut-off value was determined by preparing dose response curves in triplicate at decreasing concentrations by spiking $0.5 \mathrm{~mL}$ of serum with $50 \mu \mathrm{L}$ of a methanolic spiking solution of the targeted analyte $(10-100,000 \mathrm{ng} / \mathrm{mL})$ to achieve concentrations in the range of 1 $10,000 \mathrm{ng} / \mathrm{mL}$. These samples were subjected to the dilution as previously described before analysis. The absorbance values at each concentration were averaged and displacement was calculated. The cut-off value with a displacement between 30 and $60 \%$ was chosen to be the 'positive cut-off' for all future experiments with that assay. Negative controls and positive cut-off controls, made fresh daily, were run in duplicate 
with each assay during an experiment. A sample whose absorbance was greater than or equal to 1.2 times the absorbance of the positive cut-off control was considered negative. A sample whose absorbance was less than or equal to the positive cut-off control was considered positive. A sample whose absorbance was between that of the positive cut-off control and 1.2 times the absorbance of the positive cut-off controls was considered ' + /-' or indeterminate.

For the EMIT assays, calibrators and controls were purchased from the manufacturer. To calibrate the Amphetamines assay for a $300 \mathrm{ng} / \mathrm{mL}$ cut-off, EMIT ${ }^{\circledR}$ Calibrator/Control Level 1 was used. To calibrate the Ecstasy assay for a $300 \mathrm{ng} / \mathrm{mL}$ cutoff, EMIT® Ecstasy Calibrator/Control Level 2 was used. For a negative control, EMIT® Calibrator/Control Level 0 was used for both assays. For positive controls, EMIT® Calibrator/Control Level 5 (2,000 ng/mL) was used for Amphetamines and EMIT® Calibrator/Control Level 4 (1,000 ng/mL) was used for Ecstasy.

\subsubsection{Determining cross-reactivity}

In order to initially assess cross-reactivity by ELISA, $50 \mu \mathrm{L}$ of each analyte of interest at $100,000 \mathrm{ng} / \mathrm{mL}$ was spiked into $0.5 \mathrm{~mL}$ of serum, in duplicate, for a final concentration of $10,000 \mathrm{ng} / \mathrm{mL}$. This concentration level was chosen based on the crossreactivity studies performed by the manufacturers as outlined in the package inserts. These samples were diluted as previously described before analysis. The absorbance values at each concentration were averaged. If a drug resulted in a 'positive' on the DSX report at this concentration when compared to the positive cut-off level, a dose response curve was then prepared and analyzed to calculate the cross-reactivity. For these compounds, dose response curves were prepared in duplicate at decreasing 
concentrations by spiking $0.5 \mathrm{~mL}$ of serum with $50 \mu \mathrm{L}$ of a spiking solution (97.6$100,000 \mathrm{ng} / \mathrm{mL}$ ) to achieve concentrations in the range of 9.76 to $10,000 \mathrm{ng} / \mathrm{mL}$. In order to calculate the percent cross-reactivity, the percent binding (calculated as $\left.\left[\mathrm{A}_{\text {sample }} / \mathrm{A}_{\text {negative }}\right]^{*} 100\right)$ was determined for each analyte at each concentration tested. ${ }^{(121)}$ From these values, the $\mathrm{EC}_{50}$ (half-maximal effective concentration) was also calculated for each targeted analyte and each analyte of interest. The concentration of each analyte of interest that produced an absorbance reading closest to that of the positive cut-off control was also calculated. This value is represented by the $\mathrm{A}_{\text {sample }} / \mathrm{A}_{\text {negative }}$ with a ratio closest to 1 . The positive cut-off level was then divided by the concentration of each analyte with the same absorbance value and expressed as a percent, representing the percent cross-reactivity. ${ }^{(121)}$ For terminology purposes, 'cross-reactive' is used for a compound of interest which exhibits a positive result by the DSX when compared to the positive cut-off control.

In order to initially assess cross-reactivity via EMIT, $50 \mu \mathrm{L}$ of each analyte of interest at $100,000 \mathrm{ng} / \mathrm{mL}$ was spiked into $0.5 \mathrm{~mL}$ of urine, in duplicate, for a final concentration of $10,000 \mathrm{ng} / \mathrm{mL}$. The samples were analyzed after calibration was validated with appropriate controls. If a drug resulted in a "positive" on the V-Twin report at this concentration when compared to the cut-off level, a dose response curve was then prepared and analyzed to calculate cross-reactivity. For these compounds, dose response curves were prepared in duplicate at decreasing concentrations by spiking 0.5 $\mathrm{mL}$ of urine with $50 \mu \mathrm{L}$ of a spiking solution $(97.6-100,000 \mathrm{ng} / \mathrm{mL})$ to achieve concentrations in the range of $9.76-10,000 \mathrm{ng} / \mathrm{mL}$. In order to calculate the percent cross-reactivity, the concentration of each analyte of interest that produced an absorbance 
reading equivalent to that of the $300 \mathrm{ng} / \mathrm{mL}$ cut-off control was used (as described for the ELISA calculations above).

\subsection{Results and Discussion}

\subsubsection{Establishing cut-off values}

For each assay, the displacement was calculated for each level of targeted analyte in the dose response curve. The concentration with a displacement value from $30-60 \%$ was chosen as the cut-off and used as positive cut-off controls for future experiments. A summary of these concentrations can be found in Table 2. An example of a dose response curve used for the determination of a cut-off value for Neogen Ketamine can be found in Figure 5. The values ranged from $1.25-100 \mathrm{ng} / \mathrm{mL}$ and were comparable to those cited in the package inserts. While some of these levels are quite low, the assays are not quantitative and can only presumptively identify a class of compounds. An analytical method with lower detection limits (such as LC-MS/MS) is recommended for confirmation or quantification of such compounds. For the EMIT assays, there were several cut-off levels available among the various levels of EMIT® calibrators and controls. For both the Amphetamines and Ecstasy assays, the lowest level $(300 \mathrm{ng} / \mathrm{mL})$ was chosen. 


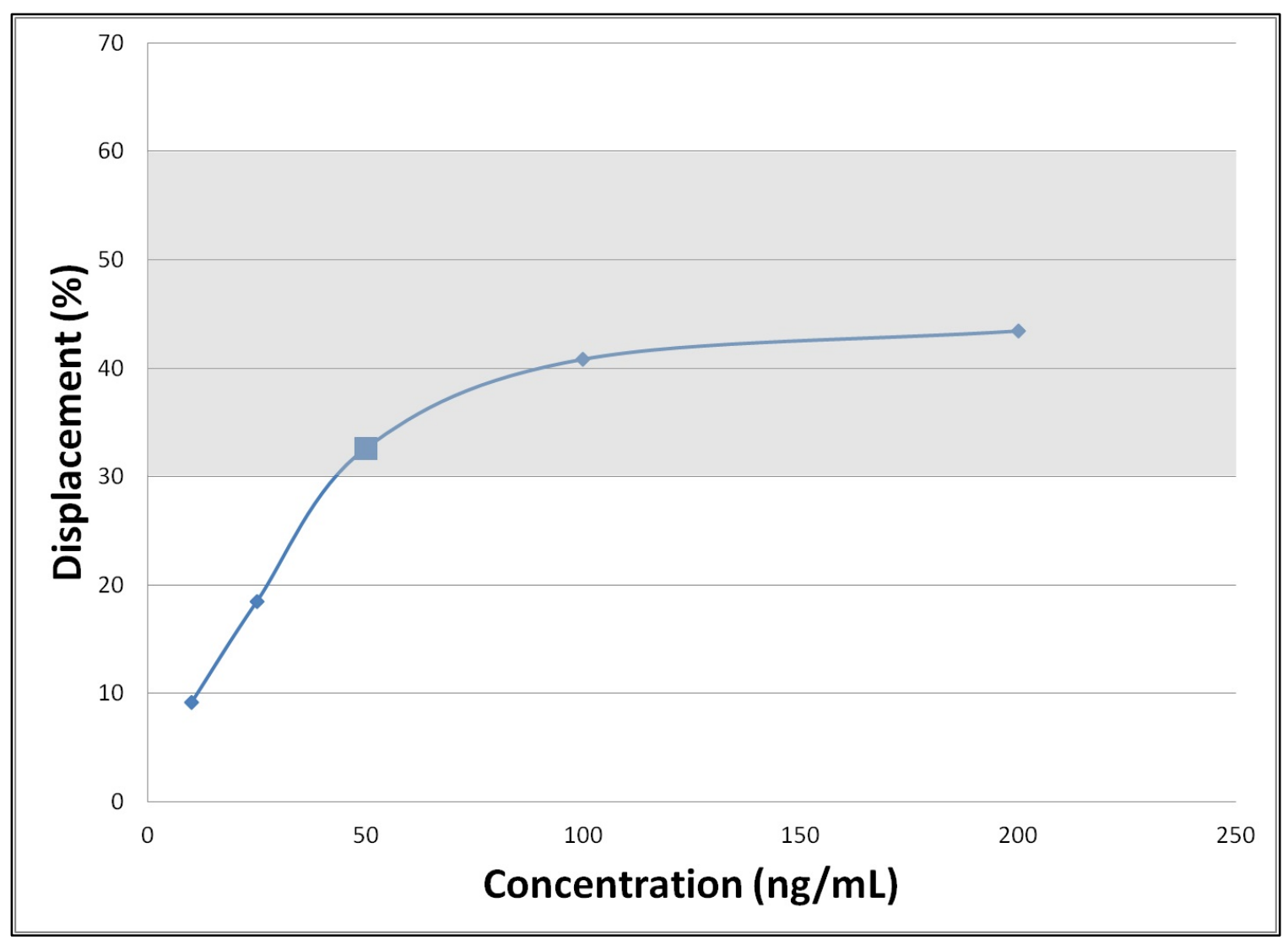

Figure 5: Ketamine Dose Response Curve

Demonstrates displacement $(\%)$ versus concentration $(\mathrm{ng} / \mathrm{mL})$. The ideal range for percent displacement is shaded. The data point for the chosen cutoff level is indicated by 


\subsubsection{Determining cross-reactivity}

\subsubsection{ELISA}

The analytes of interest which did not generate a positive result for a specific assay at 10,000 ng/mL were not further analyzed for that assay. The cut-off equivalent concentration, percent cross-reactivity, and $\mathrm{EC}_{50}$ for these analytes were calculated using the value at that level. Compounds which did indicate a positive result at $10,000 \mathrm{ng} / \mathrm{mL}$ were further analyzed down to concentrations as low as $10 \mathrm{ng} / \mathrm{mL}$ or until a negative result was produced. The dose response curves for these analytes were constructed (\% binding vs. analyte concentration) in order to visually examine the cross-reactivity as well as the $\mathrm{EC}_{50}$. Detailed results for individual platforms are presented in Appendix 4 for all 16 assays. A brief summary of the findings can also be found in Table 4 .

Several assays did not exhibit cross-reactivity with any of the analytes of interest: Neogen Ketamine, Neogen Methylphenidate, OraSure PCP, and OraSure Cotinine. This was not unexpected, due to the structural differences between the analytes targeted by the assay and those under investigation here. The Neogen BZP assay demonstrated minimal cross-reactivity with MDEA, MDMA, and DMT at concentrations $(5,000$ to 10,000 $\mathrm{ng} / \mathrm{mL}$ ) which most likely would not be encountered in a case. There are other more sensitive assays useful for detecting MDEA and MDMA. The cross-reactivity values for these compounds were less than $0.5 \%$ and are probably not significant. As reported in the manufacturer package inserts, amphetamine and/or methamphetamine were without any cross-reactivity, consequently positives from similar compounds to the amphetamines would not be anticipated. As mephentermine is structurally similar to methamphetamine, it was not a surprise that methamphetamine and MDMA 
demonstrated cross-reactivity at concentrations as low as 250 and $200 \mathrm{ng} / \mathrm{mL}$, respectively, with cross-reactivity values of $4 \%$ and $5 \%$, respectively. These concentrations are well within the range of those typically encountered in forensic specimens. The Neogen mephentermine assay also demonstrated minimal crossreactivity with MDEA and ethylamphetamine, analytes that are also structurally similar. This cross-reactivity is also likely to be of less significance, since the positive results occurred at relatively high concentrations: 1,250 and $1,750 \mathrm{ng} / \mathrm{mL}$, respectively. 
Table 4: Summary of Cross-Reactivity Data by Assay

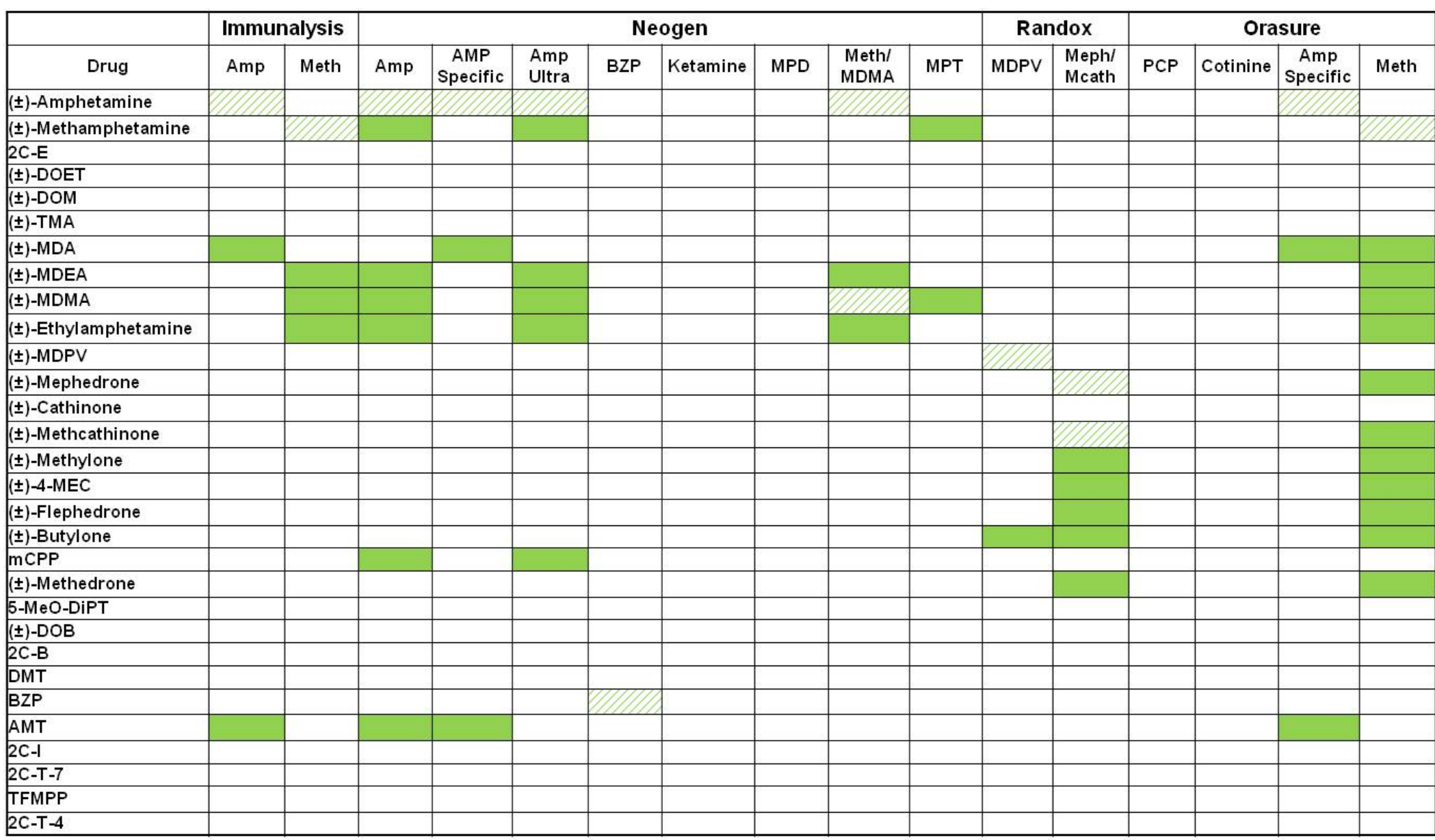

Target analyte

Cross-reactive at concentrations $<650 \mathrm{ng} / \mathrm{mL}$

Amp - amphetamine; BZP - benzylpiperazine; Meph - mephedrone; Meth - methamphetamine; Mcath - methcathinone; MPD - methylphenidate; MPT - mephentermine 
Upon investigation of the amphetamine-targeting assays, it became apparent these assays are quite selective. The Immunalysis amphetamine, Neogen amphetar specific, and OraSure amphetamine specific assays all produced positive test results MDA and AMT at concentrations between 10-150 ng/mL, depending on the kit. $\mathrm{Tl}$ extensive cross-reactivity with MDA (90-250\%) was expected, per the manufacture data. The cross-reactivity with AMT (30-120\%) was not entirely surprising, given cross-reactivity reported by Boland et al. for the same compound in post-mortem ur and gastric contents when analyzed by EMIT amphetamine immunoassay. ${ }^{(25)}$ The $\mathrm{c}$ two assays, Neogen Amphetamine and Neogen Amphetamine Ultra, were less speci and demonstrated cross-reactivity with methamphetamine, MDEA, MDMA, ethylamphetamine, $\mathrm{mCPP}$, and AMT in the range of $10-1,250 \mathrm{ng} / \mathrm{mL}$. The results $\mathrm{f}$ methamphetamine and MDMA were consistent with those reported in the package inserts. MDEA and ethylamphetamine, both structurally similar to amphetamine, wt not included in the manufacturer's data but the results appear reasonable given thos MDMA. The cross-reactivity towards AMT was also not unexpected, given the res from the more specific amphetamine assays. The most remarkable result was that $\mathrm{ft}$ mCPP, with cross-reactivity noted at concentrations of approximately $150 \mathrm{ng} / \mathrm{mL}$ fo of these assays, resulting in cross-reactivity values of $32 \%$. Without additional information regarding the specific antibody used in the kits (e.g., hapten and carrier for immunization, method of purification), it is difficult to explain this phenomenon However, it is corroborated by the fact that TFMPP, similar in structure to mCPP, a demonstrated cross-reactivity at concentrations around $2,500 \mathrm{ng} / \mathrm{mL}$. This result co further explored by analysis with authentic specimens. 
After examining the analytes of interest by methamphetamine-based assays, it was evident that the results were comparable to those using assays targeting amphetamine, except with regard to the cathinone derivatives. The Immunalysis Methamphetamine, Neogen Methamphetamine/MDMA, and OraSure Methamphetamine assays displayed positive test results for MDEA, MDMA, and ethylamphetamine at low concentrations, with cross-reactivities between 15 and 250\%. While cross-reactivity was less than $2 \%$ for the cathinone derivatives using the Immunalysis or Neogen methamphetamine assays, with positive test results at levels as low as $1,250 \mathrm{ng} / \mathrm{mL}$, the OraSure assay demonstrated greater cross-reactivity for this class of compounds. Positive test results for mephedrone, methcathinone, methylone, 4-MEC, flephedrone, butylone, and methedrone were still observed at concentrations as low as $40-450 \mathrm{ng} / \mathrm{mL}$, with cross-reactivity values in the range of $2-25 \%$. While these findings indicate that the OraSure methamphetamine assay is less specific than those from Immunalysis or Neogen, they also demonstrate that this assay may be a viable screening tool for presumptively detecting bath salts in biological fluids at concentrations that can be encountered in forensic specimens, without necessarily targeting overdose levels. It is important to note that the OraSure Methamphetamine kit is designed for screening in oral fluid, so it may not be commonly used by laboratories screening other matrices and may require additional validation.

While the previously described assays targeted amphetamine, methamphetamine, or other commonly encountered drugs, the Randox assays were specifically designed to detect bath salts or cathinone derivatives. The Randox MDPV assay was extremely selective, with only butylone demonstrating cross-reactivity at levels as low as 150 
$\mathrm{ng} / \mathrm{mL}$. Since the MDPV assay did not produce positive test results with other cathinone derivatives, it can be hypothesized that the side chain on the alpha-carbon of MDPV behaves similarly to the side chain on butylone. The Randox

Mephedrone/Methcathinone assay was less specific, since the other cathinone derivatives were still positive by the DSX at $150 \mathrm{ng} / \mathrm{mL}$ when compared to the positive cut-off control. Alternatively, the Mephedrone/Methcathinone assay did not demonstrate crossreactivity towards MDPV, which might indicate that the activity is hindered by the nitrogen-containing ring system on MDPV. This assay, however, did not demonstrate cross reactivity towards other phenethylamines. While decomposed specimens have not yet been evaluated in the present study, the Randox Mephedrone/Methcathinone assay may be beneficial as a screening tool for targeting bath salts, as putrefactive amines may not interfere due to the high selectivity of these assays.

\subsubsection{EMIT}

The analytes of interest that did not generate a positive result for a specific assay at $10,000 \mathrm{ng} / \mathrm{mL}$ were not further analyzed for that kit. The cut-off equivalent concentration and percent cross-reactivity were calculated using the value at that level. Compounds which did indicate a positive result at $10,000 \mathrm{ng} / \mathrm{mL}$ were further analyzed down to concentrations as low as $10 \mathrm{ng} / \mathrm{mL}$ or until a negative result was produced. The dose response curves for these analytes were constructed in order to examine the crossreactivity. These data are summarized in Table 5. 
Table 5: Cross-Reactivity Data for EMITs

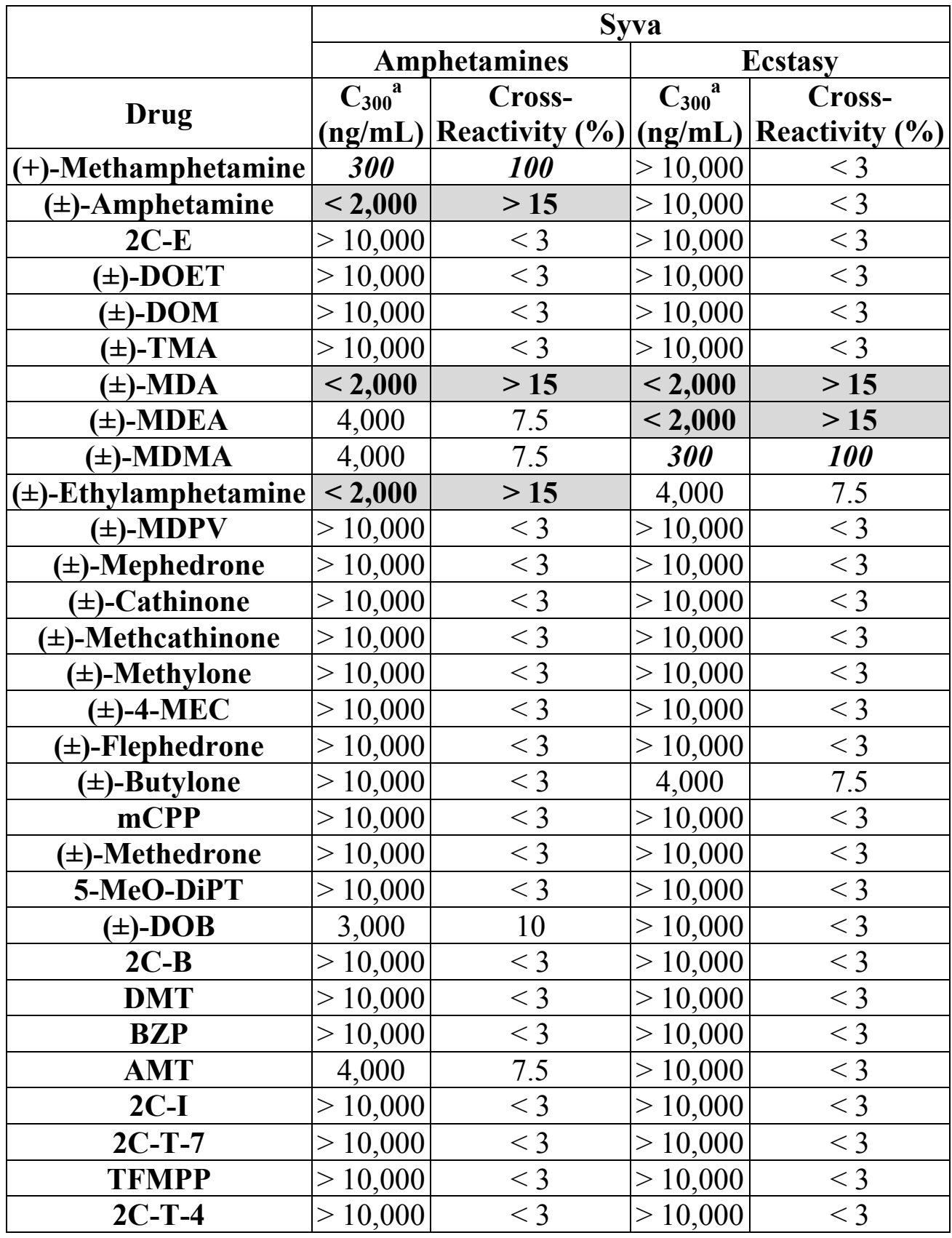

${ }^{\text {a }}$ Concentration of the drug that produces an absorbance reading equivalent to the 300 $\mathrm{ng} / \mathrm{mL}$ cut-off.

Analytes demonstrating high cross-reactivity are highlighted and bolded.

The target analytes for each assay are italicized and bolded. 
The values for cross-reactivity for the compounds of interest were consistent with literature and the package inserts. The Amphetamines assay uses $d$-methamphetamine as the cut-off control, so the results for amphetamine were to be expected. The crossreactivity with MDA, MDEA, and MDMA are comparable to those in the kit insert. From the behavior of AMT in the serum ELISAs, the reactivity of AMT was not unexpected, although it was not very high. With regard to the Ecstasy assay, the crossreactivities for MDA and MDEA were comparable to those stated in the package insert. Surprisingly, butylone exhibited some cross-reactivity down to $4,000 \mathrm{ng} / \mathrm{mL}$, which may indicate the level at which antibody binding occurs. However, the cathinone derivatives remained undetected by these assays at high concentrations and would not be expected to be identified in urine by either of these assays.

\subsection{Conclusions}

In this comprehensive study, 30 designer drug entities from the phenethylamine, tryptamine, and piperazine structural classes were evaluated against 16 different commercial ELISA kits in order to determine cross-reactivity. Since few assays are currently available that target these analytes, particularly the bath salts, it was important to understand how they may react, especially in presumptive screens. For the assays targeting amphetamine or methamphetamine, cross-reactivity towards the cathinone derivatives was minimal. MDA, MDMA, ethylamphetamine, and $\alpha$-methyltryptamine (AMT) demonstrated cross-reactivity at low concentrations, but results were consistent with those published by the manufacturer or as reported in the literature. Of note, the cathinone derivatives demonstrated cross-reactivity at low concentrations $(<150 \mathrm{ng} / \mathrm{mL})$ 
when analyzed against the Randox Mephedrone/Methcathinone assay. While this assay seemed less selective, there was no cross-reactivity with other amphetamine-like compounds. This finding suggests that the Randox assay may be useful for detecting a wide range of bath salts in postmortem specimens, without the usual interference from putrefactive amines formed during decomposition. However, a majority of the assays analyzed, particularly those targeting phenethylamines, did not exhibit cross-reactivity with the compounds of interest, particularly the cathinone derivatives.

An important conclusion from the present study is that current immunoassaybased screening methods may not be ideal for presumptively identifying most designer drugs, including the bath salts. Recently, there has been a trend toward the introduction of new immunoassays with specificity for individual designer drugs or groups of drugs, a development that can, at least to some extent, help address this problem. Alternatively, as more laboratories move towards LC-MS/MS as an in-house analytical tool, screening methods for such analytes will likely gravitate towards higher specificity approaches, in particular high-resolution, high mass accuracy MS. 


\section{COMPREHENSIVE LC-MS METHOD}

\section{Copyright (C) 2012 Springer-Verlag Berlin Heidelberg}

Swortwood, M. J., Boland, D. M., DeCaprio, A. P. (2012) Determination of 32 cathinone derivatives and other designer drugs in serum by comprehensive LC-QQQ-MS/MS analysis. Analytical and Bioanalytical Chemistry 405, 1383. DOI 10.1007/s00216-012$6548-8$

Original copyright notice is given to the above publication in which the material was originally published, with kind permission from Springer Science and Business Media.

\subsection{Overview}

Recently, the use of LC-MS for analysis of drugs of abuse has been on the rise. While GC-MS used to be the analytical method of choice, mass spectral library entries for many of the designer entities do not exist and GC-based methods are often limited to non-polar, volatile, and thermally stable compounds. LC-based methods allow for increased sensitivity of a wide variety of compounds without the need for derivatization, while offering higher sample throughput, easier sample preparation, and structural elucidation. ${ }^{(41,91,92)}$ Ultra-fast methods, such as the one presented here, can be used when applying ultrahigh-pressure to the chromatographic system. Several methods exist for the detection of these compounds in biological specimens but comprehensive methods incorporating such a high number of compounds across the three major classes are lacking. 


\subsection{Introduction}

In 2010, Wohlfarth et al. described a method for the detection of amphetamines, tryptamines, piperazines, and several cathinone derivatives in human serum by LCMS/MS with limits of detection in the 1.0 to $5.0 \mathrm{ng} / \mathrm{mL}$ range. ${ }^{(53)}$ However, the method was not fully validated and does not include some of the more popular synthetic drugs. Other research has focused on LC-MS analysis of a single drug class ${ }^{(130,131)}$ or a smaller selection of analytes. ${ }^{(128,132)}$ Currently, there are few published bioanalytical methods available for the comprehensive confirmatory analysis of all these compounds. The method presented here utilizes LC coupled to a triple quadrupole (QQQ) mass spectrometer for the quantification of over thirty designer drugs in serum, after sample processing by SPE. LC-QQQ-MS is becoming more widely available in the forensic toxicology laboratory community. In contrast, while high resolution MS, such as a quadrupole-time-of-flight (QTOF), is ideal for identifying designer drugs by exact mass analysis, the cost of instrumentation QTOF often prohibits its use in toxicology laboratories for method development or routine casework. The LC-QQQ-MS method was fully validated and was also successfully applied to the analysis of two post-mortem specimens involving suspected "bath salts" use.

\subsection{Materials and Methods}

\subsubsection{Chemicals}

The following drugs were obtained from LipoMed (Cambridge, MA) as $1 \mathrm{mg} / \mathrm{mL}$ calibrated reference standards in solvent (see Table 1 for abbreviations): 2C-B, 3,4,5TMA, 4-MEC, butylone, cathinone, DMT, DOB, DOET, DOM, flephedrone, mCPP, MDPV, mephedrone, methcathinone, methedrone, methylone, $\mathrm{N}$-ethylamphetamine, and 
TFMPP. The following drugs were obtained from Cerilliant (Round Rock, TX) as 1 $\mathrm{mg} / \mathrm{mL}$ calibrated reference standards in solvent: amphetamine, MDA, MDEA, MDMA, and methamphetamine. The following drugs were obtained from Grace Davison Discovery Sciences (Deerfield, IL) as $1 \mathrm{mg} / \mathrm{mL}$ calibrated reference standards in solvent: 2C-T-4 2C-T-7, 2C-E, 2C-I, 5-MeO-DiPT, 5-MeO-DMT, AMT, and BZP. The structures, drug classes (i.e., phenethylamines, tryptamines, and piperazines), and compound names can be found in Appendix 1. Methanolic solutions of the following deuterated internal standards were purchased from LipoMed as $0.1 \mathrm{mg} / \mathrm{mL}$ standards: $d 6$ amphetamine, $d 5$-MDMA, and $d 3$-mephedrone. Methanolic solutions of the following deuterated internal standards were purchased from Cerilliant as $0.1 \mathrm{mg} / \mathrm{mL}$ standards: $d 7$ BZP, $d 3$-methylone, and $d 4$ - TFMPP. Structures of the internal standards can be found in Table 6. DBZP was purchased as a bulk powder from Sigma-Aldrich (St. Louis, MO) as it was not available as a calibrated reference standard.

2-Propanol (IPA, analytical grade), acetonitrile (Optima® LC-MS grade), ammonium formate, hydrochloric acid ( $\mathrm{HCl}$, analytical grade), glacial acetic acid (analytical grade), and methanol (Optima ${ }^{\circledR}$ LC-MS grade) were obtained from Fisher Scientific (Fair Lawn, NJ). Ammonium hydroxide (analytical grade) from Acros Organics (NJ), dichloromethane (analytical grade) from EMD Chemicals (Gibbstown, NJ), formic acid (Optima ${ }^{\circledR}$ LC-MS grade) from Fisher Scientific (Fair Lawn, NJ), and sodium phosphate monobasic monohydrate and dibasic heptahydrate (both analytical grade) from Acros (NJ) were also purchased for preparation of SPE solutions and mobile phases. All water was purified using a Barnstead NanoPure Infinity filtration system (Dubuque, IA). Resprep Drug Prep I cartridges (200 mg; $10 \mathrm{~mL}$ ) for solid-phase 
extraction were purchased from Restek (Bellefonte, PA) for manual extraction performed on a Supelco Visiprep-DL Disposable Liner SPE vacuum manifold.

Table 6: Structures of Deuterated Internal Standards

Internal Standard




\subsubsection{Samples}

Pooled blank human serum recovered from six whole blood donations (three male, three female) was used for method development and validation and was obtained from Bioreclamation (Westbury, NY). Quantitative analysis was performed on authentic post-mortem blood specimens that were submitted to our laboratory at Florida International University. The forensic specimens contained no identifying information about the decedent and were merely labeled "Case 1" and "Case 2". All samples were stored at $-20{ }^{\circ} \mathrm{C}$

\subsubsection{Sample Preparation}

Serum samples $(1 \mathrm{~mL})$ were diluted with $2 \mathrm{~mL}$ of sodium phosphate buffer (100 $\mathrm{mM}, \mathrm{pH}$ 6.0). After addition of $20 \mu \mathrm{L}$ of internal standards (IS) containing $1 \mu \mathrm{g} / \mathrm{mL}$ each of d6-amphetamine, d7-BZP, d5-MDMA, d3-mephedrone, d3-methylone, and d4TFMPP, the samples were gently vortexed and loaded onto a mixed-mode (Drug Prep I) SPE cartridge that was previously conditioned with $3 \mathrm{~mL}$ of methanol, $3 \mathrm{~mL}$ of water, and $1 \mathrm{~mL}$ of phosphate buffer. After extraction, the cartridges were sequentially washed with $1 \mathrm{~mL}$ of water, $1 \mathrm{~mL}$ of $0.1 \mathrm{M}$ acetic acid, and then $1 \mathrm{~mL}$ of methanol. Vacuum was applied until the cartridges were dry. Analytes were then eluted slowly using two rounds of $1.5 \mathrm{~mL}$ of elution solvent, which consisted of dichloromethane, IPA, and ammonium hydroxide $(80: 20: 2 \mathrm{v} / \mathrm{v} / \mathrm{v}) .{ }^{(53,96)}$ The combined eluates were acidified with $100 \mu \mathrm{L}$ of $\mathrm{HCl}$ -IPA $(1: 3 \mathrm{v} / \mathrm{v})$ before evaporation in an Eppendorf Vacufuge at $30{ }^{\circ} \mathrm{C}$. When dry, the residue was reconstituted in $50 \mu \mathrm{L}$ of mobile phase and $5 \mu \mathrm{L}$ of extract was injected into the LC-MS/MS system. 


\subsubsection{LC-QQQ Analysis}

\subsubsection{Instrumentation}

The samples were analyzed using an Agilent 1290 Infinity Binary Pump LC coupled to an Agilent 6460 triple quadrupole MS/MS with Jet Streaming technology and electrospray ionization (ESI) using Agilent MassHunter software. Separation occurred on an Agilent Zorbax Rapid Resolution HD Eclipse Plus C18 LC column (50 x $2.1 \mathrm{~mm}$, $1.8 \mu \mathrm{m}$ particle size). Data acquisition was performed in Dynamic MRM mode with positive ESI using one principal MRM transition for quantification and one additional transition to serve as a qualifier for each analyte.

\subsubsection{LC Conditions}

Chromatographic separation occurred with gradient elution at a flow rate of 0.5 $\mathrm{mL} / \mathrm{min}$ using $2 \mathrm{mM}$ ammonium formate/ $0.1 \%$ formic acid in water as mobile phase A and acetonitrile/water $(90: 10 \mathrm{v} / \mathrm{v})$ with $0.1 \%$ formic acid as mobile phase B. The gradient was as follows: $5 \% \mathrm{~B}$ up to $35 \% \mathrm{~B}$ in 6 min as the analytical run, followed by a 30 s ramp up to $95 \%$ B and then a 1 min hold at $95 \%$ B for clean-up before a 3.5 -min reequilibration at $5 \% \mathrm{~B}$. The analytical column was kept at a temperature of $40^{\circ} \mathrm{C}$ in a thermostatted column compartment during separation.

\subsubsection{MS parameters}

MS source parameters were as follows: gas temperature, $320{ }^{\circ} \mathrm{C}$; gas flow 8 $\mathrm{L} / \mathrm{min}$; nebulizer 27 psi; sheath gas heater $380^{\circ} \mathrm{C}$; sheath gas flow $12 \mathrm{~L} / \mathrm{min}$; capillary voltage 3,750 V; and charging voltage $500 \mathrm{~V}$. Agilent MassHunter Optimizer software was used to optimize the data acquisition parameters for MRM mode by automatically selecting the best precursor ions and associated fragmentor voltages in addition to 
selecting the best fragment ions and collision energies for each transition. Enhanced sensitivity was achieved with the Dynamic MRM acquisition capabilities of the Agilent system, which utilizes analyte retention times, detection windows $\left(\Delta \mathrm{t}_{\mathrm{R}}\right)$, and a constant scan cycle time for precise detection of multiple analytes in a small $\Delta t_{R}$. Essentially, Dynamic MRM will only scan for the targeted transitions within a detection window centered around the analyte's retention time. When dealing with such a large number of compounds, this allows for increased sensitivity as the method will only be scanning for the expected transitions at a given chromatographic time. All detection windows were set at $0.4 \mathrm{~min}\left( \pm 0.2 \mathrm{~min}\right.$ around $\left.\mathrm{t}_{\mathrm{R}}\right)$. The dynamic MRM parameters are summarized in Appendix 5.

\subsubsection{Quantification}

Agilent MassHunter Quantitative Analysis software version B.04.00 was employed for the quantification of the analytes. Peak area ratios (i.e., drug vs. IS) were calculated and plotted against concentrations within the software. The internal standards for each analyte are indicated in Appendix 5.

\subsubsection{Assay Validation}

The LC-MS/MS assay was fully validated according to generally accepted guidelines. The experimental design for the validation experiments was based on those proposed by Peters et al. ${ }^{(133)}$ The parameters evaluated included selectivity, matrix effects, recovery, process efficiency, linearity, processed sample stability, freeze-thaw stability, precision, and accuracy. 


\subsubsection{Preparation of solutions}

Separate aqueous stock solutions were prepared during method development and optimization for each analyte at a concentration of $1 \mu \mathrm{g} / \mathrm{mL}$ from the commercially available calibrated reference standard $(1 \mathrm{mg} / \mathrm{mL}$ for targeted compounds, $0.1 \mathrm{mg} / \mathrm{mL}$ for internal standards). An aqueous spiking solution of the 32 analytes was prepared at a concentration of $10 \mu \mathrm{g} / \mathrm{mL}$ for each drug. This stock solution was used for the preparation of diluted aqueous spiking solutions at concentrations of 5,000, 3,000, 2,000, $1,000,500,200,20$, and $2 \mathrm{ng} / \mathrm{mL}$ each. An aqueous spiking solution of the six internal standards was prepared at a concentration of $1 \mu \mathrm{g} / \mathrm{mL}$ each. Separate aqueous spiking solutions were prepared at a concentration of $10 \mu \mathrm{g} / \mathrm{mL}$ and further diluted for the use in quality control (QC) samples. Aliquots of each solution were frozen and stored at $-20^{\circ} \mathrm{C}$.

\subsubsection{QC Samples}

Pools of QC samples containing the above-mentioned analytes in serum were prepared at four different concentrations: $10 \mathrm{ng} / \mathrm{mL}$ (LOQ), $25 \mathrm{ng} / \mathrm{mL}$ (LOW), 100 $\mathrm{ng} / \mathrm{mL}$ (MED), and $250 \mathrm{ng} / \mathrm{mL}$ (HIGH). The following volumes and concentrations were used to create the QC samples (volume of spiking solution, concentration of spiking solution, final volume): LOQ (1250 $\mu \mathrm{L}, 200 \mathrm{ng} / \mathrm{mL}, 25 \mathrm{~mL})$; LOW (1750 $\mu \mathrm{L}, 500$ ng/mL, $35 \mathrm{~mL})$; MED (1250 $\mu \mathrm{L}, 2000 \mathrm{ng} / \mathrm{mL}, 25 \mathrm{~mL})$; and HIGH (1750 $\mu \mathrm{L}, 5000$ $\mathrm{ng} / \mathrm{mL}, 35 \mathrm{~mL}$ ). Each pool was thoroughly mixed before aliquoting into $1 \mathrm{~mL}$ portions to be frozen at $-20^{\circ} \mathrm{C}$. The QC samples, prepared separately from the calibrators, are necessary for checking daily calibration curves and ensuring quality control throughout the length of a batch run. 


\subsubsection{Selectivity}

All of the analytes and internal standards were analyzed individually at a concentration of $1 \mu \mathrm{g} / \mathrm{mL}$ with the MRM method to ensure no interfering peaks. Then, samples from two different lots of blank pooled serum (each containing six donors) were prepared as described above to check for peaks that might interfere with the detection of the targeted analytes or internal standards. A zero sample (blank matrix + IS) from each lot was also analyzed in order to check that the internal standards did not interfere with the peaks of the analytes. A sample from each lot was also spiked with a solution containing all 32 analytes to check that the analytes did not interfere with the peaks of the internal standards. Agilent Mass-Hunter Qualitative Analysis software version B.03.01 was employed to analyze the resulting chromatograms.

\subsubsection{Matrix effects, recovery, and process efficiency}

Three sets of samples were prepared in this experiment: neat standards, spiked blank extracts, and extracts of spiked blanks ( $\mathrm{n}=5$ at each of two concentrations for a total of 30 samples), as recommended by Matuszewski et al. ${ }^{(134)}$ Set A consisted of adding 50 $\mu \mathrm{L}$ of spiking solution (500 or 5,000 ng/mL each), $20 \mu \mathrm{L}$ of internal standard solution (1000 ng/mL each), and $100 \mu \mathrm{L}$ of $\mathrm{HCl}-\mathrm{IPA}(1: 3 \mathrm{v} / \mathrm{v})$ to two $1.5-\mathrm{mL}$ portions of elution solvent that was mixed and then evaporated to dryness at $30{ }^{\circ} \mathrm{C}$ in a vacufuge. Then, the samples were reconstituted in $50 \mu \mathrm{L}$ of mobile phase A. Set B consisted of $1 \mathrm{~mL}$ samples of blank serum that were spiked with $70 \mu \mathrm{L}$ of water and then extracted using the procedure described above. The extracts were then spiked with $50 \mu \mathrm{L}$ of spiking solution (500 or $5,000 \mathrm{ng} / \mathrm{mL}$ each) and $20 \mu \mathrm{L}$ of IS (1,000 ng/mL each). These were acidified, evaporated to dryness, and reconstituted in $50 \mu \mathrm{L}$ of mobile phase A. Set C consisted of 
$1 \mathrm{~mL}$ samples of blank serum that were spiked with $50 \mu \mathrm{L}$ of spiking solution (500 or $5,000 \mathrm{ng} / \mathrm{mL}$ each) and $20 \mu \mathrm{L}$ of IS $(1,000 \mathrm{ng} / \mathrm{mL}$ each) to reach nominal concentrations of the targeted analytes at either 25 or $250 \mathrm{ng} / \mathrm{mL}$ each in serum. These were extracted as described above, acidified, evaporated to dryness, and reconstituted in $50 \mu \mathrm{L}$ of mobile phase A. For calculating matrix effect (ME), extraction efficiency/recovery (RE), and process efficiency (PE), absolute peak area ratios were used. In order to estimate ME, the peak areas of Set B were divided by those of Set A and multiplied by 100 to determine a percent. Values greater than $100 \%$ represent ion enhancement while those less than 100 $\%$ signify ion suppression. For determining RE, the peak areas of Set $\mathrm{C}$ were divided by those of Set B and then multiplied by 100. For PE, the peak areas of Set C were divided by those of Set A and then multiplied by 100. Means and RSDs, expressed as percentages, were calculated for each parameter.

\subsubsection{Processed sample stability}

In order to determine the stability of processed samples under the conditions of the LC-MS/MS analysis, $2 \mathrm{~mL}$ samples of blank serum ( $\mathrm{n}=8$ at each of two concentrations for a total of 16 samples) were spiked with $100 \mu \mathrm{L}$ of spiking solution (500 or $5,000 \mathrm{ng} / \mathrm{mL}$ each) and $40 \mu \mathrm{L}$ of IS $(1,000 \mathrm{ng} / \mathrm{mL}$ each) to reach nominal concentrations of 25 or $250 \mathrm{ng} / \mathrm{mL}$ each in serum. The samples were extracted as described above, acidified, evaporated to dryness, and reconstituted in $140 \mu \mathrm{L}$ of mobile phase A to ensure sufficient sample volume. These samples were then pooled and aliquoted into individual autosampler vials to be placed in the autosampler. Each sample was injected eight times over a course of $32 \mathrm{~h}$. The absolute peak areas were plotted versus time spent in autosampler. Changes within $\pm 15 \%$ were considered stable. 


\subsubsection{Linearity of calibration}

Aliquots of blank serum $(1 \mathrm{~mL})$ were spiked with $50 \mu \mathrm{L}$ of the corresponding spiking solutions to obtain calibration samples at nominal concentrations of 500, 250, $150,100,50,25,10$, and $1 \mathrm{ng} / \mathrm{mL}$ each in serum. Replicates $(\mathrm{n}=5)$ at each concentration were analyzed as described above. The regression lines were calculated in Agilent MassHunter Quantitative Analysis software using a weighted (1/x) model in order to account for heteroscedasticity. Linear regression lines were used in all but a few cases where slight curvature existed. The software was also used to check precision, accuracy, qualifier response ratios (for analyte and for internal standard), and retention times. The back-calculated concentrations were compared to their respective nominal concentrations. The calibrators whose back-calculated concentrations deviated more than $\pm 15 \%$ ( $\pm 20 \%$ around the LOQ) from the nominal values were excluded from the calculations of the daily calibration curves. For all future validation experiments, daily calibration curves at the same concentrations were prepared (single measurement per level) and analyzed with each batch.

\subsubsection{Precision and accuracy}

QC samples (LOQ, LOW, MED, HIGH; n=2 at each concentration) were analyzed as described above on each of eight days. The concentrations were calculated based on the daily calibration curves. Accuracy was calculated in terms of bias as the percent deviation of the mean calculated concentration at each concentration level from the corresponding theoretical concentration. Repeatability (within-day precision) and intermediate precision were calculated as relative standard deviation (RSD) using oneway ANOVA (analysis of variance) with the grouping variable "day". Accuracy was 
considered acceptable if bias was within $\pm 15 \%( \pm 20 \%$ around the LOQ $)$. Precision was considered acceptable if RSD was within $\pm 15 \%$ ( $\pm 20 \%$ around the LOQ). A summary of an eight-day experiment used for determining precision, accuracy, and freeze-thaw stability can be found in Table 7, as adapted from Peters et al. ${ }^{(133)}$

Table 7: Summary of Validation Experiments

\begin{tabular}{|c|c|c|c|c|c|c|c|c|}
\hline \multirow[t]{3}{*}{ Run } & \multirow[t]{3}{*}{$\begin{array}{c}\text { Cal. } \\
\text { Levels }\end{array}$} & \multicolumn{5}{|c|}{ Validation samples } & \multirow{3}{*}{$\begin{array}{c}\text { LOQ } \\
\text { Precision } \\
\& \\
\text { Accuracy } \\
\end{array}$} & \multirow[t]{3}{*}{ Total } \\
\hline & & \multicolumn{2}{|c|}{ LOW } & \multirow{2}{*}{$\begin{array}{c}\text { MED } \\
\text { Precision } \\
\& \\
\text { Accuracy }\end{array}$} & \multicolumn{2}{|c|}{ HIGH } & & \\
\hline & & $\begin{array}{c}\text { Precision } \\
\text { \& } \\
\text { Accuracy }\end{array}$ & $\begin{array}{c}\text { Freeze- } \\
\text { Thaw }\end{array}$ & & $\begin{array}{c}\text { Precision } \\
\& \\
\text { Accuracy }\end{array}$ & $\begin{array}{c}\text { Freeze- } \\
\text { Thaw }\end{array}$ & & \\
\hline 1 & 6 & 2 & 4 control & 2 & 2 & 4 control & 2 & 22 \\
\hline 2 & 6 & 2 & & 2 & 2 & & 2 & 14 \\
\hline 3 & 6 & 2 & & 2 & 2 & & 2 & 14 \\
\hline 4 & 6 & 2 & 4 treatment & 2 & 2 & 4 treatment & 2 & 22 \\
\hline 5 & 6 & 2 & & 2 & 2 & & 2 & 14 \\
\hline 6 & 6 & 2 & & 2 & 2 & & 2 & 14 \\
\hline 7 & 6 & 2 & & 2 & 2 & & 2 & 14 \\
\hline 8 & 6 & 2 & & 2 & 2 & & 2 & 14 \\
\hline Total & & & & & & & & 128 \\
\hline
\end{tabular}

\subsubsection{Freeze-thaw stability}

For evaluation of freeze-thaw stability, QC samples (LOW and HIGH) were analyzed before (control samples; $\mathrm{n}=4$ at each concentration) and after (stability samples; $\mathrm{n}=4$ at each concentration) three freeze-thaw cycles. For each cycle, the samples were frozen at $-20{ }^{\circ} \mathrm{C}$ for $21 \mathrm{~h}$, thawed, and kept at room temperature for $3 \mathrm{~h}$. The concentrations of the QC samples were calculated from the daily calibration curves. Mean concentration of stability samples was compared to mean concentration of control samples at each concentration. Stability was assumed when the mean concentration of the stability samples was within $\pm 10 \%$ of the mean concentration of the control samples and a confidence interval of $95 \%$ within $\pm 20 \%$ of the control mean concentration. 


\subsubsection{Limits}

In order to determine both the LOQs and LODs, aliquots of blank serum $(1 \mathrm{~mL})$ spiked with decreasing concentrations of analyte were analyzed as described above. Replicates $(\mathrm{n}=5)$ at varying concentrations in the range of $1 \mathrm{pg} / \mathrm{mL}$ to $500 \mathrm{ng} / \mathrm{mL}$, were analyzed as described above. Signal-to-noise ratio was not a technique that could be employed for calculating LOD or LOQ, due to the selective nature of the Dynamic MRM technique. Instead, the LOD was assessed visually. The LOQ was calculated statistically such that the precision and accuracy were within $20 \%$ RSD and $\pm 20 \%$ bias, respectively. ${ }^{(135)}$

\subsubsection{Proof of applicability}

Blood samples from two authentic post-mortem cases were submitted for analysis and assayed with the described validated method. Whole heart blood was submitted as serum was not available from these post-mortem cases.

\subsection{Results and Discussion}

\subsubsection{LC-MS/MS analysis}

The Agilent MassHunter Optimizer software was able to identify the two most common fragments, which were used for the quantifying and qualifying transitions, the collision energy, and the fragmentor voltage (summarized in Appendix 5). The gradient method allowed for separation of the 32 analytes in less than a 6-min run time (Figure 6). The Dynamic MRM capabilities of the system allowed for increased sensitivity and specificity by utilizing the expected retention time of each analyte. By determining the retention time, the method was able to differentiate between compounds with similar fragments (such as amphetamine/ methamphetamine and MDEA/MDMA) or compounds 
with similar transitions (such as DOM/2C-E and 2C-T-4/2C-T-7). This type of method is particularly useful for compounds that may co-elute or that elute close to one another because the individual transitions can be viewed separately without interference. In addition, the deuterated internal standards were able to take any variations into account. Unfortunately, at the time of method development, deuterated standards were not available for the tryptamines. If available in the future, a deuterated internal standard for this class of compounds would be recommended; alternatively, another tryptamine-like compound unlikely to be encountered in case samples may also be suitable.

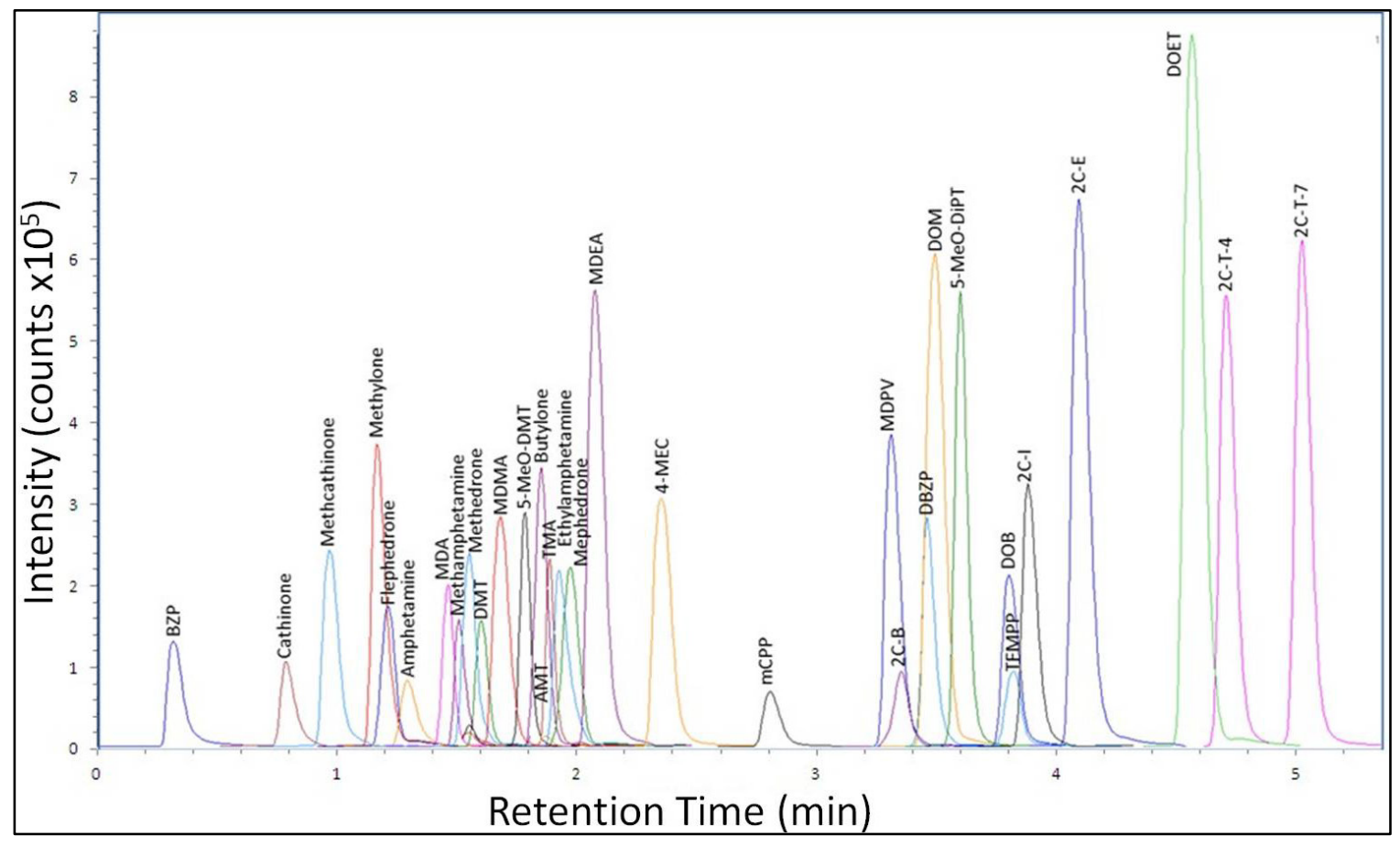

Figure 6: Chromatogram of Primary MRM Transitions for 32 Analytes 


\subsubsection{Assay validation}

\subsubsection{Selectivity}

Using dynamic MRM, no interfering peaks were observed when the analytes or internal standards were analyzed individually. Using this approach, it is not anticipated that closely eluting peaks would have significant matrix effects towards other analytes when analyzing compound mixtures. Compounds with similar transitions, such as DOM and $2 \mathrm{C}-\mathrm{E}$, could still be differentiated due to the difference in retention times. Upon analysis of blank pooled serum, interfering peaks were minor and did not elute at the same time as any of the targeted analytes or internal standards. In the present study, only deuterated compounds were chosen as internal standards, to avoid possible overestimation of the internal standard signal that can occur when using therapeutic drugs as IS. ${ }^{(96)}$ The method proved to be highly selective. The dynamic MRM method was able to filter out any interferences that may have been present and the transitions chosen for each compound were sufficient for selectively identifying the correct compound. Future studies will assess and characterize the possible interferences that may result from xenobiotics or other drugs of abuse that may be present in authentic samples. ${ }^{(133,136)}$

\subsubsection{Matrix effects, recovery, and process efficiency}

The ME, RE, and PE were calculated for each analyte as described above for both a LOW and HIGH analyte concentration (i.e., 25 and $250 \mathrm{ng} / \mathrm{mL}$ nominal concentrations, respectively). The means and RSDs, expressed as percentages, are summarized in Appendix 6. In order to calculate ME, RE, and PE, ratios of the mean values of Sets A, B, and $\mathrm{C}$ (see above) were used. An example of the calculation for the $\% \mathrm{RSD}$ used for ME is shown below, using absolute peak area means (mean) and standard deviations (SD): 


\section{Equation 1: Matrix Effect}

$$
M E=\left(\frac{B}{A}\right) \times 100 ; M E=\left(\frac{B_{\text {me an }}}{A_{\text {me an }}}\right) \times 100
$$

\section{Equation 2: Percent Relative Standard Deviation for Matrix Effect}

$$
\% R S D_{M E}=\sqrt{\left(\frac{B_{S D}}{B_{\text {mean }}}\right)^{2}+\left(\frac{A_{S D}}{A_{\text {mean }}}\right)^{2}} \times 100
$$

The ion suppression or ion enhancement from matrix effects was generally acceptable (75-125\%) at both analyte concentrations. However, DMT, 5-MeO-DMT, AMT, and 5-MeO-DiPT demonstrated some ion suppression ( $\mathrm{ME}<75 \%)$ at 25 and 250 ng/mL but with acceptable \%RSD. No compounds exhibited significant ion enhancement $(\mathrm{ME}>125 \%)$. While the selectivity experiment did not demonstrate any interferences when analyzing single compounds, future experiments will investigate ion suppression/ion enhancement that may occur in the analyte mixture as compared to the individual analytes. ${ }^{(136)}$ Recoveries were generally higher than $80 \%$, demonstrating a sufficient extraction technique for most analytes. Lower recoveries were noted for 2C-T4 and $2 \mathrm{C}-\mathrm{T}-7$, possibly due to different chemistries because of the presence of sulfur in the molecules. Recovery values higher than $100 \%$ may represent losses that could have occurred in the dry down stage when Set B included spiked elutions. The overall process efficiency was fairly reproducible and overall acceptable, taking into account both the matrix effects and recoveries. The sample preparation approach as described is believed to be adequate for all specified analytes. 


\subsubsection{Processed sample stability}

The samples ( $\mathrm{n}=8$ at each 25 and $250 \mathrm{ng} / \mathrm{mL}$ nominal concentrations) were each injected every $4 \mathrm{~h}$ over $32 \mathrm{~h}$. The data for eight samples at each time point were then averaged (as absolute peak area) and plotted versus the time present in the autosampler. The changes between the final and initial values were calculated relative to the regression line. ${ }^{(137)}$ Values within $\pm 15 \%$ were considered acceptable. The data summary can be found in Appendix 7, including the percent change calculated for the analyte peak area over the course of the run. The $\%$ change $(\% \Delta)$ as calculated by the regression lines was less than $15 \%$ for all compounds at both analyte concentrations, with the exception of amphetamine, MDMA, TMA and the tryptamines (DMT, 5-MeO-DMT, AMT, TMA, and 5-MeO-DiPT). For the latter compounds, substantially higher concentrations were noted at the end of the run as compared to initial. These values may be attributed to sample evaporation — an effect that could potentially be mitigated by using a temperature controlled auto-sampler. Amphetamine was stable for $22 \mathrm{~h}$ at the higher concentration level. MDMA was stable for $29 \mathrm{~h}$ at the higher concentration level. TMA was stable for only $12 \mathrm{~h}$ at the lower concentration level. The tryptamines were stable for approximately $6 \mathrm{~h}$ at the lower level and approximately $21 \mathrm{~h}$ at the higher concentration. If an error were to occur during a batch analysis suspected of containing one of these substances, re-extraction may be necessary. Consequently, extracts should not be reanalyzed if left to sit for more than one day without a temperature controlled autosampler. However, approximate run time for a typical experiment (which would equate to about 20 case samples with calibrators and QC samples) was $6 \mathrm{~h}$, which is sufficient for the stability of all analytes. Figure 7 is an example graph for one drug 
(methylone) illustrating the stability of the compound at both low and high concentrations over the length of the batch run.

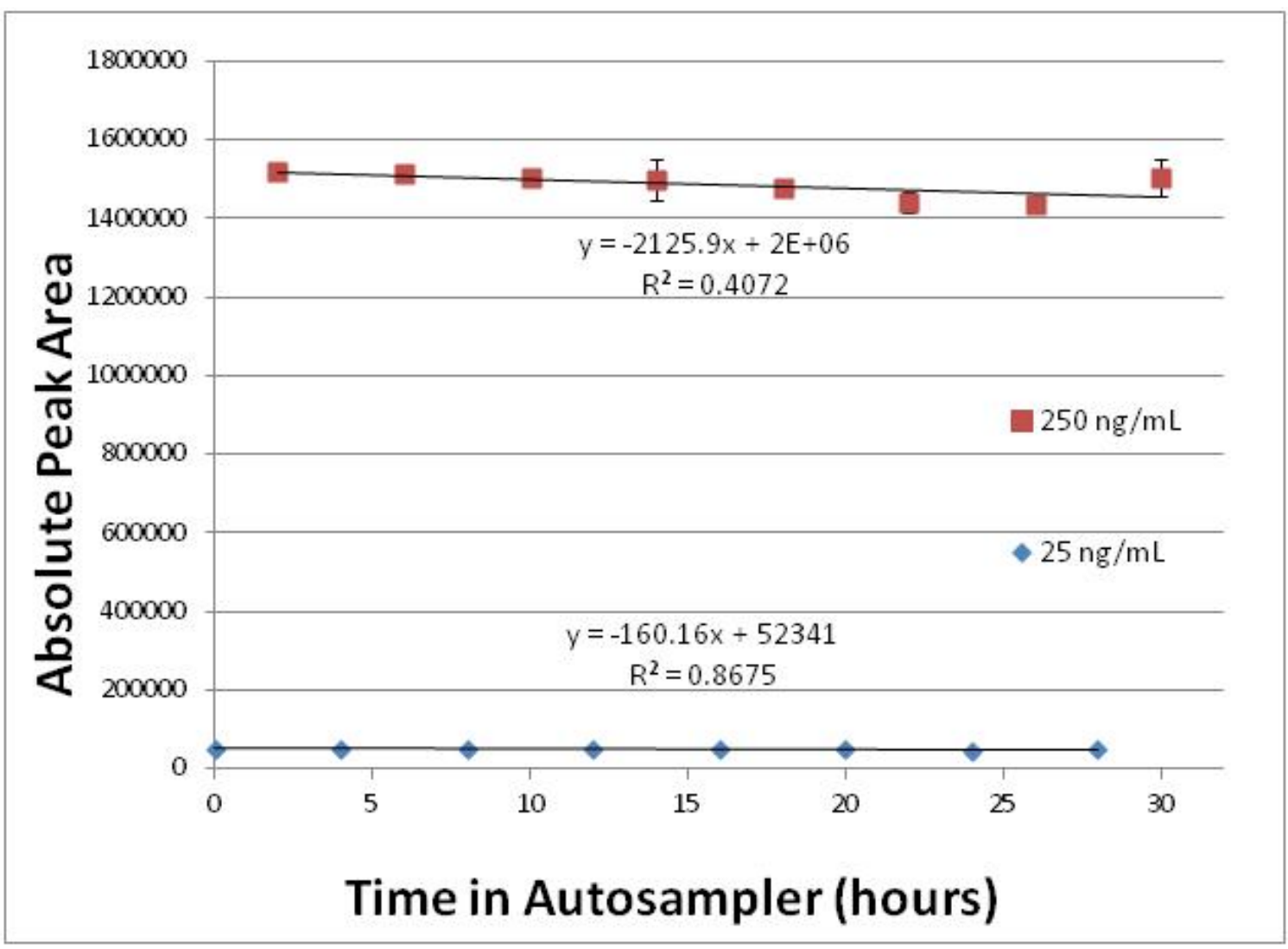

Figure 7: Processed Sample Stability for Methylone

\subsubsection{Linearity of calibration}

Agilent MassHunter Quantitative Analysis software was used to determine regression lines as well as to check precision, accuracy, ion response ratios, and retention times. Linear regression models were weighted by a factor of $1 / x$ to account for heteroscedasticity. All $\mathrm{R}^{2}$ values were a minimum of 0.990 in this experiment. Bias within $\pm 15 \%( \pm 20 \%$ around the LOQ $)$ and precision within $\pm 15 \% \mathrm{RSD}( \pm 20 \%$ around the LOQ) were observed for all compounds from 10 up to $250 \mathrm{ng} / \mathrm{mL}$. For all further 
experiments, the following levels were used for calibration: 10, 25, 50, 100, 150, and 250 $\mathrm{ng} / \mathrm{mL}$. Data for all analytes were linear between 10 and $250 \mathrm{ng} / \mathrm{mL}$. This calibration range is expected to be adequate detecting designer drugs at trace levels. Concentrations outside the upper limit of quantification may exhibit non-linearity; however, such specimens can be diluted prior to extraction in order to avoid this occurrence.

\subsubsection{Precision and accuracy}

The QC samples were analyzed at LOQ (10 ng/mL), LOW (25 ng/mL), MED (100 ng/mL), and HIGH (250 ng/mL) in duplicate on each of eight days. Accuracy, repeatability, and intermediate precision were calculated for each analyte at the four concentrations. The values were considered acceptable if bias was within $\pm 15 \%( \pm 20 \%$ around LOQ) and if precision was within $\pm 15 \% \mathrm{RSD}$ ( $\pm 20 \%$ around LOQ). A summary of these values can be found in Appendix 8. The results for 27 analytes met all of the criteria for validation in terms of accuracy, repeatability, and precision as calculated for all four concentrations. The results for DMT, 5-MeO-DMT, AMT, DBZP, and DOET demonstrated higher $\%$ bias for one or more concentration levels during the assessment of accuracy in QC samples, likely due to the lack of proper internal standards. In addition, the stability of these compounds under auto-sampler conditions may also play a role in failing validation criteria. However, in a working laboratory, values within $20 \%$ RSD are generally considered acceptable. As the data show both high and low biases for these analytes, it is difficult to account for the observations by any one factor alone. Efforts will continue to investigate potential causes of unacceptable bias for these specific analytes. Consequently, the assay can only be considered semi-quantitative for these 
compounds, and data must be evaluated based on acceptance of daily calibration curves and the results of the daily QC samples.

\subsubsection{Freeze-thaw stability}

QC samples at LOW and HIGH levels were analyzed on the first day of an 8-day experiment. Additional samples were frozen and thawed with each batch before reanalysis on the fourth day. The concentrations were calculated from the daily calibration curves. The means were compared between the "treated" and "untreated" samples at both concentrations and considered acceptable if the mean concentration of the treated samples was within $\pm 10 \%$ of the mean concentration of the control samples and $95 \% \mathrm{CI}$ within $\pm 20 \%$ of the nominal concentration. A summary of the results can be found in Table 8. All analytes were found to be stable after three freeze-thaw cycles, as demonstrated by the calculated differences between the treated and untreated control samples. All of the changes at both the LOW and HIGH concentrations were within \pm 10 $\%$ as required for validation. The concentrations of the untreated controls were within $\pm 20 \%$ of the mean concentration of the controls at a $95 \%$ confidence interval. This experiment demonstrated that samples containing these analytes can safely be analyzed within three freeze-thaw cycles. However, longer-term storage stability has not been evaluated. 
Table 8: Freeze-Thaw Stability of Targeted Analytes

\begin{tabular}{|c|c|c|c|c|c|}
\hline Compound & $\begin{array}{l}\text { LOW } \\
(\% \Delta)^{a}\end{array}$ & $\begin{array}{c}\text { HIGH } \\
(\% \Delta)\end{array}$ & Compound & $\begin{array}{l}\text { LOW } \\
(\% \Delta)^{a}\end{array}$ & $\begin{array}{l}\text { HIGH } \\
(\% \Delta)\end{array}$ \\
\hline BZP & 9.3 & -7.4 & Mephedrone & 5.7 & -1.2 \\
\hline Cathinone & -2.8 & -3.1 & MDEA & 6 & -6.8 \\
\hline Methcathinone & -9 & -9.3 & 4-MEC & -3.5 & -9.7 \\
\hline Methylone & 7.6 & -6.2 & $\mathrm{mCPP}$ & -5.4 & 1.3 \\
\hline Flephedrone & -6.6 & -6.6 & MDPV & -2 & -1.9 \\
\hline Amphetamine & 3.8 & 0.5 & $2 \mathrm{C}-\mathrm{B}$ & 8.5 & -5.5 \\
\hline MDA & 2.7 & -4.9 & DBZP & -0.9 & -5.6 \\
\hline Methedrone & 6.6 & -1.8 & $\mathrm{DOM}$ & 5.1 & $\overline{9.6}$ \\
\hline Methamphetamine & 2.6 & -3.6 & 5-MeO-DiPT & -0.6 & -3.1 \\
\hline DMT & 4.6 & -5.2 & DOB & -3.1 & 5.4 \\
\hline MDMA & 8.7 & -1.1 & TFMPP & 6.3 & 1.4 \\
\hline 5-MeO-DMT & 0.7 & 6.3 & $2 \mathrm{C}-\mathrm{I}$ & 2.2 & -8.5 \\
\hline Butylone & -2.9 & -6.6 & $2 \mathrm{C}-\mathrm{E}$ & 3.7 & $\overline{0.8}$ \\
\hline AMT & 8 & -6.8 & DOET & 7.8 & -4.7 \\
\hline TMA & 3.5 & 4.3 & $2 \mathrm{C}-\mathrm{T}-4$ & 5.2 & 3.4 \\
\hline Ethylamphetamine & 5.5 & 1.3 & $2 \mathrm{C}-\mathrm{T}-7$ & 6.7 & $\overline{7.6}$ \\
\hline
\end{tabular}

${ }^{a}$ Data expressed as $\%$ change in concentration from initial to final time point.

\subsubsection{Limits}

The LOQs and LODs were determined by spiking samples with internal standard and decreasing concentrations of drug and analyzing along with a calibration curve. LOQs were established when bias was within $\pm 20 \%$ and precision was within \pm 20 \%RSD as calculated within the Agilent MassHunter Quantitative Analysis software. LODs were established visually, since traditional methods such as calculating the LOD as three times the standard deviation of the signal-to-noise ratio is not appropriate with a selective method such as Dynamic MRM. LOQs were in the range of $1-10 \mathrm{ng} / \mathrm{mL}$, whereas LODs were in the range of $10-100 \mathrm{pg} / \mathrm{mL}$. For the validation experiments, 10 
$\mathrm{ng} / \mathrm{mL}$ was used at the LOQ level for calculations. These LODs allow for identification of designer drugs at very low levels, which is extremely useful when such drugs are taken at sub-milligram dosages. The LOQs accommodate very low level concentrations with the ability to accurately and precisely quantify the drugs that are present. As demonstrated below, LOQs for the method were sufficiently sensitive to allow confirmation of MDPV in a case sample that was undetected by previous screens.

\subsubsection{Proof of applicability}

Post-mortem heart blood specimens from two forensic cases were submitted for analysis, as designer drugs were suspected to be present in these cases. The first case was a 31 year-old black male. The decedent died as a result of a suicidal gunshot wound to the head. During routine urinalysis, MDMA was found by GC-MS in the drug screen and was later confirmed in urine by GC-MS. Methylone was suspected in the GC-MS full scan confirmatory method but since a quantitative method was not in place the specimen was submitted for confirmation and quantification by the present validated LCMS/MS method. The second case was a 26-year-old white male. The decedent had been huffing computer aerosol and was ruled an accidental death with cause of death attributed to acute poly-drug toxicity, specifically citing 1,1-difluoroethane, MDMA, and 5-MeODiPT. In the initial GC-MS urine drug screen, MDA, MDMA, and 5-MeO-DiPT ("Foxy”) were found. In addition, BZP, MDMA, 5-MeO-DiPT, and TFMPP were found in blood during a basic drug screen by GC-MS. In both cases, the urine immunoassays were negative for amphetamines. Duplicate 1-mL portions of blood from each case were spiked with internal standard solution and extracted as described above. The concentrations of the analytes were calculated using a calibration curve and the QC 
samples in the same run were checked for acceptable accuracy and precision. A summary of the quantitative results can be found in Table 9. Chromatograms for each case can be found in Figure 8 and Figure 9.

Table 9: Summary of Quantitative Results for Case Samples

\begin{tabular}{|c|r|r|}
\hline Compound & ${\text { Case } \mathbf{1}^{\boldsymbol{a}}}^{\boldsymbol{1}}$ & Case $^{\boldsymbol{a}}$ \\
\hline BZP & $\mathrm{nd}^{\boldsymbol{b}}$ & $>250^{\boldsymbol{c}}$ \\
\hline Methylone & 63 & $\mathrm{nd}$ \\
\hline MDA & nd & 36 \\
\hline MDMA & 58 & 115 \\
\hline MDPV & nd & 11 \\
\hline 5-MeO-DiPT & nd & $>250^{\boldsymbol{c}}$ \\
\hline TFMPP & nd & 93 \\
\hline
\end{tabular}

${ }^{a}$ Data in $\mathrm{ng} / \mathrm{mL}$.

${ }^{b}$ Not detected.

${ }^{c}$ Present above highest calibration level

The concentrations of BZP and 5-MeO-DiPT were greater than the upper limit of quantification and would need to be re-analyzed after performing a sample dilution in order to ensure that they would be within the linear range. Insufficient sample volume was available for dilution of these specimens in the present study. Future experiments assessing the validity of this additional step would need to be performed in order to determine precision and accuracy of diluted samples. In addition, these values were extremely high relative to some other reported cases and were probably contributing factors to the decedent's death. ${ }^{(2,6)}$ It is important to note that the calibration curve for 5MeO-DiPT and the daily QC samples were acceptable on the day that these samples were analyzed. It is not uncommon to see the combination of BZP with TFMPP, as was noted for Case $2 .^{(2,138)}$ The concentrations of the other compounds detected were comparable to those that were initially quantified by the submitting laboratory. Significantly, MDPV was found in Case 2 by the present method but had been missed in the initial GC-MS 
screens. The presence of "bath salts" was confirmed for both cases (methylone and MDPV, respectively) and establishes that these compounds are present in the local community. As the validated serum extraction procedure was adapted to whole blood in these cases, additional validation studies would be investigated in the future for this type of biological specimen, particularly with regard to matrix effects and recovery.

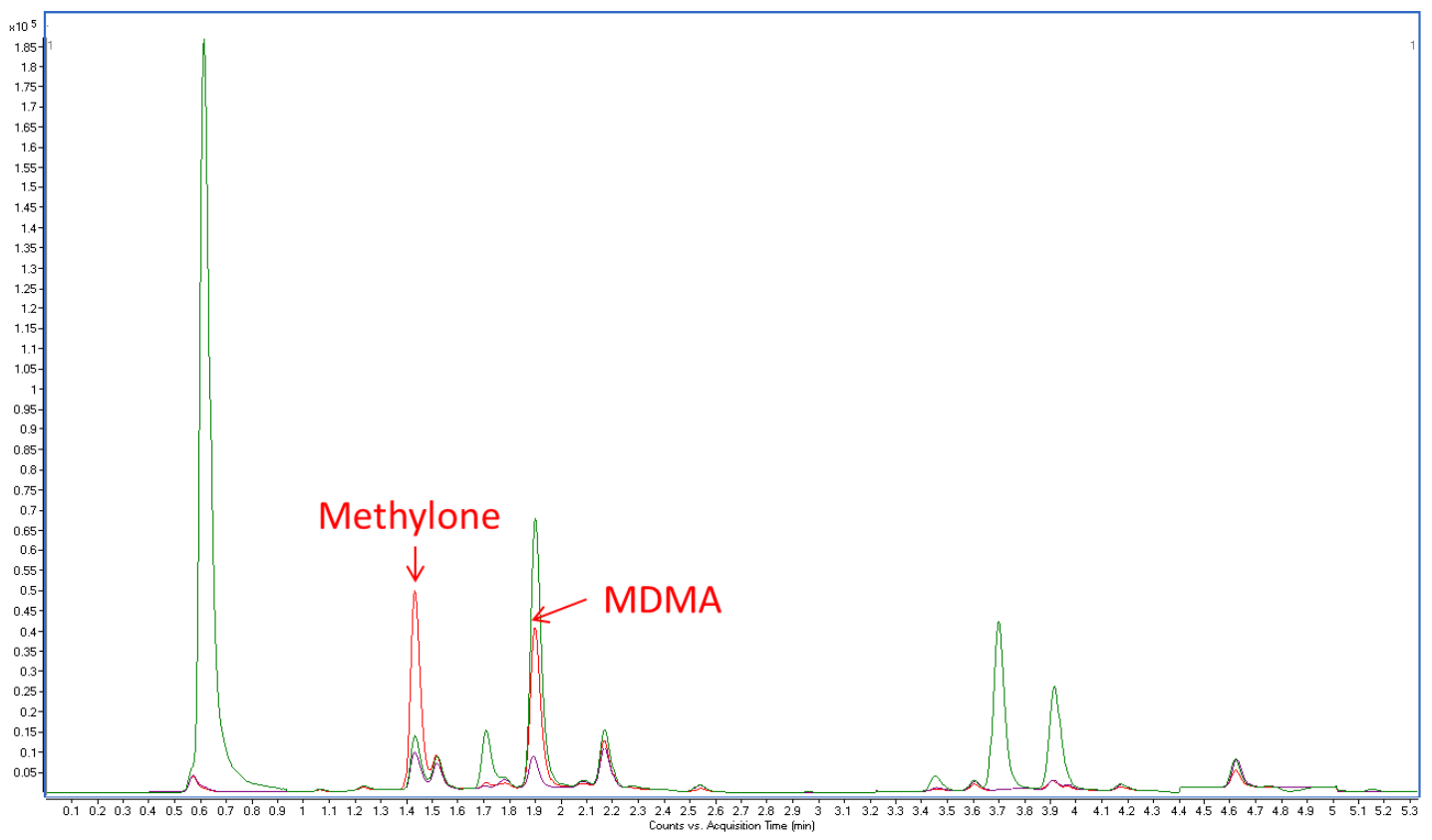

Figure 8: Chromatogram of Case 1 (counts vs. acquisition time) 


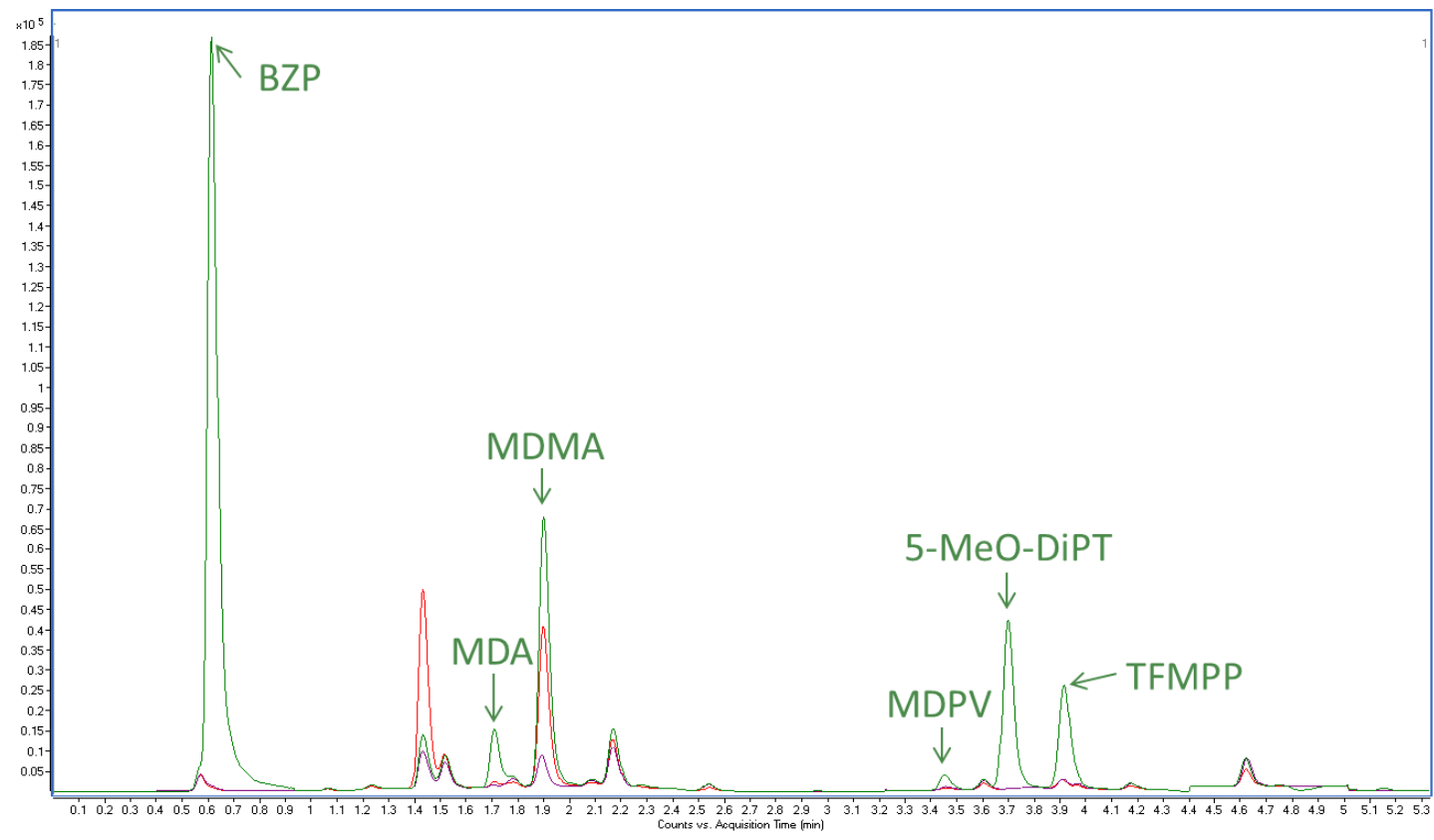

Figure 9: Chromatogram of Case 2 (counts vs. acquisition time) 


\subsection{Conclusions}

A LC-QQQ-MS/MS assay developed for the determination of 32 important designer drug entities in serum was fully validated for 27 analytes as per international guidelines. The remaining analytes, all from the tryptamine group, did not completely meet the criteria for precision and accuracy. Consequently, the method can only be considered semi-quantitative with regard to these compounds, necessitating the use of daily calibration curves and QC samples for acceptability. The extraction was successfully applied to serum specimens with high recovery and minimal matrix effects. In addition, the method was also effectively utilized for the analysis of two forensic whole blood specimens suspected of involving bath salts. This comprehensive technique has demonstrated value as a validated analytical assay with applicability to forensic toxicological casework. It is currently being expanded to encompass many additional designer drugs that have been introduced to the illicit market since the conclusion of this project. 


\section{ANALYSIS OF FORENSIC CASE SAMPLES}

\subsection{Overview}

In forensic science, one of the most important tasks in regard to method development is the application. Specimens were analyzed by both immunoassays and the confirmatory LC-MS method that was previously validated. The dual-analysis allowed for true comparison of the two techniques (immunoassay and LC-MS) as well as assessment of the comprehensive LC-MS method when applied towards forensic case samples.

\subsection{Introduction}

Obtaining biological case samples from forensic laboratories is very difficult due to pending investigations and following proper chain-of-custody. In an attempt to compare the immunoassay and confirmatory techniques previously described in Chapters

3 and 4 , specimens were prepared in a blind study by the research advisor at varying concentrations and in various combinations in order to test the screening capabilities of the two methods in an unbiased manner and confirm any false positives or false negatives that might occur. In addition, several authentic forensic specimens were received from Palm Beach County Sheriff's Office Toxicology Unit.

\subsection{Materials and Methods}

\subsubsection{Materials}

\subsubsection{Chemicals}

The following drugs were obtained from LipoMed (Cambridge, MA) as $1 \mathrm{mg} / \mathrm{mL}$ calibrated reference standards in solvent: $2 \mathrm{C}-\mathrm{B},( \pm)-3,4,5-\mathrm{TMA},( \pm)-4-$ 
methylethcathinone, $( \pm)$-butylone, $( \pm)$-cathinone, DMT, $( \pm)$-DOB, $( \pm)$-DOET, $( \pm)-\mathrm{DOM}$, ( \pm -flephedrone, mCPP, $( \pm)$-MDPV,$( \pm)$-mephedrone, $( \pm)$-methcathinone, $( \pm)$ methedrone, $( \pm)$-methylone, $( \pm)$-N-ethylamphetamine, and TFMPP. The following drugs were obtained from Cerilliant (Round Rock, TX) as $1 \mathrm{mg} / \mathrm{mL}$ calibrated reference standards in solvent: $d$-amphetamine, $d$-methamphetamine, ketamine, methylphenidate, $( \pm)$-amphetamine, $( \pm)-\operatorname{MDA},( \pm)-\operatorname{MDEA},( \pm)-\mathrm{MDMA}$, and $( \pm)$-methamphetamine. The following drugs were obtained from Grace Davison Discovery Sciences (Deerfield, IL) as $1 \mathrm{mg} / \mathrm{mL}$ calibrated reference standards in solvent: 2C-T-4, 2C-T-7, 2C-E, 2C-I, 5-MeODiPT, AMT, and BZP. An in-house standard of mephentermine, from powder, was available at a concentration of $1.02 \mathrm{mg} / \mathrm{mL}$ in methanol. The structures for each of the assay-targeted analytes and each of the analytes under investigation can be found in Figure 4 and Appendix 2, respectively. Methanol $\left(\mathrm{GC}^{2 \circledR}\right)$ was obtained from Honeywell Burdick \& Jackson (Muskegon, MI). Dilution buffer (EIA buffer) and wash buffer (Wash Buffer Concentrate 10X) were obtained from Neogen Corporation (Lexington, KY). All other solutions and materials were included in the individual immunoassays listed below.

Iso-Propanol (IPA, analytical grade), acetonitrile (Optima ${ }^{\circledR}$ LC-MS grade), ammonium formate, hydrochloric acid ( $\mathrm{HCl}$, analytical grade), glacial acetic acid (analytical grade), water (Optima ${ }^{\circledR}$ LC-MS grade), and methanol (Optima ${ }^{\circledR}$ LC-MS grade) were obtained from Fisher Scientific (Fair Lawn, NJ). Ammonium hydroxide (analytical grade) from Acros Organics (NJ), dichloromethane (analytical grade) from EMD Chemicals (Gibbstown, NJ), formic acid (Optima ${ }^{\circledR}$ LC-MS grade) from Fisher Scientific (Fair Lawn, NJ), and sodium phosphate monobasic monohydrate and dibasic 
heptahydrate (both analytical grade) from Acros (NJ) were also purchased for preparation of SPE solutions and mobile phases. Clean Screen ${ }^{\circledR}$ Extraction Columns (CSDAU, 200 $\mathrm{mg} ; 10 \mathrm{~mL}$ ) for solid-phase extraction were purchased from United Chem (Bristol, PA) for manual extraction performed on a positive pressure manifold from United Chem (Bristol, PA).

\subsubsection{ELISAs}

Sixteen immunoassay kits were obtained from four commercial manufacturers: Immunalysis Amphetamine Direct ELISA and Methamphetamine Direct ELISA (Pomona, CA); Neogen Amphetamine ELISA, Amphetamine Specific Forensic ELISA, Amphetamine Ultra Forensic ELISA, Benzylpiperazine Forensic ELISA, Ketamine Forensic ELISA, Methylphenidate Forensic ELISA, Methamphetamine/ MDMA Forensic ELISA, and Mephentermine Forensic ELISA (Lexington, KY, USA); Randox MDPV ELISA and Mephedrone/Methcathinone ELISA (Co. Antrim, UK); and OraSure Technologies PCP Intercept ${ }^{\circledR}$ Micro-Plate EIA, Cotinine Serum Micro-Plate EIA, Amphetamine-Specific Serum Micro-Plate EIA, and Methamphetamine Intercept ${ }^{\circledR}$ Micro-Plate EIA (Bethlehem, PA, USA). All of the antibodies were polyclonal in nature, with the exception of the PCP and Amphetamine-Specific assays from OraSure. Each kit consisted of 96-well microtiter plates coated with antibody for the targeted analyte, enzyme conjugate (3,3',5,5'-tetramethylbenzidine or TMB substrate solution), and an acid stop solution. A summary of the commercial immunoassays tested in the current study can be found in Table 2 . 


\subsubsection{Samples}

Drug-free frozen serum, pooled from nine donors, was obtained from Utak Laboratories (Valencia, CA, USA) and screened negative by ELISA for amphetamine, benzoylecgonine, ethanol, methamphetamine, morphine, oxazepam, phencyclidine, secobarbital, and 11-nor-9-carboxy-THC. The blank serum was used for the preparation of matrix-matched controls. After thawing, it was stored at $4^{\circ} \mathrm{C}$. For the preparation of whole blood controls, blank donor blood was obtained from Biological Specialty Corporation (Colmar, PA) as a single unit. It had been screened negative by ELISA for benzoylecgonine, secobarbital, carisoprodol, oxazepam, morphine, and oxycodone. It was also stored at $4^{\circ} \mathrm{C}$.

For comparison of results using ELISA and LC-MS screening assays, 22 five $\mathrm{mL}$ serum samples were prepared and analyzed in a blind manner (i.e., without analyst knowledge of drug identity or concentration). For the blind study, drug-free serum was spiked by the research advisor with known amounts of drug reference standards in methanolic solution. Samples were prepared that included single or mixtures of drugs and were prepared at a range of concentrations simulating those expected to be encountered in authentic specimens. The samples were given a random ID number (122) and frozen at $-20^{\circ} \mathrm{C}$ until analysis by ELISA and LC-MS. Blind spiked sample compositions are summarized in Table 10. In regard to the two case samples analyzed during LC-MS method validation (Chapter 4), there was insufficient volume for additional analysis in this study.

In addition to the spiked specimens, five authentic specimens were received from Palm Beach County Sheriff's Office (PBSO) Toxicology Unit. The whole blood 
specimens were stored in $10 \mathrm{~mL}$ grey top (fluoride and oxalate) vacutainers for 1-2 years mostly at room temperature but never opened. The samples were supplied with no personal identifying information; each was assigned an ID number (7-001, 11-001, 11002, 12-001, and 12-002) for internal tracking purposes only. It was indicated by PBSO that the samples were "positive for drugs," but no cathinone derivatives had been previously detected by their screening techniques. Upon receipt at FIU, the specimens were stored at $4^{\circ} \mathrm{C}$.

Table 10: Composition of Serum Samples Spiked in Blind Study

\begin{tabular}{|c|c|c|}
\hline ID & Drug(s) & nominal concentration $(\mathrm{ng} / \mathrm{mL})$ \\
\hline 1 & methylone & 20 \\
\hline 2 & methylone & 20 \\
\hline 3 & ethylamphetamine & 100 \\
\hline 4 & ethylamphetamine & 100 \\
\hline 5 & no spike & 0 \\
\hline 6 & methamphetamine + methedrone & $100+100$ \\
\hline 7 & methamphetamine + methylone & $100+100$ \\
\hline 8 & methamphetamine $+2 \mathrm{C}-\mathrm{I}$ & $100+100$ \\
\hline 9 & methamphetamine + MDMA & $120+120$ \\
\hline 10 & methylone + flephedrone & $120+120$ \\
\hline 11 & amphetamine $+\mathrm{mCPP}$ & $100+100$ \\
\hline 12 & methylone + 5-MeO-DiPT & $100+100$ \\
\hline 13 & $2 \mathrm{C}-\mathrm{I}+2 \mathrm{C}-\mathrm{T}-7$ & $100+100$ \\
\hline 14 & MDPV + mephedrone & $100+100$ \\
\hline 15 & AMT + butylone + ethylamphetamine & $100+100+100$ \\
\hline 16 & no spike & 0 \\
\hline 17 & $2 \mathrm{C}-\mathrm{I}$ & 20 \\
\hline 18 & $2 \mathrm{C}-\mathrm{I}$ & 60 \\
\hline 19 & $2 \mathrm{C}-\mathrm{I}$ & 200 \\
\hline 20 & flephedrone & 20 \\
\hline 21 & flephedrone & 60 \\
\hline 22 & flephedrone & 200 \\
\hline
\end{tabular}




\subsubsection{Sample preparation}

For immunoassay screening by ELISA, all calibrators, controls, and samples were subjected to a 1:4 (i.e., five-fold) dilution with buffer (EIA buffer) using a Hamilton Microlab® 500 Dual Syringe Diluter (Reno, NV). The dilution factor chosen was recommended by the manufacturer for forensic blood specimens.

For analysis by LC-MS, a solid phase extraction was performed to clean up the sample and isolate the drug. Serum samples $(1 \mathrm{~mL})$ were diluted with $2 \mathrm{~mL}$ of phosphate buffer ( $0.1 \mathrm{M}, \mathrm{pH} 6.0)$. The samples were gently vortexed and loaded onto a Clean Screen ${ }^{\circledR}$ SPE cartridge previously conditioned with $3 \mathrm{~mL}$ of methanol, $3 \mathrm{~mL}$ of water, and $1 \mathrm{~mL}$ of phosphate buffer. After extraction, the cartridges were sequentially washed with $1 \mathrm{~mL}$ of water, $1 \mathrm{~mL}$ of $0.1 \mathrm{M}$ acetic acid, and then $1 \mathrm{~mL}$ of methanol. Pressure was applied until the cartridges were dry. Analytes were eluted slowly with $3 \mathrm{~mL}$ of elution solvent, which consisted of dichloromethane, IPA, and ammonium hydroxide (80:20:2 $v / v / v)$. The eluates were acidified with $100 \mu \mathrm{L}$ of $1 \% \mathrm{HCl}$ in methanol before evaporation under nitrogen at $40^{\circ} \mathrm{C}$ in a TurboVap ${ }^{\circledR}$ LV by Caliper Life Sciences (Hopkinton, MA). When dry, the residue was reconstituted in $50 \mu \mathrm{L}$ of mobile phase A ( $2 \mathrm{mM}$ ammonium formate, $0.1 \%$ formic acid in water) and $5 \mu \mathrm{L}$ were injected into the LC-MS system. 


\subsubsection{Instrumentation}

\subsubsection{ELISA}

Enzyme-linked immunosorbent assays were performed using a DSX ${ }^{\circledR}$ Four-Plate Automated ELISA processing System (Dynex Technologies; Chantilly, VA) operating Revelation version 6.15 software. The plates were read using a $450 \mathrm{~nm}$ filter. Test procedures were carried out according to manufacturers' instructions listed in the package inserts, as summarized in Appendix 3. All incubations were performed at ambient temperature. Wash buffer was diluted 10X with deionized (DI) water for use in the wash step (unless otherwise noted). Conjugates that were not "ready-to-use" were diluted according to the package inserts with the appropriate diluents provided from the manufacturer.

\subsubsection{LC-MS}

The LC-MS analysis was performed using two systems. Qualitative screening by LC-QQQ-MS employed an Agilent 1290 Infinity Binary Pump LC coupled to an Agilent 6460 triple quadrupole MS/MS with Jet Streaming Technology and electrospray ionization (ESI) using Agilent MassHunter software. Separation occurred on an Agilent Zorbax Rapid Resolution HD Eclipse Plus $\mathrm{C}_{18}$ LC column $(50$ x $2.1 \mathrm{~mm}, 1.8 \mu \mathrm{m}$ particle size). Data acquisition was performed in Dynamic MRM mode with positive ESI using one principal MRM transition for quantification and one additional transition to serve as a qualifier for each analyte. Samples were also analyzed by high-resolution MS for confirmation and library matching. For this purpose, an Agilent 1290 Infinity Binary Pump LC coupled to an Agilent 6530 quadrupole time-of-flight (QTOF) MS was utilized. 
The same LC column as described above was used for separation. Data acquisition was performed in full-scan mode with positive ESI.

Chromatographic separation occurred with gradient elution at a flow rate of 0.5 $\mathrm{mL} / \mathrm{min}$ using $2 \mathrm{mM}$ ammonium formate $/ 0.1 \%$ formic acid in water as mobile phase $\mathrm{A}$ and acetonitrile/water $(90: 10 v / v)$ with $0.1 \%$ formic acid as mobile phase B. The gradient was as follows: $5 \% \mathrm{~B}$ up to $35 \% \mathrm{~B}$ in 6 minutes as the analytical run, followed by a $30 \mathrm{~s}$ ramp up to $95 \%$ B and then a 1 minute hold for clean-up before a 3.5 minute reequilibration at $5 \% \mathrm{~B}$. The analytical column was kept at a temperature of $40^{\circ} \mathrm{C}$ in a thermostatted column compartment during separation.

Source parameters for QQQ-MS were as follows: gas temperature $320^{\circ} \mathrm{C}$; gas flow $8 \mathrm{~L} / \mathrm{min}$; nebulizer 27 psi; sheath gas heater $380^{\circ} \mathrm{C}$; sheath gas flow $12 \mathrm{~L} / \mathrm{min}$; capillary voltage $3,750 \mathrm{~V}$; and charging voltage $500 \mathrm{~V}$. The method parameters are summarized in Appendix 5. Data were acquired in Dynamic MRM mode with two transitions per analyte and compounds were identified using Agilent MassHunter Qualitative Analysis software. Compounds were identified qualitatively by examining retention time and ion ratios for both transitions. Compounds were quantified against a calibration curve using Agilent MassHunter Quantitative Analysis software.

Source parameters for QTOF-MS analysis were as follows: gas temperature $320^{\circ} \mathrm{C}$; gas flow $8 \mathrm{~L} / \mathrm{min}$; nebulizer 27 psi; sheath gas heater $380^{\circ} \mathrm{C}$; sheath gas flow 12 $\mathrm{L} / \mathrm{min}$; capillary voltage $3,750 \mathrm{~V}$; nozzle voltage $500 \mathrm{~V}$; fragmentor 125 ; skimmer 65 ; octapole RF peak 750. Agilent MassHunter Qualitative Analysis software was employed for the identification of analytes. An in-house library with exact mass data was used for confirmation of the analytes. Retention time, as known from the QQQ method, was also 
considered when making matches. A software score of 90 or greater was considered a match if there was also minimal difference between the actual and expected mass.

\subsubsection{QC Samples}

When analyzing the spiked samples by ELISA, fresh negative and positive cut-off controls (Chapter 3) were prepared and analyzed as described above. When analyzing the spiked samples by LC-MS, calibrators and QC samples (Chapter 4) were prepared and analyzed as described above.

\subsection{Results and Discussion}

The 22 spiked blinded serum samples were thawed and screened by all 16 ELISA assays as listed in Table 2. The samples were diluted as described above and analyzed against fresh positive and negative serum controls. The results are shown in Appendix 9. All of the samples screened positive for cotinine using the OraSure assay. The blank serum used for the preparation of the controls was different than the lot of blank serum used to prepare the blind spiked specimens and therefore likely contained higher levels of the nicotine metabolite. Since this assay did not exhibit any cross-reactivity towards the analytes of interest during the initial stages of this study, it was determined that the positive reactions were from the matrix alone and not from any of the drugs that may have been added. Several samples gave indeterminate results, as indicated by " \pm " in the table.

Spiked samples were extracted by SPE as described under Materials and Methods. The results obtained by LC-QQQ-MS confirmed many of the "false-positives" obtained during the ELISA screening of these samples. For example, the ELISA assays targeting methamphetamine gave positive results for samples that did not contain 
methamphetamine, (i.e., samples $3,4,11,14$, and 15). The assay targeting amphetamine gave positives for samples that did not contain amphetamine (i.e., samples 3, 4, 6, 7, 8, 9, and 15). The MDPV assay successfully detected the analyte in sample 14 but gave indeterminate results for samples $3,4,8$, and 15 , which did not contain this compound. The Mephedrone/Methcathinone assay was able to successfully detect cathinone derivatives in 10 out of the 11 samples which contained such analytes. The other case, sample 20, was determined to contain flephedrone at a low concentration that was otherwise undetected by the immunoassays. Samples such as 13, 17, 18, and 19, which were assumed negative by immunoassay, were determined to contain $2 \mathrm{C}$ compounds when analyzed by LC-QQQ-MS.

The blind spiked samples were also analyzed by LC-QTOF-MS to confirm the results of the ELISA and LC-QQQ-MS analyses by means of high-resolution mass spectral library matching. The samples were analyzed in full-scan mode and compared to a full-scan library, while also considering retention time in identification of the analyte. The results are summarized in Table 11. An example of an extracted ion chromatogram and a library match for sample 1 can be found in Figure 10. Methamphetamine, amphetamine, and MDMA were not included in the mass spectral library and therefore could not be confirmed in samples $6,7,8,9$, and 11 . There were no library matches found for samples 5 and 16, an expected result since these were negative samples. With the exceptions noted above, all of the compounds were successfully identified by QTOFMS with high confidence, based on the high-resolution parent mass data obtained. With the exceptions of methedrone, butylone, and AMT, all of the compounds identified by the library had ID scores of at least 90 as provided by the Agilent MassHunter software. 


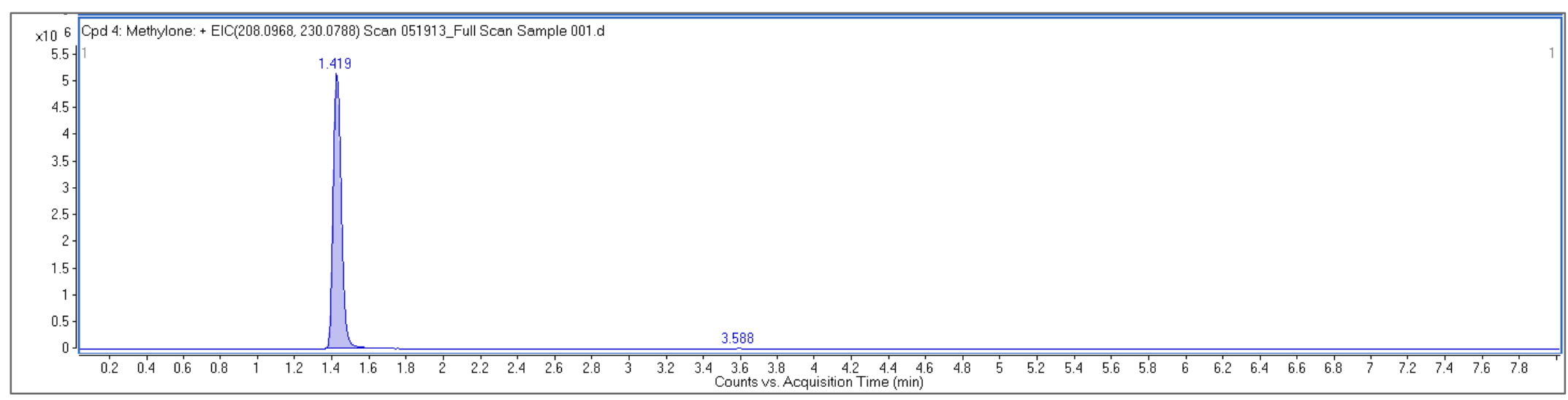

\begin{tabular}{|lllllllllllllllllllll}
\hline Cpd $\nabla$ & Label & $\nabla$ & Name & $\nabla$ & Formula & $\nabla$ & Mass & $\nabla$ & RT & $\nabla$ & Score & $\nabla \nabla$ & Flags (Tgt) & $\nabla$ & Diff (Tgt, ppm) & $\nabla$ & Mass (Tgt) & $\nabla$ & Mass (DB) & $\nabla$
\end{tabular}

Figure 10: Extracted Ion Chromatogram and Library Match for Sample 1 
Table 11: LC-QTOF Data for Blind Spiked Samples

\begin{tabular}{|c|c|c|c|c|c|}
\hline Sample & Match & $\begin{array}{c}\text { Observed } \\
\text { Mass }\end{array}$ & $\begin{array}{l}\text { Target } \\
\text { Mass }\end{array}$ & $\begin{array}{c}\text { Difference } \\
(\mathrm{ppm})\end{array}$ & Score \\
\hline $\begin{array}{c}\text { Sample } \\
01\end{array}$ & Methylone & 207.0886 & 207.0895 & -4.3 & 94.99 \\
\hline $\begin{array}{c}\text { Sample } \\
02\end{array}$ & Methylone & 207.0889 & 207.0895 & -2.9 & 94.45 \\
\hline $\begin{array}{c}\text { Sample } \\
03\end{array}$ & Ethylamphetamine & 163.1352 & 163.1361 & -5.48 & 94.77 \\
\hline $\begin{array}{c}\text { Sample } \\
04\end{array}$ & Ethylamphetamine & 163.1354 & 163.1361 & -4.58 & 96.91 \\
\hline $\begin{array}{c}\text { Sample } \\
05\end{array}$ & None & & & & \\
\hline $\begin{array}{c}\text { Sample } \\
06\end{array}$ & Methedrone & 193.1086 & 193.1103 & -8.54 & 79.17 \\
\hline $\begin{array}{c}\text { Sample } \\
07\end{array}$ & Methylone & 207.0883 & 207.0895 & -5.96 & 91.92 \\
\hline $\begin{array}{c}\text { Sample } \\
08\end{array}$ & $2 \mathrm{C}-\mathrm{I}$ & 307.006 & 307.0069 & -2.96 & 97.08 \\
\hline $\begin{array}{c}\text { Sample } \\
09\end{array}$ & None & & & & \\
\hline \multirow{2}{*}{$\begin{array}{c}\text { Sample } \\
10\end{array}$} & Methylone & 207.0892 & 207.0895 & -1.47 & 96.22 \\
\hline & Flephedrone & 181.0899 & 181.0903 & -1.88 & 99.24 \\
\hline $\begin{array}{c}\text { Sample } \\
11\end{array}$ & $\mathrm{mCPP}$ & 196.0759 & 196.0767 & -4.04 & 95.37 \\
\hline \multirow{2}{*}{$\begin{array}{c}\text { Sample } \\
12\end{array}$} & Methylone & 207.0883 & 207.0895 & -5.93 & 91.66 \\
\hline & 5-MeO-DiPT & 274.2034 & 274.2045 & -4.18 & 93.9 \\
\hline \multirow{2}{*}{$\begin{array}{c}\text { Sample } \\
13\end{array}$} & $2 \mathrm{C}-\mathrm{I}$ & 307.0057 & 307.0069 & -4.05 & 94.85 \\
\hline & 2C-T-7 & 255.128 & 255.1293 & -5.16 & 92.26 \\
\hline \multirow{2}{*}{$\begin{array}{c}\text { Sample } \\
14\end{array}$} & Mephedrone & 177.1146 & 177.1154 & -4.23 & 96.86 \\
\hline & MDPV & 275.1508 & 275.1521 & -4.75 & 93.07 \\
\hline \multirow{3}{*}{$\begin{array}{c}\text { Sample } \\
15\end{array}$} & AMT & 174.1145 & 174.1157 & -6.62 & 80.41 \\
\hline & Butylone & 221.1037 & 221.1052 & -6.95 & 88.85 \\
\hline & Ethylamphetamine & 163.1353 & 163.1361 & -5.07 & 94.3 \\
\hline $\begin{array}{c}\text { Sample } \\
16\end{array}$ & None & & & & \\
\hline $\begin{array}{c}\text { Sample } \\
17\end{array}$ & $2 \mathrm{C}-\mathrm{I}$ & 307.0078 & 307.0069 & 2.78 & 97.21 \\
\hline $\begin{array}{c}\text { Sample } \\
18\end{array}$ & 2C-I & 307.0057 & 307.0069 & -3.86 & 95.05 \\
\hline $\begin{array}{c}\text { Sample } \\
19\end{array}$ & $2 \mathrm{C}-\mathrm{I}$ & 307.0059 & 307.0069 & -3.35 & 96.3 \\
\hline $\begin{array}{c}\text { Sample } \\
20\end{array}$ & Flephedrone & 181.0899 & 181.0903 & -2.41 & 98.28 \\
\hline
\end{tabular}




\begin{tabular}{|c|c|c|c|c|c|}
\hline Sample & Match & $\begin{array}{c}\text { Observed } \\
\text { Mass }\end{array}$ & $\begin{array}{c}\text { Target } \\
\text { Mass }\end{array}$ & $\begin{array}{c}\text { Difference } \\
\text { (ppm) }\end{array}$ & Score \\
\hline $\begin{array}{c}\text { Sample } \\
\mathbf{2 1}\end{array}$ & Flephedrone & 181.0892 & 181.0903 & -6.23 & 92.78 \\
\hline $\begin{array}{c}\text { Sample } \\
\mathbf{2 2}\end{array}$ & Flephedrone & 181.0893 & 181.0903 & -5.7 & 94.01 \\
\hline
\end{tabular}


The five authentic blood samples obtained from PBSO were screened by all 16 ELISA assays as listed in Table 2. The samples were diluted as described above and analyzed against fresh positive and negative serum controls as well as whole blood controls (to ensure appropriate displacement with the different matrix). The results are shown in Appendix 10. None of the samples tested positive in any of the 16 assays, except for 11-002, 12-001, and 12-002, which were positive for cotinine. Since this assay did not exhibit any cross-reactivity towards the analytes of interest during the initial stages of this study, it was determined that the positive reactions were from nicotine use.

The PBSO samples were also analyzed by LC-QTOF-MS to confirm the results of the ELISA by means of high-resolution mass spectral library and/or database matching. A library search provides matching based on spectral data while a database search provides matching based on mass. The samples were analyzed in full-scan mode and compared to an in-house designer drug library and database as well as a forensic toxicology library and database from Agilent Technologies. The results are summarized in Table 12. The positive cotinine ELISA results were confirmed for 11-002, 12-001, and 12-002 by the identification of cotinine and/or 3-hydroxycotinine, indicative of nicotine use. None of the targeted designer drug analytes of this research were identified by the in-house designer drug library or database. The negative LC-QTOF findings for the designer drugs are consistent with the negative ELISA results for the amphetaminetype compounds. However, other drugs and their metabolites were detected as summarized in the table. These results remain presumptive as these analytes were not a part of this study and certified reference standards were not available to confirm retention time or the library results. 
Table 12: LC-QTOF Data for PBSO Samples

\begin{tabular}{|c|c|}
\hline Sample & Library Matches \\
\hline $\mathbf{7 - 0 0 1}$ & diphenhydramine, methadone, EDDP (methadone metabolite) \\
\hline $\mathbf{1 1 - 0 0 1}$ & tramadol \\
\hline $\mathbf{1 1 - 0 0 2}$ & Benzoylecgonine, morphine, dihydromorphine, cyclobenzaprine, 3- \\
hydroxycotinine
\end{tabular}

\subsection{Conclusions}

The comparison of immunoassays to the LC-MS methods demonstrated that false positives and false negatives can occur and require confirmatory techniques, such as LCQQQ or LC-QTOF, to accurately identify drugs that may be present in a biological sample. The immunoassays were able to detect some of the compounds present, but gave some indeterminate or negative results in cases that were not truly negative. The two LCMS methods were able to confirm and identify, with MRM and/or exact mass data, the identities of the compounds that were present, even at low levels. The current study reiterates the need for laboratories to gravitate towards LC-based methods, as screening techniques such as immunoassays are not sufficient for detecting most of these designer drugs. As the structures of these compounds constantly evolve, screening techniques will require more sensitive, selective methods, such as LC-QTOF, in order to positively identify this type of analyte, since designing antibodies for immunoassays will be too lengthy of a process. 


\section{SUMMARY AND PROSPECT}

Current immunoassay-based screening methods are not ideal for presumptively identifying most designer drugs, including the "bath salts". Recently, there has been a trend toward the introduction of new immunoassays with specificity for individual designer drugs or groups of drugs, a development that can, at least to some extent, help address this problem. Alternatively, as more laboratories move towards LC-MS/MS as an in-house analytical tool, screening methods for such analytes will likely gravitate towards higher specificity approaches, in particular high-resolution, high mass accuracy MS.

The expected results of this study were obtained, as it was hypothesized that commercial immunoassays would not detect the cathinone derivatives and other designer drugs outside the realm of the traditional phenethylamines, such as amphetamine, methamphetamine, and MDMA. The lack of cross-reactivity demonstrates that forensic toxicology laboratories will not be able to solely rely on immunoassays for screening procedures. More advanced analytical techniques, such as LC-MS, are required for the identification of these compounds, as demonstrated by the LC-QQQ and LC-QTOF analyses. Laboratories should keep cross-reactivity, or the lack thereof, in mind when performing routine screens so that these types of compounds are not overlooked. With the exception of the Randox kits, few immunoassays have been developed to target these analytes. While oral fluid may not be a commonly analyzed matrix, the results obtained for the cross-reactivity of the cathinone derivatives in serum by the OraSure Methamphetamine assay indicate its possible use for detecting such compounds, but would require extensive validation for this matrix and would not be applicable to every 
cathinone derivative as MDPV was not cross-reactive. In addition, this study only incorporates thirty designer drugs, of which only eight were cathinone derivatives. Many more compounds exist in the drug market and continue to be synthesized such that this research cannot be considered comprehensive or complete. Toxicology labs should and will continue to move towards LC-MS or other advanced techniques for the detection of these compounds in routine screenings of biological specimens.

For future studies, additional commercial immunoassays could be investigated to determine the cross-reactivity for those thirty compounds of interest. As the designer drugs in the market become more diversified, additional analytes may need to be examined for cross-reactivity. While computational modeling can help to predict crossreactivity, actual experiments will be necessary to indicate the real-life nature of forensic specimens. Since cathinone derivatives have only been made popular over the past few years, it is difficult to forecast the long-term trends of abuse for these drugs. If persistent, antibodies may need to be developed to create more commercial immunoassays like the one already released by Randox, so that high-throughput, automated screens can be used to presumptively identify these compounds. However, since there are so many designer drugs with similar masses and structures, high-resolution mass spectrometry will be the best technique for identifying these compounds and will likely be the future focus of qualitative and quantitative methods. As standards become available, updating the confirmatory LC-MS method presented in this research would allow for more broadbased screening. Further incorporation of LC-QTOF would allow for exact-mass capabilities and structural elucidation. Data mining could also be performed using high resolution mass spectral data as standards become available and libraries are updated. 


\section{REFERENCES}

1. Coppola, M., Mondola, R. (2012) Synthetic cathinones: Chemistry, pharmacology and toxicology of a new class of designer drugs of abuse marketed as 'bath salts' or 'plant food'. Toxicol. Lett. 211, 144-149.

2. Elliott, S., Smith, C. (2008) Investigation of the first deaths in the United Kingdom involving the detection and quantitation of the piperazines BZP and 3-TFMPP. $J$. Anal. Toxicol. 32, 172-177.

3. Lusthof, K. J., Oosting, R., Maes, A., Verschraagen, M., Dijkhuizen, A., Sprong, A. GA. (2011) A case of extreme agitation and death after the use of mephedrone in The Netherlands. Forensic. Sci. Int. 206(1), e93-e95.

4. McClean, J. M., Anspikian, A., Tsuang, J. W. (2012) Bath Salt Use: A case report and review of the literature. J. Dual Diagnosis 8(3), 250-256.

5. Murray, B. L., Murphy, C. M., Beuhler, M. C. (2012) Death following recreational use of designer drug 'bath salts' containing 3,4-methylenedioxypyrovalerone (MDPV). J. Med. Toxicol. 8(1), 69-75.

6. Tanaka, E., Kamata, T., Katagi, M., Tsuchihashi, H., Honda, K. (2006) A fatal poisoning with 5-methoxy-N,N-diisopropyltryptamine, Foxy. Forensic. Sci. Int. 163(1-2), 152-154.

7. Torrance, H., Cooper, G. (2010) The detection of mephedrone (4methylmethcathinone) in 4 fatalities in Scotland. Forensic Sci. Int. 202, e62-e63.

8. Verschraagen, M., Maes, A., Ruiter, B., Bosman, I. J., Smink, B. E., Lusthof, K. J. (2007) Post-mortem cases involving amphetamine-based drugs in the Netherlands Comparison with driving under the influence cases. Forensic Sci. Int. 170, 163-170.

9. Wikstrom, M., Thelander, G., Nystrom, I., Kronstrand, R. (2010) Two fatal intoxications with the new designer drug methedrone (4-methoxymethcathinone). $J$. Anal. Toxicol. 34, 594-598.

10. Zwingenberger, S., Pietsch, J., Hommola, A., Drebler, J. (2010) Illegal drug-related deaths in East Germany between 1995 and 2004. Forensic Sci. Int. 199, 58-62. 
11. Warrick, B. J., Wilson, J., Hedge, M., Freeman, S., Leonard, K., Aaron, C. (2012) Lethal serotonin syndrome after methylone and butylone ingestion. J. Med. Toxicol. 8,65 .

12. Stoica, M. V., Felthouse, A. R. (2012) Acute psychosis induced by bath salts: A case report with clinical and forensic implications. J. Forensic Sci. Ahead of print.

13. Regunath, H., Ariyamuthu, V. K., Dalal, P., Misra, M. (2012) Bath salt intoxication causing acute kidney injury requiring hemodialysis. Hemodial. Int. 16, S47-S49.

14. Rojek, S., Klys, M., Strona, M., Maciow, M., Kula, K. (2012) "Legal highs" Toxicity in the clinical and medico-legal aspect as exemplified suicide with bkMBDB administration. Forensic Sci. Int. 222(1-3), e1-6.

15. Zuba, D., Adamowicz, P., Byrska, B. (2012) Detection of buphedrone in biological and non-biological material - Two case reports. Forensic Sci. Int. 227, 15.

16. Sadeg, N., Darie, A., Vilamot, B., Passamar, M., Frances, B., Belhadj-Tahar, H. (2013) Case report of cathinone-like designer drug intoxication psychosis and addiction with serum identification. Addict. Disord. Their Treat. Ahead of print.

17. Gaillard, Y. P., Cuquel, A., Boucher, A., Romeuf, L., Bevalot, F., Prevosto, J., Menard, J. (2013) A fatality following ingestion of the designer drug metachlorophenylpiperazine (mCPP) in an asthmatic - HPLC-MS/MS detection in biofluids and hair. J. Forensic Sci. 58(1), 263-269.

18. Bosak, A., LoVecchio, F., Levine, M. (2013) Recurrent seizures and serotonin syndrome following "2C-I" ingestion. J. Med. Toxicol. Ahead of print.

19. Thornton, S. L., Lo, J., Clark, R. F., Wu, A. HB., Gerona, R. R. (2012) Simultaneous detection of multiple designer drugs in serum, urine, and CSF in a patient with prolonged psychosis. Clin. Toxicol. 50(10), 1165-1168.

20. Wohlfarth, A., Weinmann, W. (2010) Bioanalysis of new designer drugs. Bioanalysis 2, 965-979.

21. Henderson, G. L. (1988) Designer drugs: past history and future prospects. $J$. Forensic Sci. 33, 569-575. 
22. Carroll, F. I., Lewin, A. H., Mascarella, S. W., Seltzman, H. H., Reddy, P. A. (2012) Designer drugs: a medicinal chemistry perspective. Ann. NY Acad. Sci. 1248, 18-38.

23. McGrane, O., Simmons, J., Jacobson, E., Skinner, C. (2011) Alarming trends in a novel class of designer drugs. J. Clin. Toxicol. 1(2).

24. Prosser, J. M., Nelson, L. S. (2012) The toxicology of bath salts: a review of synthetic cathinones. J. Med. Toxicol. 8, 33-42.

25. Boland, D. M., Andollo, W., Hime, G. W., Hearn, W. L. (2005) Fatality due to acute alpha-methyltryptamine intoxication. J. Anal. Toxicol. 29, 394-397.

26. Hill, S. L., Thomas, S. H. (2011) Clinical toxicology of newer recreational drugs. Clin. Toxicol. 49, 705-719.

27. Brunt, T. M., Poortman, A., Niesink, R. JM., van den Brink, W. (2011) Instability of the ecstasy market and a new kid on the block: mephedrone. J. Psychopharm. 25, 1543-1547.

28. McClean, J. M., Anspikian, A., Tsuang, J. W. (2012) Bath salt use: A case report and review of the literature. J. Dual Diagn. 8, 250-256.

29. Borek, H. A., Holstege, C. P. (2012) Hyperthermia and multiorgan failure after abuse of "bath salts" containing 3,4-methylenedioxypyrovalerone. Ann. Emerg. Med. 60, 103-105.

30. Young, A. C., Schwarz, E. S., Velez, L. I. (2012) Two cases of disseminated intravascular coagulation due to "bath salts" resulting in fatalities, with laboratory confirmation. Amer. J. Emerg. Med. 31, 445.e3-445.e5.

31. Pearson, J. M., Hargraves, T. L., Hair, L. S., Massucci, C. J., Frazee, C. C., Garg, U., Pietak, B. R. (2012) Three fatal intoxications due to methylone. J. Anal. Toxicol. 36, 444-451.

32. van Vrancken, M. J., Benavides, R., Wians, F. H. (2013) Identification of designer drug 2C-E in urine following a drug overdose. Proc. (Bayl. Univ. Med. Cent.) 26, $58-61$.

33. Peters, F. T., Maurer, H. H., Musshoff, F. (2011) Forensic Toxicology. Anal. Bioanal. Chem. 400, 7-8. 
34. Rust, K. Y., Baumgartner, M. R., Dally, A. M., Kraemer, T. (2012) Prevalence of new psychoactive substances: A retrospective study in hair. Drug Test. Analysis 4.

35. Martin, M., Muller, J. F., Turner, K., Duez, M., Cirimele, V. (2012) Evidence of mephedrone chronic abuse through hair analysis using GC/MS. Forensic Sci. Int. 218, 44-48.

36. Shah, S. AB., Deshmukh, N. IK., Barker, J., Petroczi, A., Cross, P., Archer, R., Naughton, D. P. (2012) Quantitative analysis of mephedrone using liquid chromatography tandem mass spectrometry: Application to human hair. Analysis 61.

37. Strano-Rossi, S., Anzillotti, L., Castrignano, E., Romolo, F. S., Chiarotti, M. (2012) Ultra high performance liquid chromatography-electrospray ionization-tandem mass spectrometry method for direct analysis of designer drugs, "spice" and stimulants in oral fluid. J. Chromatogr. A $\mathbf{1 2 5 8 .}$

38. Moore, C., Crouch, D. (2013) Oral fluid for the detection of drugs of abuse using immunoassay and LC-MS/MS. Bioanalysis 5, 1555-1569.

39. Concheiro, M., de Castro, A., Quintela, O., Lopez-Rivadulla, M., Cruz, A. (2006) Determination of drugs of abuse and their metabolites in human plasma by liquid chromatography-mass spectrometry: An application to 156 road fatalities. $J$. Chromatrogr. B 832, 81-89.

40. Antia, U., Tingle, M. D., Russell, B. R. (2010) Validation of an LC-MS method for the detection and quantification of BZP and TMFPP and their hydroxylated metabolites in human plasma and its application to the pharmacokinetic study of TFMPP in humans. J. Forensic Sci. 55, 1311-1318.

41. Apollonio, L. G., Pianca, D. J., Whittall, I. R., maher, W. A., Kyd, J. M. (2006) A demonstration of the use of ultra-performance liquid chromatography-mass spectrometry in the determination of amphetamine-type substances and ketamine in forensic and toxicological analysis. J. Chromatogr. B 836, 111-115.

42. Maurer, H. H. (2009) Mass spectrometric approaches in impaired driving toxicology. Anal. Bioanal. Chem. 393, 97-107.

43. Bucelli, F., Fratini, A., Bavazzano, P., Comodo, N. (2009) Quantification of drugs of abuse and some stimulants in hair samples by liquid chromatography-electrospray ionization ion trap mass spectrometry. J. Chromatogr. B 877, 3931-3936. 
44. Beck, O., Leine, K., Palmskog, G., Franck, J. (2010) Amphetamines detected in exhaled breath from drug addicts: A new possible method for drugs-of-abuse testing. J. Anal. Toxicol. 34, 233-237.

45. Fritch, D., Blum, K., Nonnemacher, S., Haggerty, B. J., Sullivan, M. P., Cone, E. J. (2009) Identification and quantitation of amphetamines, cocaine, opitates, and phencyclidine in oral fluid by liquid chromatography-tandem mass spectrometry. $J$. Anal. Toxicol. 33, 569-577.

46. Farrell, L. J., Kerrigan, S., Logan, B. K. (2007) Recommendations for toxicological investigation of drug impaired driving. J. Forensic Sci. 52, 1214-1218.

47. Nakashima, K. (2005) High-performance liquid chromatographic analysis of drugs of abuse in biologic samples. J. Health Sci. 51, 272-277.

48. Fernandez, M. DR., Wille, S. MR., Samyn, N., Wood, M., Lopez-Rivadulla, M. (2009) High-throughput analysis of amphetamines in blood and urine with online solid-phase extraction-liquid chromatography-tandem mass spectrometry. J. Anal. Toxicol. 33, 578-587.

49. Peters, F. T., Drvarov, O., Lottner, S., Spellmeier, A., Rieger, K., Haefeli, W. E., Maurer, H. H. (2009) A systematic comparison of four different workup procedures for systematic toxicological analysis of urine samples using gas chromatographymass spectrometry. Anal. Bional. Chem. 393, 735-745.

50. Chiuminatto, U., Gosetti, F., Dossetto, P., Mazzucco, E., Zampieri, D., Robotti, E., Gennaro, M. C., Marengo, E. (2010) Automated online solid phase extraction ultra high performance liquid chromatography method coupled with tandem mass spectrometry for determination of forty-two therapeutic drugs and drugs of abuse in human urine. Anal. Chem. 82, 5636-5645.

51. Remane, D., Meyer, M. R., Peters, F. T., Wissenbach, D. K., Maurer, H. H. (2010) Fast and simple procedure for liquid-liquid extraction of 136 analytes from different drug classes for development of a liquid chromatographic-tandem mass spectrometric quantification method in human blood plasma. Anal. Bioanal. Chem. 397, 2303-2314. 
52. Bijlsma, L., Sancho, J. V., Pitarch, E., Ibanez, M., Hernandez, F. (2009)

Simultaneous ultra-high-pressure liquid chromatography-tandem mass spectrometry determination of amphetamine and amphetamine-like stimulants, cocaine and its metabolites, and a cannabis metabolite in surface water and urban wastewater. $J$. Chromatogr. A 1216, 3078-3089.

53. Wohlfarth, A., Weinman, W., Dresen, S. (2010) LC-MS/MS screening method for designer amphetamines, tryptamines, and piperazines in serum. Anal. Bioanal. Chem. 396, 2403-2414.

54. Jickells, S., Negrusz, A., eds. (2008) Clarke's Analytical Forensic Toxicology. Pharmaceutical Press.

55. Apollonio, L. G., Whittall, I. R., Pianca, D. J., Kyd, J. M., Maher, W. A. (2007) Matrix effect and cross-reactivity of select amphetamine-type substances, designer analogues, and putrefactive amines using the Bio-Quant Direct ELISA presumptive assays for amphetamine and methamphetamine. J. Anal. Toxicol. 31, 208-213.

56. Drummer, O. H. (2007) Requirements for bioanalytical procedures in postmortem toxicology. Anal. Bioanal. Chem. 31, 208-213.

57. Park, M., Choi, H., Son, H., Lim, M., Chung, H. (2003) Cross-reactivity of amphetamine analogues in various immunoassays. J. Pharm. Soc. Korea 47, 266270.

58. Marin, S. J., Moore, C., McMillin, G. A. (2009) Cross-reactivity of phentermine with an immunoassay designed to detect amphetamine in a meconium specimen. Clin. Chem. 55, 589-590.

59. Crooks, C. R., Brown, S. (2010) Roche DAT immunoassay: Sensitivity and specificity testing for amphetamines, cocaine, and opiates in oral fluid. J. Anal. Toxicol. 34, 103-109.

60. Christophersen, A. S. (2000) Amphetamine designer drugs - an overview and epidemiology. Toxicol. Lett. 112-113, 127-131.

61. Allen, K. R., Azad, R., Field, H. P., Blake, D. K. (2005) Replacement of immunoassay by LC tandem mass spectrometry for the routine measurement of drugs of abuse in oral fluid. Annals. Clin. Biochem. 42, 277-284. 
62. Crowther, J. (2008) Enzyme linked immunosorbent assay (ELISA). In Walker, J. M., Rapley, R., eds. : Molecular Biomethods Handbook 2nd edn. Humana Press, Totowa 657-682.

63. Nakanishi, K., Miki, A., Zaitsu, K., Kamata, H., Shima, N., Kamata, T., katagi, M., Tatsuno, M., Tsuchihashi, H., Suzuki, K. (2012) Cross-reactivities of various phenethylamine-type designer drugs to immunoassays for amphetamines, with special attention to the evaluation of the one-step urine drug test Instant-View(TM), and the Emit(R) assays for use in drug enforcement. Forensic Sci. Int. 217, 174-181.

64. Ullman, E. F. (2005) Homogeneous Immunoassays. In Wild, D., ed. : The Immunoassay Handbook. Elsevier Ltd., San Diego 212-232.

65. Koivunen, M. E., Krogsrud, R. L. (2006) Principles of immunochemical techniques used in clinical laboratories. Lab. Med. 37, 490-497.

66. Peters, F. T., Martinez-Ramirez, J. A. (2010) Analytical toxicology of emerging drugs of abuse. Ther. Drug Monitor. 32, 532-539.

67. Peters, F. T., Schaefer, S., Staack, R. F., Kraemer, T., Maurer, H. H. (2003) Screening for and validated quantification of amphetamines and of amphetamineand piperazine-derived designer drugs in human blood plasma by gas chromatography/mass spectrometry. J. Mass Spectrom. 38, 659-676.

68. Kudo, K., Ishisa, T., Hara, K., Kashimura, S., Tsuji, A., Ikeda, N. (2007) Simultaneous determination of 13 amphetamine related drugs in human whole blood using an enhanced polymer column and gas chromatography-mass spectrometry. $J$. Chromatogr. B 855, 115-120.

69. Takahashi, M., Nagashima, M., Suzuki, J., Seto, T., Yasuda, I., Yoshida, T. (2008) Analysis of phenethylamines and tryptamines in designer drugs using gas chromatography-mass spectrometry. J. Health Sci. 54, 89-96.

70. Springer, D., Fritschi, G., Maurer, H. H. (2003) Mtabolism of the new designer drug alpha-pyrrolidinopropiophenone (PPP) and the toxicological detection of PPP and 4'-methyl-alpha-pyrrolidinopropiophenone (MPPP) studied in rat urine using gas chromatography-mass spectrometry. J. Chromatogr. B 796, 253-266. 
71. Staack, R. F., Fritschi, G., Maurer, H. H. (2003) New designer drug 1-(3trifluoromethylphenyl)piperazine (TFMPP): gas chromatography/mass spectrometry and liquid chromatography/mass spectrometry studies on its phase I and phase II metabolism and on its toxicological detection in rat urine. J. Mass Spectrom. 38, 971-981.

72. Tsutsumi, H., Katagi, M., Miki, A., Shima, N., Kamata, T., Nishikawa, M., Nakajima, K., Tsuchihashi, H. (2005) Development of simultaneous gas chromatography-mass spectrometric and liquid chromatography-electrospray ionization mass spectrometric determination method for the new designer drugs BZP, TFMPP, and their main metabolites in urine. J. Chromatogr. B 819, 315-322.

73. Theobald, D. S., Maurer, H. H. (2006) Studies on the metabolism and toxicological detection of the designer drug 2,5-dimethoxy-4-methyl-beta-phenethylamine (2C-D) in rat urine using gas chromatography/mass spectrometric techniques. J. Mass Spectrom. 41, 1509-1519.

74. Zaitsu, K., Katagi, M., Kamata, T., Kamata, H., Shima, N., Tsuchihashi, H., Hayashi, T., Kuroki, H., Matoba, R. (2008) Determination of a newly encountered designer drug "p-methoxyethylamphetamine" and its metabolites in human urine and blood. Forensic Sci. Int. 177, 77-84.

75. Pellegrini, M., Rosati, R., Zuccaro, P., Romolo, F. S., Lopez, A. (2002) Rapid screening method for determination of Ecstasy and amphetamines in urine samples using gas chromatography-chemical ionization mass spectrometry. J. Chromatrogr. B 769, 243-251.

76. Habrdova, V., Peters, F. T., Theobald, D. S., Maurer, H. H. (2005) Screening for and validated quantification of phenethylamine-type designer drugs and mescaline in human blood plasma by gas chromatography/mass spectrometry. J. Mass Spectrom. 40, 785-795.

77. Pirnay, S. O., Abraham, T. T., Huestis, M. A. (2006) Sensitive gas chromatographymass spectrometry method for simultaneous meansurement of MDEA, MDMA, and metabolites HMA, MDA, and HMMA in human urine. Clin. Chem. 52, 1728-1734.

78. Maresova, V., Chadt, J., Prikryl, L. (2006) Simultaneous determination of amphetamines and amphetamine-derived designer drugs in human urine by GC-MS. Neuroendocrin. Lett. 27, 121-124. 
79. Kanai, K., Takekawa, K., Jumamoto, T., Ishikawa, T., Ohmori, T. (2008)

Simultaneous analysis of six phenethylamine-type designer drugs by TLC, LC-MS, and GC-MS. Forensic. Toxicol. 26, 6-12.

80. Kudo, K., Ishia, T., Hikiji, W., Hayashida, M., Uekusa, K., Usumoto, Y., Tsuji, A., Ikeda, N. (2009) Construction of calibration-locking databases for rapid and reliable drug screening by gas chromatography-mass spectrometry. Forensic Toxicol. 27, 2731.

81. Takahashi, M., Nagashima, M., Suzuki, J., Seto, T., Yasuda, I., Yoshida, T. (2009) Creation and application of psychoactive designer drugs data library using liquid chromatography with photodiode array spectrophotometry detector and gas chromatography-mass spectrometry. Talanta 77, 1245-1272.

82. Kolbrich, E. A., Lowe, R. H., Huestis, M. A. (2008) Two-dimensional gas chromatography/electron-impact mass spectrometry with cryofocusing for simultaneous quantification of MDMA, MDA, HMMA, HMA, and MDEA in human plasma. Clin. Chem. 54, 279-287.

83. Maurer, H. H., Bickeboeller-Friedrich, J., Kraemer, T., Peters, F. T. (2000) Toxicokinetics and analytical toxicology of amphetamine-derived designer drugs. Toxicol. Lett. 112-113, 133-142.

84. Namera, A., Nakamoto, A., Saito, T., Nagao, M. (2011) Colorimetric detection and chromatographic analyses of designer drugs in biological materials: a comprehensive review. Forensic Toxicol. 29, 1-24.

85. Drummer, O. H. (1999) Chromatographic screening techniques in systematic toxicological analysis. J. Chromatogr. B 733, 27-45.

86. Yahata, M., Namera, A., Nishida, M., Yashiki, M., Kuramoto, T., Kimura, K. (2006) In-matrix derivatization and automated headspace solid-phase microextraction for GC-MS determination of amphetamine-related drugs in human hair. Forensic Toxicol. 24, 51-57.

87. Leis, H. J., Windischofer, W., Wintersteiger, R. (1994) Quantitative meansurement of amphetamine in human plasma by gas chromatography/negative ion chemical ionization mass spectrometry. Biol. Mass Spectrom. 23, 637-641. 
88. Uhl, M. (2000) Tandem mass spectrometry: a helpful tool in hair analysis for the forensic expert. Forensic Sci. Int. 107, 169-179.

89. Strano-Rossi, S., Botre, F., Bermejo, A. M., Tabernero, M. J. (2009) A rapid method for the extraction, enantiomeric separation and quantification of amphetamines in hair. Forensic Sci. Int.(193).

90. Maurer, H. H. (2007) Current role of liquid chromatography-mass spectrometry in clinical and forensic toxicology. Anal. Bional. Chem. 388, 1315-1325.

91. Kolliker, S., Oehme, M. (2004) Structure elucidation of nanogram quantities of unknown designer drugs based on phenalkylamine derivatives by ion trap multiple mass spectrometry. Anal. Bioanal. Chem. 378, 1294-1304.

92. Concheiro, M., de Castro, A., Quintela, O., Cruz, A., Lopez-Rivadulla, M. (2007) Determination of illicit drugs and their metabolites in human urine by liquid chromatography tandem mass spectrometry including relative ion intensity criterion. J. Anal. Toxicol. 31, 573-580.

93. Mortier, K. A., Dams, R., Lambert, W. E., de Letter, E. A., van Calenbergh, S., de Leenheer, A. P. (2002) Determination of paramethoxyampheatmine and other amphetamine-related designer drugs by liquid chromatography/sonic spray ionization mass spectrometry. Rapid Comm. Mass Spectrom. 16, 865-870.

94. Nieddu, M., Boatto, G., Pirisi, M. A., Azara, E., Marchetti, M. (2008) LC-MS analysis of trimethoxyamphetamine designer drugs (TMA series) from urine samples. J. Chromatogr. B 867, 126-130.

95. Sturm, S., Hammann, F., Drewe, J., Maurer, H. H., Scholer, A. (2010) An automated screening method for drugs and toxic compounds in human serum and urine using liquid chromatography-tandem mass spectrometry. J. Chromatogr. B 878, 27262732 .

96. Vorce, S. P., Sklerov, J. H. (2004) A general screening and confirmation approach to the analysis of designer tryptamines and phenethylamines in blood and urine using GC-EI-MS and HPLC-electrospray-MS. J. Anal. Toxicol. 28, 407-410.

97. Nordgren, H. K., Beck, O. (2004) Multicomponent screenings for drugs of abuse. Ther. Drug Monit. 26, 90-97. 
98. Kikura-Hanajiri, R., Hayashi, M., Saisho, K., Goda, Y. (2005) Simultaneous determination of nineteen hallucinogenic tryptamines/b-calbolines and phenethylamines using gas chromatography-mass spectrometry and liquid chromatography-electrospray ionization-mass spectrometry. J. Chromatogr. B 825, 29-37.

99. Pichini, S., Pujadas, M., Marchei, E., Pellegrini, M., Fiz, J., Pacifici, R., Zuccaro, P., Farre, M., de la Torre, R. (2008) Liquid chromatography-atmospheric pressure ionization electrospray mass spectrometry determination of "hallucinogenic designer drugs" in urine of consumers. J. Pharm. Biomed. Analysis 47, 335-342.

100. van de Casteele, S. R., Bouche, M. L., van Bocxlaer, J. F. (2005) LC-MS/MS in the elucidation of an isomer of the recreational drug methylenedioxy ethylamphetamine: methylenedioxy dimethylamphetamine. J. Sep. Sci. 28, 1729-1734.

101. Menet, M., Fonsart, J., Herve, F., Fompeydie, D., Gaillot-Guilley, M., Noble, F., Schermann, J. (2010) Determination of 3,4-methylenedioxymethamphetamine and its five main metabolites in rat urine by solid-phase extraction and high performance liquid chromatography with on-line mass spectrometry. J. Chromatogr. B 878, 2905-2910.

102. Meyer, M. R., Du, P., Schuster, F., Maurer, H. H. (2010) Studies on the metabolism of the alpha-pyrrolidinophenone designer drug MDPV in rat and human urine and human liver microsomes using GC-MS and LC-high resolution MS and its detectability in urine by GC-MS. J. Mass Spectrom. 45, 1426-1442.

103. Min, J. Z., Shimizu, Y., Toyo'oka, T., Inagaki, S., Kikura-Hanajiri, R., Goda, Y. (2008) Simultaneous determination of 11 designated hallucinogenic phenethylamines by ultra-fast liquid chromatography with fluorescence detection. $J$. Chromatogr. B 873, 187-194.

104. Nieddu, M., Boatto, G., Pirisi, M. A., Baralla, E. (2009) Multi-residue analysis of eight thioamphetamine designer drugs in human urine by liquid chromatography/mass spectrometry. Rapid Comm. Mass Spectrom. 23, 3051-3056.

105. Blachut, D., Wojtasiewicz, K., Czarnocki, Z., Szukalski, B. (2009) The analytical profile of some 4-methylthioamphetamine (4-MTA) homologues. Forensic Sci. Int. 2009, 98-114. 
106. Brandt, S. D., Martins, C. PB. (2010) Analytical methods for psychoactive N,Ndialkylated tryptamines. Trends Anal. Chem. 29, 858-869.

107. Al-Saffar, Y., Stephanson, N. N., Beck, O. (2013) Multicomponent LC-MS/MS screening method for the detection of new psychoactive drugs, legal highs, in urine: Experience from the Swedish population. J. Chromatogr. A 930, 112-120.

108. Ambach, L., Redondo, A. H., Konig, S., Weinmann, W. (2013) Rapid and simple LC-MS/MS screening of 64 novel psychoactive substances using dried blood spots. Drug Test. Analysis Early View.

109. Guale, F., Shahreza, S., Walterscheid, J. P., Chen, H. H., Arndt, C., Kelly, A. T., Mozayani, A. (2013) Validation of LC-TOF-MS screening for drugs, metabolites, and collateral compounds in forensic toxicology specimens. J. Anal. Toxicol. 37, $17-$ 24.

110. Sundstrom, M., Pelander, A., Angerer, V., Hutter, M., Kneisel, S., Ojanpera, I. (2013) A high-sensitivity ultra-high performance liquid chromatography/highresolution time-of-flight mass spectrometry method for screening synthetic cannabinoids and other drugs of abuse in urine..

111. Pelander, A., Ojanpera, I., Laks, S., Rasanen, I., Vuori, E. (2003) Toxicological screening with formula-based metabolite identification by liquid chromatography/time-of-flight mass spectrometry. Anal. Chem. 75, 5710-5718.

112. Chen, B. H., Liu, J. T., Chen, W. X., Chen, H. M., Lin, C. H. (2008) A general approach to the screening and confirmation of tryptamines and phenethylamines by mass spectral fragmentation. Talanta 74, 512-517.

113. Concheiro, M., de Castro, A., Quintela, O., Lopez-Rivadulla, M., Cruz, A. (2005) Determination of MDMA, MDA, MDEA, and MBDB in oral fluid using high performance liquid chromatography with native fluorescence detection. Forensic Sci. Int. 150, 221-226.

114. Pelander, A., Ristimaa, J., Ojanpera, I. (2010) Vitreous humor as an alternative matrix for comprehensive drug screening in postmortem toxicology by liquid chromatography-time-of-flight mass spectrometry. J. Anal. Toxicol. 34, 312-318. 
115. Bjork, M. K., Nielsen, M. KK., Markussen, L. O., Klinke, H. B., Linnet, K. (2010) Determination of 19 drugs of abuse and metabolites in whole blood by highperformance liquid chromatography-tandem mass spectrometry. Anal. Bioanal. Chem. 396, 2393-2401.

116. Kraemer, T., Paul, L. D. (2007) Bioanalytical procedures for determination of drugs of abuse in blood. Anal. Bioanal. Chem. 388, 1415-1435.

117. Jian, W., Edom, R. W., Xu, Y., Gallagher, J., Weng, N. (2010) Potential bias and mitigations when using stable isotope labeled parent drug as internal standard for LC-MS/MS quantitation of metabolites. J. Chromatogr. B 878, 3267-3276.

118. Brown, S. D., Melton, T. C. (2011) Trends in bioanalytical methods for the determination and quantification of club drugs: 2000-2010. Biomed. Chromatogr. 25, 300-321.

119. del mar Ramirez Fernandez, M., Wille, S. MR., di Fazio, V., Gosselin, M., Samyn, N. (2010) Analysis of amphetamines and metabolites in urine with ultra performance liquid chromatography tandem mass spectrometry. J. Chromatogr. B 878, 1616-1622.

120. Cody, J. T., Schwarzhoff, R. (1993) Fluorescence polarization immunoassay detection of amphetamine, methamphetamine, and illicit amphetamine analogs. $J$. Anal. Toxicol. 17, 26-30.

121. Kerrigan, S., Mellon, M. B., Banuelos, S., Arndt, C. (2011) Evaluation of commercial enzyme-linked immunosorbent assays to identify psychedelic phenethylamines. J. Anal. Toxicol. 35, 444-451.

122. de Boer, D., Bosman, I. J., Hidvegi, E., Manzoni, C., Benko, A. A., Reys, L. JALd., Maes, R. AA. (2001) Piperazine-like compounds: a new group of designer drugs-ofabuse on the European market. Forensic Sci. Int. 121, 47-56.

123. Vorce, S. P., Holler, J. M., Levine, B., Past, M. R. (2008) Detection of 1benzylpiperazine and 1-(3-trifluoromethylphenyl)-piperazine in urine analysis specimens using GC-MS and LC-ESI-MS. J. Anal. Toxicol. 32, 444-450. 
124. Logan, B. K., Constantino, A. G., Rieders, E. F., Sanders, D. (2010) Trazodone, meta-chlorophenylpiperazine (an hallucinogenic drug and trazodone metabolite), and the hallucinogenic trifluoromethylphenylpiperazine cross-react with the EMIT(R)II Ecstasy immunoassay in urine. J. Anal. Toxicol. 34, 587-589.

125. Balikova, M. (2005) Nonfatal and fatal DOB (2,5-dimethoxy-4-bromoamphetamine) overdose. Forensic Sci. Int. 153, 85-91.

126. Miyajima, M., Matsumoto, T., Ito, S. (2008) 2C-T-4 intoxication: Acute psychosis caused by a designer drug. Psych. Clin. Neurosci. 62, 243.

127. Dickson, A. J., Vorce, S. P., Levine, B., Past, M. R. (2010) Multiple-drug toxicity caused by coadministration of 4-methylmethcathinone (mephedrone) and heroin. $J$. Anal. Toxicol. 34, 162-168.

128. Bell, C., George, C., Kicman, A. T., Traynor, A. (2011) Development of a rapid LCMS/MS method for direct urinalysis of designer drugs. Drug Test. Anal. 3, 496.

129. Macher, A. M., Penders, T. M. (2012) False-positive phencyclidine immunoassay results caused by 3,4-methylenedioxypyrovalerone (MDPV). Drug Test. Anal., online.

130. Ammann, D., McClaren, J. M., Gerostamoulos, D., Beyer, J. (2012) Detection and quantification of new designer drugs in human blood: Part 2 - Designer cathinones. J. Anal. Toxicol. 36, 381-389.

131. Kerrigan, S., Banuelos, S., Perrella, L., Hardy, B. (2011) Simultaneous detection of ten psychedelic phenethylamines in urine by gas chromatography-mass spectrometry. J. Anal. Toxicol. 35, 459-469.

132. Sorensen, L. K. (2011) Determination of cathinones and related ephedrines in forensic whole-blood samples by liquid-chromatography-electrospray tandem mass spectrometry. J. Chromatogr. B 879, 727-736.

133. Peters, F. T., Drummer, O. H., Musshoff, F. (2007) Validation of new methods., 216-224.

134. Matuszewski, B. K., Constanzer, M. L., Chavez-Eng, C. M. (2003) Strategies for the assessment of matrix effect in quantitative bioanalytical methods based on HPLCMS/MS. Anal. Chem. 75, 3019-3030. 
135. Araujo, P. (2009) Key aspects of analytical method validation and linearity evaluation. J. Chromatogr. B 877, 2224-2234.

136. Peters, F. T., Remane, D. (2012) Aspects of matrix effects in applications of liquid chromatography-mass spectrometry to forensic and clinical toxicology - a review. Anal. Bioanal. Chem. 403, 2155-2172.

137. Wieling, J., Hendriks, G., Tamminga, W. J., Hempenius, J., Mensink, C. K., Oosterhuis, B., Jonkman, J. HG. (1996) Rational experimental design for bioanalytical methods validation illustration using an assay method for total captopril in plasma. J. Chromatogr. A(730), 381-394.

138. Cohen, B. MZ., Butler, R. (2011) BZP-party pills: A reivew of reserach on benzylpiperazine as a recreational drug. Int. J. Drug Policy 22, 95-101. 


\section{APPENDICES}

Appendix 1: Designer Drugs by Class and Sub-class

\begin{tabular}{|c|c|c|c|}
\hline Class & Basic Structure & Substituents & Name/Abbreviation \\
\hline $\begin{array}{c}\text { PHENETHYLAMINES } \\
\text { 2,5-dimethoxy-amphetamines }\end{array}$ & & $\begin{array}{r}\mathrm{R}^{1}=\mathrm{Br}, \mathrm{R}^{2}=\mathrm{H} \\
\mathrm{R}^{1}=\mathrm{C}_{2} \mathrm{H}_{5}, \mathrm{R}^{2}=\mathrm{H} \\
\mathrm{R}^{1}=\mathrm{CH}_{3}, \mathrm{R}^{2}=\mathrm{H} \\
\mathrm{R}^{1}=\mathrm{O}-\mathrm{CH}_{3}, \mathrm{R}^{2}=\mathrm{H}\end{array}$ & $\begin{array}{l}\text { DOB } \\
\text { DOET } \\
\text { DOM } \\
\text { TMA }\end{array}$ \\
\hline $\begin{array}{l}\text { PHENETHYLAMINES } \\
\text { 2Cs }\end{array}$ & & $\begin{array}{r}\mathrm{R}=\mathrm{Br} \\
\mathrm{R}=\mathrm{C}_{2} \mathrm{H}_{5} \\
\mathrm{R}=\mathrm{I} \\
\mathrm{R}=\mathrm{S}-\mathrm{CH}\left(\mathrm{CH}_{3}\right)_{2} \\
\mathrm{R}=\mathrm{S}-\mathrm{C}_{3} \mathrm{H}_{7}\end{array}$ & $\begin{array}{l}2 \mathrm{C}-\mathrm{B} \\
2 \mathrm{C}-\mathrm{E} \\
2 \mathrm{C}-\mathrm{I} \\
2 \mathrm{C}-\mathrm{T}-4 \\
2 \mathrm{C}-\mathrm{T}-7\end{array}$ \\
\hline $\begin{array}{c}\text { PHENETHYLAMIMES } \\
\text { 3,4-methylene- } \\
\text { dioxyamphetamines }\end{array}$ & & $\begin{array}{r}\mathrm{R}=\mathrm{H} \\
\mathrm{R}=\mathrm{C}_{2} \mathrm{H}_{5} \\
\mathrm{R}=\mathrm{CH}_{3}\end{array}$ & $\begin{array}{l}\text { MDA } \\
\text { MDEA } \\
\text { MDMA }\end{array}$ \\
\hline
\end{tabular}




\begin{tabular}{|c|c|c|c|}
\hline Class & Basic Structure & Substituents & Name/Abbreviation \\
\hline $\begin{array}{c}\text { PHENETHYLAMINES } \\
\text { Amphetamines }\end{array}$ & & $\begin{array}{r}\mathrm{R}=\mathrm{H} \\
\mathrm{R}=\mathrm{CH}_{3} \\
\mathrm{R}=\mathrm{C}_{2} \mathrm{H}_{5}\end{array}$ & $\begin{array}{l}\text { Amphetamine } \\
\text { Methamphetamine } \\
\text { Ethylamphetamine }\end{array}$ \\
\hline $\begin{array}{c}\text { PHENETHYLAMINES } \\
\text { Pyrrolidinophenones }\end{array}$ & & $\mathrm{R}^{1}=\mathrm{R}^{2}=\mathrm{O}-\mathrm{CH}_{2}-\mathrm{O}, \mathrm{R}^{3}=\mathrm{C}_{3} \mathrm{H}_{7}$ & MDPV \\
\hline $\begin{array}{c}\text { PHENETHYLAMINES } \\
\beta \text {-keto-amphetamines }\end{array}$ & & $\begin{array}{r}\mathrm{R}^{1}=\mathrm{R}^{2}=\mathrm{CH}_{3} \\
\mathrm{R}^{1}=\mathrm{R}^{2}=\mathrm{H} \\
\mathrm{R}^{1}=\mathrm{H}, \mathrm{R}^{2}=\mathrm{CH}_{3} \\
\mathrm{R}^{1}=\mathrm{O}-\mathrm{CH}_{3}, \mathrm{R}^{2}=\mathrm{CH}_{3} \\
\mathrm{R}^{1}=\mathrm{CH}_{3}, \mathrm{R}^{2}=\mathrm{C}_{2} \mathrm{H}_{5} \\
\mathrm{R}^{1}=\mathrm{F}, \mathrm{R}^{2}=\mathrm{CH}_{3} \\
\mathrm{R}^{1}=\mathrm{R}^{2}=\mathrm{CH}_{3} \\
\mathrm{R}^{1}=\mathrm{C}_{2} \mathrm{H}_{5}, \mathrm{R}^{2}=\mathrm{CH}_{3}\end{array}$ & $\begin{array}{l}\text { Mephedrone } \\
\text { Cathinone } \\
\text { Methcathinone } \\
\text { Methedrone } \\
\text { 4-Methylethcathinone } \\
\text { Flephedrone } \\
\text { Methylone } \\
\text { Butylone }\end{array}$ \\
\hline
\end{tabular}




\begin{tabular}{|c|c|c|c|}
\hline Class & Basic Structure & Substituents & Name/Abbreviation \\
\hline $\begin{array}{l}\text { PIPERAZINES } \\
\text { Benzylpiperazines }\end{array}$ & & $\begin{array}{r}\mathrm{R}=\mathrm{H} \\
\mathrm{R}=\mathrm{CH}_{2}-\mathrm{C}_{6} \mathrm{H}_{5}\end{array}$ & $\begin{array}{l}\text { BZP } \\
\text { DBZP }\end{array}$ \\
\hline $\begin{array}{l}\text { PIPERAZINES } \\
\text { Phenylpiperazines }\end{array}$ & & $\begin{array}{r}\mathrm{R}=\mathrm{Cl} \\
\mathrm{R}=\mathrm{CF}_{3}\end{array}$ & $\begin{array}{l}\text { mCPP } \\
\text { TFMPP }\end{array}$ \\
\hline TRYPTAMINES & & $\begin{array}{r}\mathrm{R}^{1}=\mathrm{R}^{3}=\mathrm{R}^{4}=\mathrm{H}, \mathrm{R}^{2}=\mathrm{CH}_{3} \\
\mathrm{R}^{1}=\mathrm{R}^{2}=\mathrm{H}, \mathrm{R}^{3}=\mathrm{R}^{4}=\mathrm{CH}_{3} \\
\mathrm{R}^{1}=\mathrm{O}-\mathrm{CH}_{3}, \mathrm{R}^{2}=\mathrm{H}, \mathrm{R}^{3}=\mathrm{R}^{4}=\mathrm{CH}_{3} \\
\mathrm{R}^{1}=\mathrm{O}-\mathrm{CH}_{3}, \mathrm{R}^{2}=\mathrm{H}, \mathrm{R}^{3}=\mathrm{R}^{4}=\mathrm{CH}\left(\mathrm{CH}_{3}\right)_{2}\end{array}$ & $\begin{array}{l}\text { AMT } \\
\text { DMT } \\
5-\mathrm{MeO}-\mathrm{DMT} \\
\text { 5-MeO-DiPT }\end{array}$ \\
\hline
\end{tabular}




\section{Appendix 2: Designer Drugs of Interest by Structure}

\section{Phenethylamines}

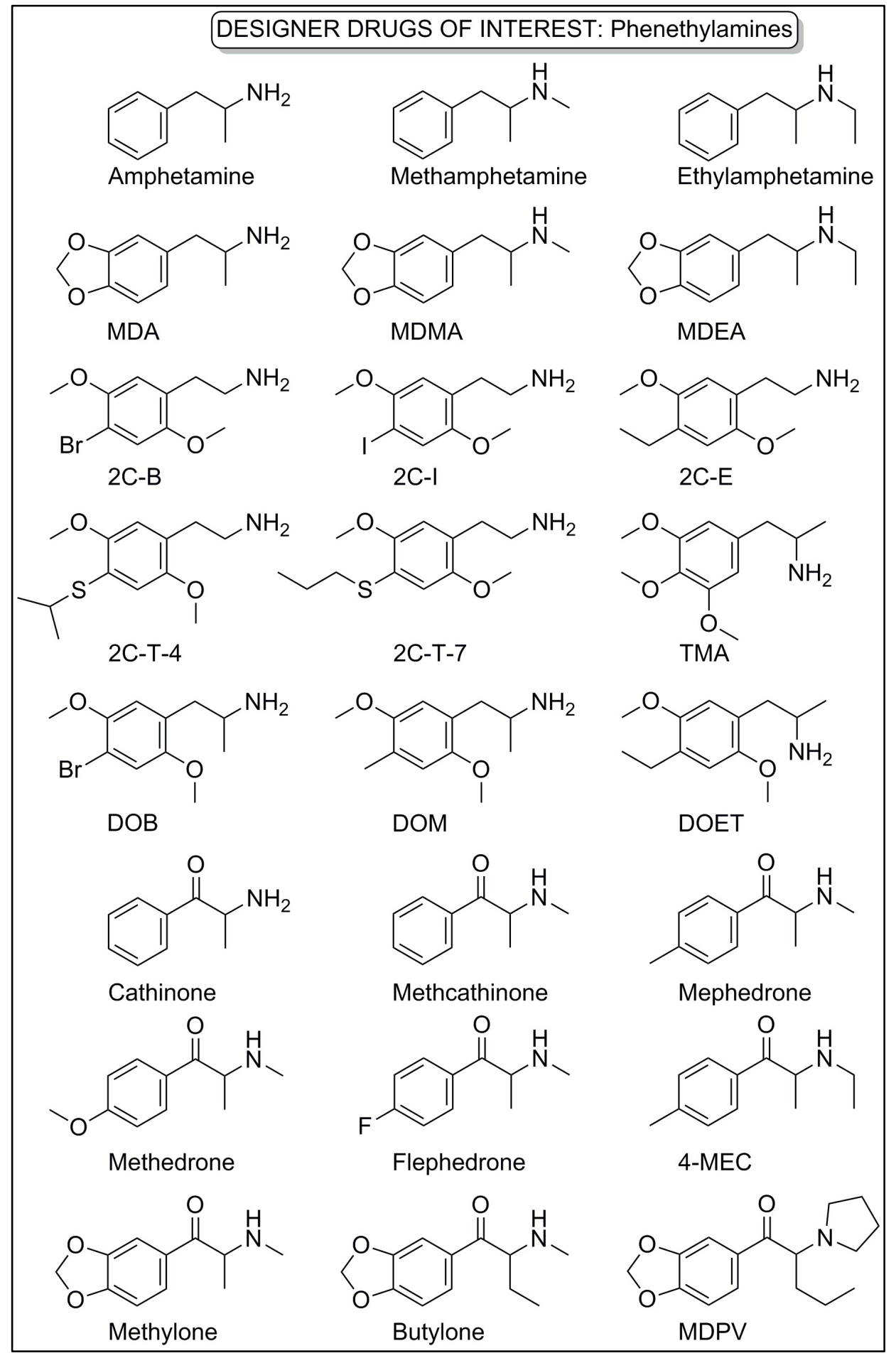


Piperazines and Tryptamines

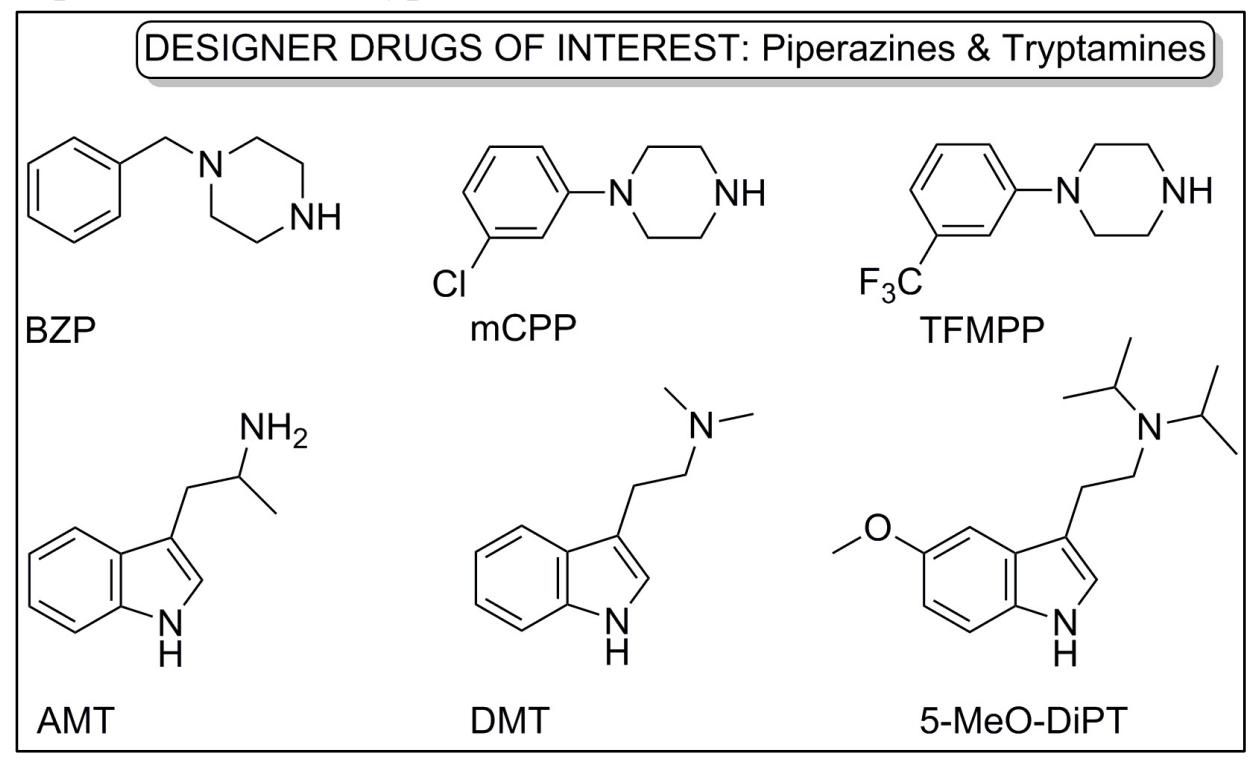


Appendix 3: Test Procedures for ELISA Analysis

\begin{tabular}{|c|c|c|c|c|c|c|c|c|c|c|}
\hline Manufacturer & Assay & $\begin{array}{c}\text { Sample } \\
\text { Volume } \\
(\mu L)\end{array}$ & $\begin{array}{c}\text { Conjugate } \\
\text { Volume }(\mu \mathrm{L})\end{array}$ & $\begin{array}{l}\text { Incubation } \\
\text { Time (min) }\end{array}$ & $\begin{array}{l}\text { No. of } \\
\text { Wash } \\
\text { Cycles }\end{array}$ & $\begin{array}{c}\text { Wash } \\
\text { Volume } \\
(\mu \mathrm{L})\end{array}$ & $\begin{array}{c}\text { Wash } \\
\text { Solution }\end{array}$ & $\begin{array}{c}\text { Substrate } \\
\text { Volume }(\mu \mathrm{L})\end{array}$ & $\begin{array}{l}\text { Incubation } \\
\text { Time (min) }\end{array}$ & $\begin{array}{l}\text { Stop Reagent } \\
\text { Volume }(\mu \mathrm{L})\end{array}$ \\
\hline \multirow{2}{*}{ Immunalysis } & Amphetamine & 10 & 100 & 60 & 6 & 350 & DI water & 100 & 30 & 100 \\
\hline & Methamphetamine & 10 & 100 & 60 & 6 & 350 & DI water & 100 & 30 & 100 \\
\hline \multirow{8}{*}{ Neogen } & Amphetamine & 20 & 180 & 45 & 5 & 300 & $\begin{array}{l}\text { Wash } \\
\text { buffer }\end{array}$ & 150 & 30 & 50 \\
\hline & Amphetamine Specific & 10 & 100 & 45 & 5 & 300 & $\begin{array}{l}\text { Wash } \\
\text { buffer }\end{array}$ & 100 & 30 & 100 \\
\hline & Amphetamine Ultra & 10 & 100 & 45 & 5 & 300 & $\begin{array}{l}\text { Wash } \\
\text { buffer }\end{array}$ & 100 & 30 & 100 \\
\hline & Benzylpiperazine & 20 & 50 & 45 & 5 & 300 & $\begin{array}{l}\text { Wash } \\
\text { buffer }\end{array}$ & 150 & 30 & 50 \\
\hline & Ketamine & 20 & 100 & 45 & 5 & 300 & $\begin{array}{l}\text { Wash } \\
\text { buffer }\end{array}$ & 100 & 30 & 100 \\
\hline & Methylphenidate & 20 & 100 & 45 & 5 & 300 & $\begin{array}{l}\text { Wash } \\
\text { buffer }\end{array}$ & 100 & 30 & 100 \\
\hline & Methamphetamine/MDMA & 20 & 100 & 45 & 5 & 300 & $\begin{array}{l}\text { Wash } \\
\text { buffer }\end{array}$ & 100 & 30 & 100 \\
\hline & Mephentermine & 20 & 180 & 45 & 5 & 300 & $\begin{array}{l}\text { Wash } \\
\text { buffer }\end{array}$ & 150 & 30 & 50 \\
\hline \multirow{2}{*}{ Randox } & MDPV & 50 & 75 & 60 & 6 & 300 & $\begin{array}{l}\text { Wash } \\
\text { buffer }\end{array}$ & 125 & 20 & 100 \\
\hline & Mephedrone/Methcathinone & 25 & 100 & 60 & 6 & 300 & $\begin{array}{l}\text { Wash } \\
\text { buffer }\end{array}$ & 125 & 20 & 100 \\
\hline \multirow{4}{*}{ OraSure } & PCP & $50^{\mathrm{a}}$ & 50 & 30 & 6 & 300 & DI water & 100 & 30 & 100 \\
\hline & Cotinine & 10 & 100 & 30 & 6 & 300 & DI water & 100 & 30 & 100 \\
\hline & Amphetamine Specific & 25 & 100 & 30 & 6 & 300 & DI water & 100 & 30 & 100 \\
\hline & Methamphetamine & 25 & 100 & 30 & 6 & 300 & Di water & 100 & 30 & 100 \\
\hline
\end{tabular}

a $50 \mu \mathrm{L}$ OraSure Pre-Buffer added to wells after samples were dispensed. 
Appendix 4: Cross-Reactivity Data for ELISAs

Cross-Reactivity Data for Immunoassays Targeting Amphetamine

\begin{tabular}{|c|c|c|c|c|c|c|c|c|c|}
\hline \multirow[b]{3}{*}{ Drug } & \multicolumn{9}{|c|}{ Neogen } \\
\hline & \multicolumn{3}{|c|}{ Amphetamine } & \multicolumn{3}{|c|}{ Amphetamine Specific } & \multicolumn{3}{|c|}{ Amphetamine Ultra } \\
\hline & $\begin{array}{c}\mathrm{C}_{50}^{\mathrm{b}} \\
(\mathrm{ng} / \mathrm{mL})\end{array}$ & $\begin{array}{c}\text { Cross- } \\
\text { Reactivity (\%) }\end{array}$ & $\begin{array}{c}\mathrm{EC}_{50} \\
(\mathrm{ng} / \mathrm{mL})\end{array}$ & $\begin{array}{c}\mathrm{C}_{50}^{\mathrm{b}} \\
(\mathrm{ng} / \mathrm{mL})\end{array}$ & $\begin{array}{c}\text { Cross- } \\
\text { Reactivity (\%) }\end{array}$ & $\begin{array}{c}\mathrm{EC}_{50} \\
(\mathrm{ng} / \mathrm{mL})\end{array}$ & $\begin{array}{c}\mathrm{C}_{50}^{\mathrm{b}} \\
(\mathrm{ng} / \mathrm{mL})\end{array}$ & $\begin{array}{c}\text { Cross- } \\
\text { Reactivity (\%) }\end{array}$ & $\begin{array}{c}\mathrm{EC}_{50} \\
(\mathrm{ng} / \mathrm{mL})\end{array}$ \\
\hline (+)-Amphetamine & 50 & 100 & 200 & 50 & 100 & 100 & 50 & 100 & 10 \\
\hline ( \pm )-Methamphetamine & $<10$ & $>500$ & 10 & $>10,000$ & $<0.5$ & $>10,000$ & $<10$ & $>500$ & 15 \\
\hline $2 \mathrm{C}-\mathrm{E}$ & $>10,000$ & $<0.5$ & $>10,000$ & $>10,000$ & $<0.5$ & $>10,000$ & $>10,000$ & $<0.5$ & $>10,000$ \\
\hline$( \pm)$-DOET & $>10,000$ & $<0.5$ & $>10,000$ & 5,000 & 1 & $>10,000$ & $>10,000$ & $<0.5$ & $>10,000$ \\
\hline ( \pm )-DOM & $>10,000$ & $<0.5$ & $>10,000$ & 5,000 & 1 & $>10,000$ & $>10,000$ & $<0.5$ & $>10,000$ \\
\hline ( \pm )-TMA & $>10,000$ & $<0.5$ & $>10,000$ & 2,500 & 2 & 10,000 & $>10,000$ & $<0.5$ & $>10,000$ \\
\hline ( \pm )-MDA & 1,250 & 4 & 5,000 & 78 & 64 & 100 & 2,500 & 2 & 7,000 \\
\hline$( \pm)$-MDEA & 156 & 32 & 625 & $>10,000$ & $<0.5$ & $>10,000$ & 313 & 16 & 1,000 \\
\hline ( \pm )-MDMA & 156 & 32 & 1,250 & $>10,000$ & $<0.5$ & $>10,000$ & 625 & 8 & 2,500 \\
\hline$( \pm)$-Ethylamphetamine & $<10$ & $>500$ & $<10$ & $>10,000$ & $<0.5$ & $>10,000$ & $<10$ & $>500$ & 19 \\
\hline (土)-MDPV & $>10,000$ & $<0.5$ & $>10,000$ & $>10,000$ & $<0.5$ & $>10,000$ & $>10,000$ & $<0.5$ & $>10,000$ \\
\hline ( \pm )-Mephedrone & $>10,000$ & $<0.5$ & $>10,000$ & $>10,000$ & $<0.5$ & $>10,000$ & $>10,000$ & $<0.5$ & $>10,000$ \\
\hline ( \pm )-Cathinone & 2,500 & 2 & 10,000 & $>10,000$ & $<0.5$ & $>10,000$ & 10,000 & 0.5 & $>10,000$ \\
\hline ( \pm )-Methcathinone & 1,250 & 4 & 5,000 & $>10,000$ & $<0.5$ & $>10,000$ & 4,250 & 1 & 4,500 \\
\hline ( \pm )-Methylone & $>10,000$ & $<0.5$ & $>10,000$ & $>10,000$ & $<0.5$ & $>10,000$ & $>10,000$ & $<0.5$ & $>10,000$ \\
\hline$( \pm)-4-M E C$ & 10,000 & 0.5 & $>10,000$ & $>10,000$ & $<0.5$ & $>10,000$ & $>10,000$ & $<0.5$ & $>10,000$ \\
\hline ( \pm )-Flephedrone & 1,250 & 4 & $>10,000$ & $>10,000$ & $<0.5$ & $>10,000$ & 10,000 & 0.5 & $>10,000$ \\
\hline ( \pm )-Butylone & $>10,000$ & $<0.5$ & $>10,000$ & $>10,000$ & $<0.5$ & $>10,000$ & $>10,000$ & $<0.5$ & $>10,000$ \\
\hline mCPP & 156 & 32 & 625 & $>10,000$ & $<0.5$ & $>10,000$ & 156 & 32 & 1,000 \\
\hline ( \pm )-Methedrone & 10,000 & 0.5 & $>10,000$ & $>10,000$ & $<0.5$ & $>10,000$ & $>10,000$ & $<0.5$ & $>10,000$ \\
\hline 5-MeO-DiPT & $>10,000$ & $<0.5$ & $>10,000$ & $>10,000$ & $<0.5$ & $>10,000$ & $>10,000$ & $<0.5$ & $>10,000$ \\
\hline$( \pm)$-DOB & 10,000 & 0.5 & $>10,000$ & $>10,000$ & $<0.5$ & $>10,000$ & 10,000 & 0.5 & $>10,000$ \\
\hline 2C-B & $>10,000$ & $<0.5$ & $>10,000$ & $>10,000$ & $<0.5$ & $>10,000$ & $>10,000$ & $<0.5$ & $>10,000$ \\
\hline DMT & 5,000 & 1 & $>10,000$ & $>10,000$ & $<0.5$ & $>10,000$ & 5,000 & 1 & $>10,000$ \\
\hline BZP & 5,000 & 1 & $>10,000$ & $>10,000$ & $<0.5$ & $>10,000$ & 3,000 & 1.67 & 10,000 \\
\hline AMT & 625 & 8 & 4,000 & $<156$ & $>32$ & 156 & 1,250 & 4 & 4,500 \\
\hline 2C-I & $>10,000$ & $<0.5$ & $>10,000$ & $>10,000$ & $<0.5$ & $>10,000$ & $>10,000$ & $<0.5$ & $>10,000$ \\
\hline 2C-T-7 & $>10,000$ & $<0.5$ & $>10,000$ & $>10,000$ & $<0.5$ & $>10,000$ & $>10,000$ & $<0.5$ & $>10,000$ \\
\hline TFMPP & 2,500 & 2 & 10,000 & $>10,000$ & $<0.5$ & $>10,000$ & 2,500 & 2 & $>10,000$ \\
\hline 2C-T-4 & $>10,000$ & $<0.5$ & $>10,000$ & $>10,000$ & $<0.5$ & $>10,000$ & $>10,000$ & $<0.5$ & $>10,000$ \\
\hline
\end{tabular}

${ }^{\text {a }}$ Concentration of the drug that produces an absorbance reading equivalent to the $25 \mathrm{ng} / \mathrm{mL}$ cut-off of the targeted analyte.

${ }^{\mathbf{b}}$ Concentration of the drug that produces an absorbance reading equivalent to the $50 \mathrm{ng} / \mathrm{mL}$ cut-off of the targeted analyte.

Analytes demonstrating high cross-reactivity are highlighted and bolded.

The target analytes for each assay are italicized and bolded. 


\section{Appendix 4: Cross-Reactivity Data for ELISAs}

Cross-Reactivity Data for Immunoassays Targeting Amphetamine

\begin{tabular}{|c|c|c|c|c|c|c|}
\hline \multirow[b]{3}{*}{ Drug } & \multicolumn{3}{|c|}{ Immunalysis } & \multicolumn{3}{|c|}{ OraSure } \\
\hline & \multicolumn{3}{|c|}{ Amphetamine } & \multicolumn{3}{|c|}{ Amphetamine Specific } \\
\hline & $\begin{array}{c}\mathrm{C}_{25}^{\mathrm{a}} \\
(\mathrm{ng} / \mathrm{mL}) \\
\end{array}$ & \begin{tabular}{|c|} 
Cross- \\
Reactivity (\%)
\end{tabular} & $\begin{array}{c}\mathrm{EC}_{50} \\
(\mathrm{ng} / \mathrm{mL})\end{array}$ & $\begin{array}{c}\mathrm{C}_{50}^{\mathrm{b}} \\
(\mathrm{ng} / \mathrm{mL}) \\
\end{array}$ & \begin{tabular}{|c|} 
Cross- \\
Reactivity (\%)
\end{tabular} & $\begin{array}{c}\mathrm{EC}_{50} \\
(\mathrm{ng} / \mathrm{mL})\end{array}$ \\
\hline$(+)$-Amphetamine & 25 & 100 & 18 & 50 & 100 & 70 \\
\hline ( \pm -Methamphetamine & $>10,000$ & $<0.25$ & $>10,000$ & $>10,000$ & $<0.5$ & $>10,000$ \\
\hline 2C-E & $>10,000$ & $<0.25$ & $>10,000$ & $>10,000$ & $<0.5$ & $>10,000$ \\
\hline$( \pm)-$ DOET & $>10,000$ & $<0.25$ & $>10,000$ & $>10,000$ & $<0.5$ & $>10,000$ \\
\hline$( \pm)-$ DOM & 10,000 & 0.25 & 6,750 & $>10,000$ & $<0.5$ & $>10,000$ \\
\hline$( \pm)$-ТМА & 5,000 & 0.5 & 6,750 & $>10,000$ & $<0.5$ & $>10,000$ \\
\hline$( \pm)$-MDA & $<10$ & $>250$ & $<10$ & 56 & 89 & 64 \\
\hline$( \pm)$-MDEA & 7,000 & 0.36 & 6,500 & $>10,000$ & $<0.5$ & $>10,000$ \\
\hline ( \pm -MDMA & 5,000 & 0.5 & 4,250 & $>10,000$ & $<0.5$ & $>10,000$ \\
\hline$( \pm)$-Ethylamphetamine & $>10,000$ & $<0.25$ & $>10,000$ & $>10,000$ & $<0.5$ & $>10,000$ \\
\hline ( \pm -MDPV & $>10,000$ & $<0.25$ & $>10,000$ & $>10,000$ & $<0.5$ & $>10,000$ \\
\hline ( \pm )-Mephedrone & $>10,000$ & $<0.25$ & $>10,000$ & $>10,000$ & $<0.5$ & $>10,000$ \\
\hline$( \pm)$-Cathinone & $>10,000$ & $<0.25$ & $>10,000$ & $>10,000$ & $<0.5$ & $>10,000$ \\
\hline$( \pm)$-Methcathinone & $>10,000$ & $<0.25$ & $>10,000$ & $>10,000$ & $<0.5$ & $>10,000$ \\
\hline$( \pm)$-Methylone & $>10,000$ & $<0.25$ & $>10,000$ & $>10,000$ & $<0.5$ & $>10,000$ \\
\hline$( \pm)-4-M E C$ & $>10,000$ & $<0.25$ & $>10,000$ & $>10,000$ & $<0.5$ & $>10,000$ \\
\hline$( \pm)$-Flephedrone & $>10,000$ & $<0.25$ & $>10,000$ & $>10,000$ & $<0.5$ & $>10,000$ \\
\hline ( \pm )-Butylone & $>10,000$ & $<0.25$ & $>10,000$ & $>10,000$ & $<0.5$ & $>10,000$ \\
\hline mCPP & $>10,000$ & $<0.25$ & $>10,000$ & $>10,000$ & $<0.5$ & $>10,000$ \\
\hline$( \pm)$-Methedrone & $>10,000$ & $<0.25$ & $>10,000$ & $>10,000$ & $<0.5$ & $>10,000$ \\
\hline 5-MeO-DiPT & $>10,000$ & $<0.25$ & $>10,000$ & $>10,000$ & $<0.5$ & $>10,000$ \\
\hline$( \pm)-\mathrm{DOB}$ & $>10,000$ & $<0.25$ & $>10,000$ & $>10,000$ & $<0.5$ & $>10,000$ \\
\hline $2 C-B$ & $>10,000$ & $<0.25$ & $>10,000$ & $>10,000$ & $<0.5$ & $>10,000$ \\
\hline DMT & $>10,000$ & $<0.25$ & $>10,000$ & $>10,000$ & $<0.5$ & $>10,000$ \\
\hline BZP & $>10,000$ & $<0.25$ & $>10,000$ & $>10,000$ & $<0.5$ & $>10,000$ \\
\hline AMT & 30 & 83 & 20 & 43 & 116 & 48 \\
\hline $2 \mathrm{C}-\mathrm{I}$ & $>10,000$ & $<0.25$ & $>10,000$ & $>10,000$ & $<0.5$ & $>10,000$ \\
\hline 2C-T-7 & $>10,000$ & $<0.25$ & $>10,000$ & $>10,000$ & $<0.5$ & $>10,000$ \\
\hline TFMPP & $>10,000$ & $<0.25$ & $>10,000$ & $>10,000$ & $<0.5$ & $>10,000$ \\
\hline 2C-T-4 & $>10,000$ & $<0.25$ & $>10,000$ & $>10,000$ & $<0.5$ & $>10,000$ \\
\hline
\end{tabular}

${ }^{a}$ Concentration of the drug that produces an absorbance reading equivalent to the $25 \mathrm{ng} / \mathrm{mL}$ cut-off of targeted analyte.

${ }^{\text {b }}$ Concentration of the drug that produces an absorbance reading equivalent to the $50 \mathrm{ng} / \mathrm{mL}$ cut-off of targeted analyte. Analytes demonstrating high cross-reactivity are highlighted and bolded.

The target analytes for each assay are italicized and bolded. 


\section{Appendix 4: Cross-Reactivity Data for ELISAs}

\section{Cross-Reactivity Data for Immunoassays Targeting Methamphetamine}

\begin{tabular}{|c|c|c|c|c|c|c|c|c|c|}
\hline \multirow{3}{*}{ Drug } & \multirow{2}{*}{\multicolumn{3}{|c|}{$\begin{array}{l}\text { Immunalysis } \\
\text { Methamphetamine }\end{array}$}} & \multirow{2}{*}{\multicolumn{3}{|c|}{$\begin{array}{c}\text { Neogen } \\
\text { Methamnhetamine/MDMA }\end{array}$}} & \multirow{2}{*}{\multicolumn{3}{|c|}{$\begin{array}{c}\text { OraSure } \\
\text { Methamphetamine }\end{array}$}} \\
\hline & & & & & & & & & \\
\hline & $\begin{array}{c}\mathrm{C}_{25}{ }^{\mathrm{a}} \\
(\mathrm{ng} / \mathrm{mL})\end{array}$ & \begin{tabular}{c|} 
Cross- \\
Reactivity (\%)
\end{tabular} & $\begin{array}{c}\mathbf{E C}_{50} \\
(\mathrm{ng} / \mathrm{mL})\end{array}$ & $\begin{array}{c}\mathrm{C}_{25}{ }^{\mathrm{a}} \\
(\mathrm{ng} / \mathrm{mL})\end{array}$ & $\begin{array}{c}\text { Cross- } \\
\text { Reactivity (\%) }\end{array}$ & $\begin{array}{c}\mathbf{E C}_{50} \\
(\mathrm{ng} / \mathbf{m L})\end{array}$ & $\begin{array}{c}\mathbf{C}_{10}{ }^{b} \\
(\mathrm{ng} / \mathrm{mL})\end{array}$ & \begin{tabular}{c|} 
Cross- \\
Reactivity (\%)
\end{tabular} & $\begin{array}{c}\mathbf{E C}_{50} \\
(\mathbf{n g} / \mathbf{m L})\end{array}$ \\
\hline (+)-Methamphetamine & 25 & 100 & 35 & 25 & 100 & 50 & 10 & 100 & 10 \\
\hline ( \pm -Amphetamine & $>10,000$ & $<0.25$ & $>10,000$ & 4,000 & 0.63 & 6,750 & 2,500 & 0.4 & 1,250 \\
\hline 2C-E & $>10,000$ & $<0.25$ & $>10,000$ & $>10,000$ & $<0.25$ & $>10,000$ & $>10,000$ & $<0.1$ & $>10,000$ \\
\hline$( \pm)$-DOET & $>10,000$ & $<0.25$ & $>10,000$ & $>10,000$ & $<0.25$ & $>10,000$ & $>10,000$ & $<0.1$ & $>10,000$ \\
\hline$( \pm)-\mathrm{DOM}$ & $>10,000$ & $<0.25$ & $>10,000$ & $>10,000$ & $<0.25$ & $>10,000$ & $>10,000$ & $<0.1$ & $>10,000$ \\
\hline$( \pm)$-TMA & $>10,000$ & $<0.25$ & $>10,000$ & $>10,000$ & $<0.25$ & $>10,000$ & $>10,000$ & $<0.1$ & $>10,000$ \\
\hline ( \pm )-MDA & 5,000 & 0.5 & 6,000 & 1,250 & 2 & 2,000 & 625 & 2 & 500 \\
\hline ( \pm )-MDEA & 35 & 71 & 40 & 156 & 16 & 313 & 10 & 100 & $<10$ \\
\hline ( \pm )-MDMA & $<10$ & $>250$ & 10 & 15 & 167 & 25 & $<10$ & $>100$ & $<10$ \\
\hline$( \pm)$-Ethylamphetamine & 80 & 31 & 100 & 156 & 16 & 600 & 15 & 67 & $<10$ \\
\hline ( \pm )-MDPV & $>10,000$ & $<0.25$ & $>10,000$ & $>10,000$ & $<0.25$ & $>10,000$ & $>10,000$ & $<0.1$ & $>10,000$ \\
\hline ( \pm )-Mephedrone & 1,250 & 2 & 2,500 & 2,500 & 1 & 9,000 & 40 & 25 & 20 \\
\hline$( \pm)$-Cathinone & $>10,000$ & $<0.25$ & $>10,000$ & $>10,000$ & $<0.25$ & $>10,000$ & $>10,000$ & $<0.1$ & $>10,000$ \\
\hline ( \pm )-Methcathinone & 5,000 & 0.5 & 5,000 & 5,000 & 0.5 & $>10,000$ & 300 & \begin{tabular}{|c|c|}
3.33 \\
\end{tabular} & 150 \\
\hline$( \pm$ )-Methylone & 2,500 & 1 & 4,000 & 5,000 & 0.5 & $>10,000$ & 150 & 6.67 & $<150$ \\
\hline$( \pm)$-4-MEC & 1,250 & 2 & 1,250 & 2,500 & 1 & $>10,000$ & 40 & 25 & 20 \\
\hline$( \pm)$-Flephedrone & 10,000 & 0.25 & 10,000 & 2,500 & 1 & $>10,000$ & 450 & 2.22 & 250 \\
\hline ( \pm )-Butylone & 10,000 & 0.25 & 10,000 & 5,000 & 0.5 & $>10,000$ & 300 & 3 & 175 \\
\hline mCPP & $>10,000$ & $<0.25$ & $>10,000$ & $>10,000$ & $<0.25$ & $>10,000$ & $>10,000$ & $<0.1$ & $>10,000$ \\
\hline ( \pm )-Methedrone & 3,500 & 0.71 & 3,500 & 1,250 & 2 & 7,000 & 150 & 6.67 & 60 \\
\hline 5-MeO-DiPT & $>10,000$ & $<0.25$ & $>10,000$ & $>10,000$ & $<0.25$ & $>10,000$ & $>10,000$ & $<0.1$ & $>10,000$ \\
\hline$( \pm)$-DOB & $>10,000$ & $<0.25$ & $>10,000$ & $>10,000$ & $<0.25$ & $>10,000$ & $>10,000$ & $<0.1$ & $>10,000$ \\
\hline 2C-B & $>10,000$ & $<0.25$ & $>10,000$ & $>10,000$ & $<0.25$ & $>10,000$ & $>10,000$ & $<0.1$ & $>10,000$ \\
\hline DMT & $>10,000$ & $<0.25$ & $>10,000$ & $>10,000$ & $<0.25$ & $>10,000$ & $>10,000$ & $<0.1$ & $>10,000$ \\
\hline BZP & $>10,000$ & $<0.25$ & $>10,000$ & $>10,000$ & $<0.25$ & $>10,000$ & $>10,000$ & $<0.1$ & $>10,000$ \\
\hline AMT & $>10,000$ & $<0.25$ & $>10,000$ & 5,000 & 0.5 & $>10,000$ & 2,500 & \begin{tabular}{l|l}
0.4 \\
\end{tabular} & 2,000 \\
\hline 2C-I & $>10,000$ & $<0.25$ & $>10,000$ & $>10,000$ & $<0.25$ & $>10,000$ & $>10,000$ & $<0.1$ & $>10,000$ \\
\hline 2C-T-7 & $>10,000$ & $<0.25$ & $>10,000$ & $>10,000$ & $<0.25$ & $>10,000$ & $>10,000$ & $<0.1$ & $>10,000$ \\
\hline TFMPP & $>10,000$ & $<0.25$ & $>10,000$ & $>10,000$ & $<0.25$ & $>10,000$ & $>10,000$ & $<0.1$ & $>10,000$ \\
\hline 2C-T-4 & $>10,000$ & $<0.25$ & $>10,000$ & $>10,000$ & $<0.25$ & $>10,000$ & $>10,000$ & $<0.1$ & $>10,000$ \\
\hline
\end{tabular}

${ }^{\mathrm{a}}$ Concentration of the drug that produces an absorbance reading equivalent to the $25 \mathrm{ng} / \mathrm{mL}$ cut-off of the targeted analyte.

${ }^{b}$ Concentration of the drug that produces an absorbance reading equivalent to the $10 \mathrm{ng} / \mathrm{mL}$ cut-off of the targeted analyte.

Analytes demonstrating high cross-reactivity are highlighted and bolded.

The target analytes for each assay are italicized and bolded. 
Appendix 4: Cross-Reactivity Data for ELISAs Cross-Reactivity Data for Additional Neogen Assays

\begin{tabular}{|c|c|c|c|c|c|c|c|c|c|c|c|c|}
\hline \multirow[b]{3}{*}{ Drug } & \multicolumn{12}{|c|}{ Neogen } \\
\hline & \multicolumn{3}{|c|}{ Benzylpiperazine } & \multicolumn{3}{|c|}{ Ketamine } & \multicolumn{3}{|c|}{ Methylphenidate } & \multicolumn{3}{|c|}{ Mephentermine } \\
\hline & \begin{tabular}{|c|}
$\mathrm{C}_{25}{ }^{\mathrm{a}}$ \\
$(\mathrm{ng} / \mathrm{mL})$ \\
\end{tabular} & \begin{tabular}{c|} 
Cross- \\
Reactivity (\%) \\
\end{tabular} & $\begin{array}{c}\begin{array}{c}\mathbf{E C}_{50} \\
(\mathbf{n g} / \mathbf{m L})\end{array} \\
\end{array}$ & $\begin{array}{c}\mathbf{C}_{50}^{\mathbf{b}^{\mathrm{b}}} \\
(\mathbf{n g} / \mathbf{m L})\end{array}$ & \begin{tabular}{c|c|} 
Cross- \\
Reactivity (\%)
\end{tabular} & \begin{tabular}{|c|}
$\mathbf{E C}_{\mathbf{5 0}}$ \\
$(\mathbf{n g} / \mathbf{m L})$ \\
\end{tabular} & $\begin{array}{c}\mathrm{C}_{10}{ }^{\mathrm{c}} \\
(\mathrm{ng} / \mathrm{mL})\end{array}$ & \begin{tabular}{c|c|} 
Cross- \\
Reactivity (\%) \\
\end{tabular} & $\begin{array}{c}\begin{array}{c}\mathbf{E C}_{50} \\
(\mathbf{n g} / \mathbf{m L})\end{array} \\
\end{array}$ & $\begin{array}{c}\mathrm{C}_{10}{ }^{\mathrm{c}} \\
(\mathrm{ng} / \mathrm{mL})\end{array}$ & \begin{tabular}{c|c|} 
Cross- \\
Reactivity (\%) \\
\end{tabular} & \begin{tabular}{|c|}
$\mathbf{E C}_{50}$ \\
$(\mathbf{n g} / \mathbf{m L})$
\end{tabular} \\
\hline$( \pm)$-Amphetamine & $>10,000$ & $<0.25$ & $>10,000$ & $>10,000$ & $<0.5$ & $>10,000$ & $>10,000$ & $<0.1$ & $>10,000$ & $>10,000$ & $<0.1$ & $>10,000$ \\
\hline$( \pm)$-Methamphetamine & 10,000 & 0.25 & 10,000 & $>10,000$ & $<0.5$ & $>10,000$ & $>10,000$ & $<0.1$ & $>10,000$ & 250 & 4 & 400 \\
\hline $2 \mathrm{C}-\mathrm{E}$ & $>10,000$ & $<0.25$ & $>10,000$ & $>10,000$ & $<0.5$ & $>10,000$ & $>10,000$ & $<0.1$ & $>10,000$ & $>10,000$ & $<0.1$ & $>10,000$ \\
\hline ( \pm -DOET & $>10,000$ & $<0.25$ & $>10,000$ & $>10,000$ & $<0.5$ & $>10,000$ & $>10,000$ & $<0.1$ & $>10,000$ & $>10,000$ & $<0.1$ & $>10,000$ \\
\hline$( \pm)-\mathrm{DOM}$ & $>10,000$ & $<0.25$ & $>10,000$ & $>10,000$ & $<0.5$ & $>10,000$ & $>10,000$ & $<0.1$ & $>10,000$ & $>10,000$ & $<0.1$ & $>10,000$ \\
\hline ( \pm -TMA & $>10,000$ & $<0.25$ & $>10,000$ & $>10,000$ & $<0.5$ & $>10,000$ & $>10,000$ & $<0.1$ & $>10,000$ & $>10,000$ & $<0.1$ & $>10,000$ \\
\hline$( \pm)$-MDA & $>10,000$ & $<0.25$ & $>10,000$ & $>10,000$ & $<0.5$ & $>10,000$ & $>10,000$ & $<0.1$ & $>10,000$ & 10,000 & 0.1 & $>10,000$ \\
\hline ( \pm -MDEA & 9,000 & 0.25 & 10,000 & $>10,000$ & $<0.5$ & $>10,000$ & $>10,000$ & $<0.1$ & $>10,000$ & 1,250 & 0.80 & 7,000 \\
\hline$( \pm)$-MDMA & 10,000 & 0.25 & 10,000 & $>10,000$ & $<0.5$ & $>10,000$ & $>10,000$ & $<0.1$ & $>10,000$ & 200 & 5 & 750 \\
\hline$( \pm)$-Ethylamphetamine & $>10,000$ & $<0.25$ & $>10,000$ & $>10,000$ & $<0.5$ & $>10,000$ & $>10,000$ & $<0.1$ & $>10,000$ & 1,750 & 0.60 & 3,000 \\
\hline ( \pm -MDPV & $>10,000$ & $<0.25$ & $>10,000$ & $>10,000$ & $<0.5$ & $>10,000$ & $>10,000$ & $<0.1$ & $>10,000$ & $>10,000$ & $<0.1$ & $>10,000$ \\
\hline ( \pm )-Mephedrone & $>10,000$ & $<0.25$ & $>10,000$ & $>10,000$ & $<0.5$ & $>10,000$ & $>10,000$ & $<0.1$ & $>10,000$ & $>10,000$ & $<0.1$ & $>10,000$ \\
\hline ( \pm )-Cathinone & $>10,000$ & $<0.25$ & $>10,000$ & $>10,000$ & $<0.5$ & $>10,000$ & $>10,000$ & $<0.1$ & $>10,000$ & $>10,000$ & $<0.1$ & $>10,000$ \\
\hline ( \pm )-Methcathinone & $>10,000$ & $<0.25$ & $>10,000$ & $>10,000$ & $<0.5$ & $>10,000$ & $>10,000$ & $<0.1$ & $>10,000$ & $>10,000$ & $<0.1$ & $>10,000$ \\
\hline ( \pm )-Methylone & $>10,000$ & $<0.25$ & $>10,000$ & \begin{tabular}{|l|}
$>10,000$ \\
\end{tabular} & $<0.5$ & $>10,000$ & $>10,000$ & $<0.1$ & $>10,000$ & $>10,000$ & $<0.1$ & $>10,000$ \\
\hline ( \pm )-4-MEC & $>10,000$ & $<0.25$ & $>10,000$ & $>10,000$ & $<0.5$ & $>10,000$ & $>10,000$ & $<0.1$ & $>10,000$ & $>10,000$ & $<0.1$ & $>10,000$ \\
\hline$( \pm)$-Flephedrone & $>10,000$ & $<0.25$ & $>10,000$ & $>10,000$ & $<0.5$ & $>10,000$ & $>10,000$ & $<0.1$ & $>10,000$ & $>10,000$ & $<0.1$ & $>10,000$ \\
\hline ( \pm )-Butylone & $>10,000$ & $<0.25$ & $>10,000$ & $>10,000$ & $<0.5$ & $>10,000$ & $>10,000$ & $<0.1$ & $>10,000$ & $>10,000$ & $<0.1$ & $>10,000$ \\
\hline mCPP & $>10,000$ & $<0.25$ & $>10,000$ & $>10,000$ & $<0.5$ & $>10,000$ & $>10,000$ & $<0.1$ & $>10,000$ & $>10,000$ & $<0.1$ & $>10,000$ \\
\hline$( \pm)$-Methedrone & $>10,000$ & $<0.25$ & $>10,000$ & $>10,000$ & $<0.5$ & $>10,000$ & $>10,000$ & $<0.1$ & $>10,000$ & $>10,000$ & $<0.1$ & $>10,000$ \\
\hline 5-MeO-DiPT & $>10,000$ & $<0.25$ & $>10,000$ & $>10,000$ & $<0.5$ & $>10,000$ & $>10,000$ & $<0.1$ & $>10,000$ & $>10,000$ & $<0.1$ & $>10,000$ \\
\hline ( \pm )-DOB & $>10,000$ & $<0.25$ & $>10,000$ & $>10,000$ & $<0.5$ & $>10,000$ & $>10,000$ & $<0.1$ & $>10,000$ & $>10,000$ & $<0.1$ & $>10,000$ \\
\hline 2C-B & $>10,000$ & $<0.25$ & $>10,000$ & $>10,000$ & $<0.5$ & $>10,000$ & $>10,000$ & $<0.1$ & $>10,000$ & $>10,000$ & $<0.1$ & $>10,000$ \\
\hline DMT & 5,000 & 0.50 & 5,000 & $>10,000$ & $<0.5$ & $>10,000$ & $>10,000$ & $<0.1$ & $>10,000$ & $>10,000$ & $<0.1$ & $>10,000$ \\
\hline BZP & 25 & 100 & 35 & $>10,000$ & $<0.5$ & $>10,000$ & $>10,000$ & $<0.1$ & $>10,000$ & $>10,000$ & $<0.1$ & $>10,000$ \\
\hline AMT & $>10,000$ & $<0.25$ & $>10,000$ & $>10,000$ & $<0.5$ & $>10,000$ & $>10,000$ & $<0.1$ & $>10,000$ & $>10,000$ & $<0.1$ & $>10,000$ \\
\hline 2C-I & $>10,000$ & $<0.25$ & $>10,000$ & $>10,000$ & $<0.5$ & $>10,000$ & $>10,000$ & $<0.1$ & $>10,000$ & $>10,000$ & $<0.1$ & $>10,000$ \\
\hline 2C-T-7 & $>10,000$ & $<0.25$ & $>10,000$ & $>10,000$ & $<0.5$ & $>10,000$ & $>10,000$ & $<0.1$ & $>10,000$ & $>10,000$ & $<0.1$ & $>10,000$ \\
\hline TFMPP & $>10,000$ & $<0.25$ & $>10,000$ & $>10,000$ & $<0.5$ & $>10,000$ & $>10,000$ & $<0.1$ & $>10,000$ & $>10,000$ & $<0.1$ & $>10,000$ \\
\hline 2C-T-4 & $>10,000$ & $<0.25$ & $>10,000$ & $\mid>10,000$ & $<0.5$ & $>10,000$ & $>10,000$ & $<0.1$ & $>10,000$ & $>10,000$ & $<0.1$ & $>10,000$ \\
\hline
\end{tabular}

${ }^{a}$ Concentration of the drug that produces an absorbance reading equivalent to the $25 \mathrm{ng} / \mathrm{mL}$ cut-off of the targeted analyte.

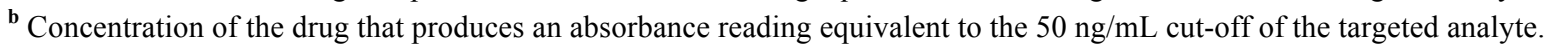

${ }^{c}$ Concentration of the drug that produces an absorbance reading equivalent to the $10 \mathrm{ng} / \mathrm{mL}$ cut-off of the targeted analyte.

Analytes demonstrating high cross-reactivity are highlighted and bolded.

The target analytes for each assay are italicized and bolded. 


\section{Appendix 4: Cross-Reactivity Data for ELISAs}

\section{Cross-Reactivity Data for Additional Randox and OraSure Assays}

\begin{tabular}{|c|c|c|c|c|c|c|c|c|c|c|c|c|}
\hline \multirow[b]{3}{*}{ Drug } & \multicolumn{6}{|c|}{ Randox } & \multicolumn{6}{|c|}{ OraSure } \\
\hline & \multicolumn{3}{|c|}{ MDPV } & \multicolumn{3}{|c|}{ Mephedrone/Methcathinone } & \multicolumn{3}{|c|}{ PCP } & \multicolumn{3}{|c|}{ Cotinine } \\
\hline & \begin{tabular}{|c|}
$\mathrm{C}_{10}{ }^{\mathrm{a}}$ \\
$(\mathrm{ng} / \mathrm{mL})$
\end{tabular} & \begin{tabular}{c|} 
Cross- \\
Reactivity (\%)
\end{tabular} & \begin{tabular}{|c|}
$\mathbf{E C}_{50}$ \\
$(\mathbf{n g} / \mathbf{m L})$
\end{tabular} & \begin{tabular}{|c|}
$\mathrm{C}_{1.25}{ }^{\mathrm{b}}$ \\
$(\mathrm{ng} / \mathrm{mL})$
\end{tabular} & \begin{tabular}{|c|} 
Cross- \\
Reactivity (\%)
\end{tabular} & \begin{tabular}{|c|}
$\mathrm{EC}_{50}$ \\
$(\mathrm{ng} / \mathrm{mL})$
\end{tabular} & \begin{tabular}{|c|}
$\mathrm{C}_{20}{ }^{\mathrm{c}}$ \\
$(\mathrm{ng} / \mathrm{mL})$
\end{tabular} & $\begin{array}{c}\text { Cross- } \\
\text { Reactivity (\%) }\end{array}$ & \begin{tabular}{|c|}
$\mathbf{E C}_{\mathbf{5 0}}$ \\
$(\mathrm{ng} / \mathrm{mL})$
\end{tabular} & \begin{tabular}{|c|}
$\mathrm{C}_{100}{ }^{\mathrm{d}}$ \\
$(\mathrm{ng} / \mathrm{mL})$
\end{tabular} & \begin{tabular}{c|} 
Cross- \\
Reactivity (\%)
\end{tabular} & \begin{tabular}{|c|}
$\mathbf{E C}_{50}$ \\
$(\mathrm{ng} / \mathrm{mL})$
\end{tabular} \\
\hline (土)-Amphetamine & $>10,000$ & $<0.1$ & $>10,000$ & $>10,000$ & $<0.0125$ & $>10,000$ & $>10,000$ & $<0.2$ & $>10,000$ & $>10,000$ & $<1$ & $>10,000$ \\
\hline (土)-Methamphetamine & $>10,000$ & $<0.1$ & $>10,000$ & 5,000 & 0.0250 & 10,000 & $>10,000$ & $<0.2$ & $>10,000$ & $>10,000$ & $<1$ & $>10,000$ \\
\hline $2 \mathrm{C}-\mathrm{E}$ & $>10,000$ & $<0.1$ & $>10,000$ & $>10,000$ & $<0.0125$ & $>10,000$ & $>10,000$ & $<0.2$ & $>10,000$ & $>10,000$ & $<1$ & $>10,000$ \\
\hline$( \pm)$-DOET & $>10,000$ & $<0.1$ & $>10,000$ & $>10,000$ & $<0.0125$ & $>10,000$ & $>10,000$ & $<0.2$ & $>10,000$ & $>10,000$ & $<1$ & $>10,000$ \\
\hline$( \pm)-\mathrm{DOM}$ & $>10,000$ & $<0.1$ & $>10,000$ & $>10,000$ & $<0.0125$ & $>10,000$ & $>10,000$ & $<0.2$ & $>10,000$ & $>10,000$ & $<1$ & $>10,000$ \\
\hline$( \pm)$-TMA & $>10,000$ & $<0.1$ & $>10,000$ & $>10,000$ & $<0.0125$ & $>10,000$ & $>10,000$ & $<0.2$ & $>10,000$ & $>10,000$ & $<1$ & $>10,000$ \\
\hline ( \pm )-MDA & $>10,000$ & $<0.1$ & $>10,000$ & $>10,000$ & $<0.0125$ & $>10,000$ & $>10,000$ & $<0.2$ & $>10,000$ & $>10,000$ & $<1$ & $>10,000$ \\
\hline (土)-MDEA & $>10,000$ & $<0.1$ & $>10,000$ & 10,000 & 0.0125 & $>10,000$ & $>10,000$ & $<0.2$ & $>10,000$ & $>10,000$ & $<1$ & $>10,000$ \\
\hline ( \pm )-MDMA & $>10,000$ & $<0.1$ & $>10,000$ & 2,500 & 0.05 & 5,000 & $>10,000$ & $<0.2$ & $>10,000$ & $>10,000$ & $<1$ & $>10,000$ \\
\hline$( \pm)$-Ethylamphetamine & $>10,000$ & $<0.1$ & $>10,000$ & $>10,000$ & $<0.0125$ & $>10,000$ & $>10,000$ & $<0.2$ & $>10,000$ & $>10,000$ & $<1$ & $>10,000$ \\
\hline 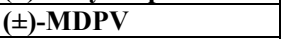 & 10 & 100 & 60 & $>10,000$ & $<0.0125$ & $>10,000$ & $>10,000$ & $<0.2$ & $>10,000$ & $>10,000$ & $<1$ & $>10,000$ \\
\hline ( \pm )-Mephedrone & $>10,000$ & $<0.1$ & $>10,000$ & 1.25 & 100 & 2.5 & $>10,000$ & $<0.2$ & $>10,000$ & $>10,000$ & $<1$ & $>10,000$ \\
\hline$( \pm)$-Cathinone & $>10,000$ & $<0.1$ & $>10,000$ & 1,000 & 0.125 & 3,500 & $>10,000$ & $<0.2$ & $>10,000$ & $>10,000$ & $<1$ & $>10,000$ \\
\hline ( \pm )-Methcathinone & $>10,000$ & $<0.1$ & $>10,000$ & $<156$ & $>0.8$ & $<156$ & $>10,000$ & $<0.2$ & $>10,000$ & $>10,000$ & $<1$ & $>10,000$ \\
\hline ( \pm )-Methylone & 5,000 & 0.2 & $>10,000$ & $<156$ & $>0.8$ & $<156$ & $>10,000$ & $<0.2$ & $>10,000$ & $>10,000$ & $<1$ & $>10,000$ \\
\hline ( \pm )-4-MEC & 7,500 & 0.13 & $>10,000$ & $<156$ & $>0.8$ & $<156$ & $>10,000$ & $<0.2$ & $>10,000$ & $>10,000$ & $<1$ & $>10,000$ \\
\hline ( \pm )-Flephedrone & $>10,000$ & $<0.1$ & $>10,000$ & $<156$ & $>0.8$ & $<156$ & $>10,000$ & $<0.2$ & $>10,000$ & $>10,000$ & $<1$ & $>10,000$ \\
\hline ( \pm -Butylone & 156 & 6.4 & 900 & $<156$ & $>0.8$ & $<156$ & $>10,000$ & $<0.2$ & $>10,000$ & $>10,000$ & $<1$ & $>10,000$ \\
\hline mCPP & $>10,000$ & $<0.1$ & $>10,000$ & $>10,000$ & $<0.0125$ & $>10,000$ & $>10,000$ & $<0.2$ & $>10,000$ & $>10,000$ & $<1$ & $>10,000$ \\
\hline ( \pm )-Methedrone & $>10,000$ & $<0.1$ & $>10,000$ & $<156$ & $>0.8$ & $<156$ & $>10,000$ & $<0.2$ & $>10,000$ & $>10,000$ & $<1$ & $>10,000$ \\
\hline 5-MeO-DiPT & $>10,000$ & $<0.1$ & $>10,000$ & 5,000 & 0.025 & $>10,000$ & $>10,000$ & $<0.2$ & $>10,000$ & $>10,000$ & $<1$ & $>10,000$ \\
\hline$( \pm)$-DOB & $>10,000$ & $<0.1$ & $>10,000$ & $>10,000$ & $<0.0125$ & $>10,000$ & $>10,000$ & $<0.2$ & $>10,000$ & $>10,000$ & $<1$ & $>10,000$ \\
\hline 2C-B & $>10,000$ & $<0.1$ & $>10,000$ & $>10,000$ & $<0.0125$ & $>10,000$ & $>10,000$ & $<0.2$ & $>10,000$ & $>10,000$ & $<1$ & $>10,000$ \\
\hline DMT & $>10,000$ & $<0.1$ & $>10,000$ & $>10,000$ & $<0.0125$ & $>10,000$ & $>10,000$ & $<0.2$ & $>10,000$ & $>10,000$ & $<1$ & $>10,000$ \\
\hline BZP & $>10,000$ & $<0.1$ & $>10,000$ & $>10,000$ & $<0.0125$ & $>10,000$ & $>10,000$ & $<0.2$ & $>10,000$ & $>10,000$ & $<1$ & $>10,000$ \\
\hline AMT & $>10,000$ & $<0.1$ & $>10,000$ & $>10,000$ & $<0.0125$ & $>10,000$ & $>10,000$ & $<0.2$ & $>10,000$ & $>10,000$ & $<1$ & $>10,000$ \\
\hline $2 \mathrm{C}-\mathrm{I}$ & $>10,000$ & $<0.1$ & $>10,000$ & $>10,000$ & $<0.0125$ & $>10,000$ & $>10,000$ & $<0.2$ & $>10,000$ & $>10,000$ & $<1$ & $>10,000$ \\
\hline 2C-T-7 & $>10,000$ & $<0.1$ & $>10,000$ & $>10,000$ & $<0.0125$ & $>10,000$ & $>10,000$ & $<0.2$ & $>10,000$ & $>10,000$ & $<1$ & $>10,000$ \\
\hline TFMPP & $>10,000$ & $<0.1$ & $>10,000$ & $>10,000$ & $<0.0125$ & $>10,000$ & $>10,000$ & $<0.2$ & $>10,000$ & $>10,000$ & $<1$ & $>10,000$ \\
\hline 2C-T-4 & $>10,000$ & $<0.1$ & $>10,000$ & $>10,000$ & $<0.0125$ & $>10,000$ & $>10,000$ & $<0.2$ & $>10,000$ & $>10,000$ & $<1$ & $>10,000$ \\
\hline
\end{tabular}

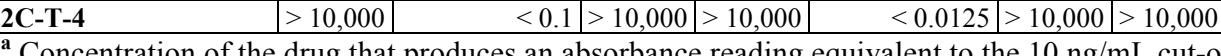

$<0.2>10,000>10,000$

${ }^{b}$ Concentration of the drug that produces an absorbance reading equivalent to the $1.25 \mathrm{ng} / \mathrm{mL}$ cut-off of the targeted analyte.

${ }^{\mathbf{c}}$ Concentration of the drug that produces an absorbance reading equivalent to the $20 \mathrm{ng} / \mathrm{mL}$ cut-off of the targeted analyte.

${ }^{\text {d }}$ Concentration of the drug that produces an absorbance reading equivalent to the $100 \mathrm{ng} / \mathrm{mL}$ cut-off of the targeted analyte.

Analytes demonstrating high cross-reactivity are highlighted and bolded.

The target analytes for each assay are italicized and bolded. 
Appendix 5: Dynamic MRM MS Parameters

\begin{tabular}{|c|c|c|c|c|c|c|}
\hline No. & Drug & Transitions $^{a}$ & CE (V) & Fragmentor (V) & $t_{R}(\min )$ & Internal Standard \\
\hline \multirow[t]{2}{*}{1} & DOB & $274.01 \rightarrow 256.9$ & 14 & 100 & 3.846 & d6-Amphetamine \\
\hline & & $274.01 \rightarrow 228.9$ & 10 & & & \\
\hline \multirow[t]{2}{*}{2} & DOET & $224.3 \rightarrow 207$ & 5 & 85 & 4.547 & d6-Amphetamine \\
\hline & & $224.3 \rightarrow 91$ & 49 & & & \\
\hline \multirow[t]{2}{*}{3} & DOM & $210.3 \rightarrow 193.1$ & 5 & 75 & 3.538 & d6-Amphetamine \\
\hline & & $210.3 \rightarrow 165$ & 13 & & & \\
\hline \multirow[t]{2}{*}{4} & TMA & $226.3 \rightarrow 209$ & 5 & 80 & 2.075 & d6-Amphetamine \\
\hline & & $226.3 \rightarrow 91$ & 45 & & & \\
\hline \multirow[t]{2}{*}{5} & $2 \mathrm{C}-\mathrm{B}$ & $260.01 \rightarrow 242.9$ & 4 & 90 & 3.403 & d5-MDMA \\
\hline & & $260.01 \rightarrow 227.9$ & 6 & & & \\
\hline \multirow[t]{2}{*}{6} & $2 \mathrm{C}-\mathrm{E}$ & $210.3 \rightarrow 193$ & 5 & 80 & 4.119 & d5-MDMA \\
\hline & & $210.3 \rightarrow 163$ & 25 & & & \\
\hline \multirow[t]{2}{*}{7} & $2 \mathrm{C}-\mathrm{I}$ & $308.1 \rightarrow 290.9$ & 9 & 90 & 3.906 & d5-MDMA \\
\hline & & $308.1 \rightarrow 91$ & 49 & & & \\
\hline \multirow[t]{2}{*}{8} & $2 \mathrm{C}-\mathrm{T}-4$ & $256.4 \rightarrow 239$ & 5 & 90 & 4.675 & d5-MDMA \\
\hline & & $256.4 \rightarrow 197$ & 17 & & & \\
\hline \multirow[t]{2}{*}{9} & $2 \mathrm{C}-\mathrm{T}-7$ & $256.4 \rightarrow 239$ & 9 & 85 & 4.959 & d5-MDMA \\
\hline & & $256.4 \rightarrow 166.9$ & 29 & & & \\
\hline \multirow[t]{2}{*}{10} & MDA & $180.1 \rightarrow 163$ & 4 & 70 & 1.658 & d6-Amphetamine \\
\hline & & $180.1 \rightarrow 105$ & 20 & & & \\
\hline \multirow[t]{2}{*}{11} & MDEA & $208.14 \rightarrow 163$ & 8 & 90 & 2.220 & d5-MDMA \\
\hline & & $208.14 \rightarrow 105$ & 24 & & & \\
\hline \multirow[t]{2}{*}{12} & MDMA & $194.1 \rightarrow 163$ & 8 & 85 & 1.849 & d5-MDMA \\
\hline & & $194.1 \rightarrow 105$ & 24 & & & \\
\hline \multirow[t]{2}{*}{13} & Amphetamine & $136.11 \rightarrow 91$ & 16 & 75 & 1.490 & d6-Amphetamine \\
\hline & & $136.11 \rightarrow 119$ & 4 & & & \\
\hline \multirow[t]{2}{*}{14} & Methamphetamine & $150.13 \rightarrow 91$ & 16 & 80 & 1.715 & d5-MDMA \\
\hline & & $150.13 \rightarrow 119$ & 4 & & & \\
\hline \multirow[t]{2}{*}{15} & Ethylamphetamine & $164.11 \rightarrow 91$ & 20 & 85 & 2.093 & d5-MDMA \\
\hline & & $164.11 \rightarrow 119$ & 8 & & & \\
\hline \multirow[t]{2}{*}{16} & MDPV & $276.3 \rightarrow 126$ & 25 & 130 & 3.383 & d3-Methylone \\
\hline & & $276.3 \rightarrow 135$ & 25 & & & \\
\hline \multirow[t]{2}{*}{17} & Mephedrone & $178.25 \rightarrow 160$ & 10 & 85 & 2.123 & d3-Mephedrone \\
\hline & & $178.25 \rightarrow 144$ & 30 & & & \\
\hline \multirow[t]{2}{*}{18} & Cathinone & $150.2 \rightarrow 132$ & 10 & 80 & 1.031 & d3-Mephedrone \\
\hline & & $150.2 \rightarrow 117$ & 22 & & & \\
\hline \multirow[t]{2}{*}{19} & Methcathinone & $164.23 \rightarrow 146$ & 10 & 85 & 1.196 & d3-Mephedrone \\
\hline & & $164.23 \rightarrow 130$ & 34 & & & \\
\hline \multirow[t]{2}{*}{20} & Methedrone & $194.25 \rightarrow 176$ & 10 & 80 & 1.745 & d3-Mephedrone \\
\hline & & $194.25 \rightarrow 161$ & 18 & & & \\
\hline
\end{tabular}




\begin{tabular}{|c|c|c|c|c|c|c|}
\hline No. & Drug & Transitions $^{a}$ & CE (V) & Fragmentor (V) & $t_{R}(\min )$ & Internal Standard \\
\hline \multirow[t]{2}{*}{21} & 4-MEC & $192.28 \rightarrow 174.1$ & 10 & 95 & 2.482 & d3-Mephedrone \\
\hline & & $192.28 \rightarrow 145$ & 18 & & & \\
\hline \multirow[t]{2}{*}{22} & Flephedrone & $182.21 \rightarrow 164$ & 10 & 85 & 1.422 & d3-Mephedrone \\
\hline & & $182.21 \rightarrow 148$ & 34 & & & \\
\hline \multirow[t]{2}{*}{23} & Methylone & $208.24 \rightarrow 160$ & 14 & 80 & 1.397 & d3-Methylone \\
\hline & & $208.24 \rightarrow 132$ & 26 & & & \\
\hline \multirow[t]{2}{*}{24} & Butylone & $222.26 \rightarrow 174$ & 14 & 95 & 2.035 & d3-Methylone \\
\hline & & $222.26 \rightarrow 204$ & 10 & & & \\
\hline \multirow[t]{2}{*}{25} & BZP & $177.11 \rightarrow 91$ & 20 & 100 & 0.589 & d7-BZP \\
\hline & & $177.11 \rightarrow 65$ & 50 & & & \\
\hline \multirow[t]{2}{*}{26} & DBZP & $267.21 \rightarrow 91$ & 32 & 125 & 3.520 & d7-BZP \\
\hline & & $267.21 \rightarrow 175$ & 12 & & & \\
\hline \multirow[t]{2}{*}{27} & $\mathrm{mCPP}$ & $197.11 \rightarrow 153.9$ & 20 & 120 & 2.878 & d4-TFMPP \\
\hline & & $197.11 \rightarrow 118$ & 36 & & & \\
\hline \multirow[t]{2}{*}{28} & TFMPP & $231.11 \rightarrow 188$ & 20 & 125 & 3.826 & d4-TFMPP \\
\hline & & $231.11 \rightarrow 118$ & 44 & & & \\
\hline \multirow[t]{2}{*}{29} & AMT & $175.2 \rightarrow 158$ & 9 & 75 & 2.037 & d6-Amphetamine \\
\hline & & $175.2 \rightarrow 143$ & 25 & & & \\
\hline \multirow[t]{2}{*}{30} & DMT & $189.11 \rightarrow 58.1$ & 8 & 85 & 1.775 & d5-MDMA \\
\hline & & $189.11 \rightarrow 144$ & 16 & & & \\
\hline \multirow[t]{2}{*}{31} & 5-MeO-DMT & $219.3 \rightarrow 58.1$ & 9 & 85 & 1.955 & d5-MDMA \\
\hline & & $219.3 \rightarrow 174$ & 9 & & & \\
\hline \multirow[t]{2}{*}{32} & 5-MeO-DiPT & $275.4 \rightarrow 174$ & 17 & 100 & 3.627 & d5-MDMA \\
\hline & & $275.4 \rightarrow 114.1$ & 13 & & & \\
\hline \multirow[t]{2}{*}{33} & d6-Amphetamine (IS) & $142.25 \rightarrow 93$ & 13 & 75 & 1.470 & - \\
\hline & & $142.25 \rightarrow 125.1$ & 5 & & & \\
\hline \multirow[t]{2}{*}{34} & d5-MDMA (IS) & $199.29 \rightarrow 165$ & 9 & 90 & 1.839 & - \\
\hline & & $199.29 \rightarrow 107$ & 25 & & & \\
\hline \multirow[t]{2}{*}{35} & d3-Mephedrone (IS) & $181.27 \rightarrow 163$ & 9 & 90 & 2.115 & - \\
\hline & & $181.27 \rightarrow 148$ & 21 & & & \\
\hline \multirow[t]{2}{*}{36} & d3-Methylone (IS) & $211.21 \rightarrow 163$ & 13 & 85 & 1.390 & - \\
\hline & & $211.21 \rightarrow 135$ & 29 & & & \\
\hline \multirow[t]{2}{*}{37} & d7-BZP (IS) & $184.11 \rightarrow 98.1$ & 21 & 105 & 0.562 & - \\
\hline & & $184.11 \rightarrow 70.1$ & 57 & & & \\
\hline \multirow[t]{2}{*}{38} & d4-TFMPP (IS) & $235.11 \rightarrow 190$ & 21 & 125 & 3.815 & - \\
\hline & & $235.11 \rightarrow 46.1$ & 21 & & & \\
\hline
\end{tabular}

${ }^{a}$ Quantifying transition in bold, qualifying transition in normal text. 
Appendix 6: Matrix Effects, Recovery, and Process Efficiency

\begin{tabular}{|c|c|c|c|c|c|c|c|c|c|c|c|c|}
\hline \multirow[b]{3}{*}{ Compound } & \multicolumn{4}{|c|}{ Matrix Effects } & \multicolumn{4}{|c|}{ Recovery } & \multicolumn{4}{|c|}{ Process Efficiency } \\
\hline & \multicolumn{2}{|c|}{ LOW } & \multicolumn{2}{|c|}{ HIGH } & \multicolumn{2}{|c|}{ LOW } & \multicolumn{2}{|c|}{ HIGH } & \multicolumn{2}{|c|}{ LOW } & \multicolumn{2}{|c|}{ HIGH } \\
\hline & $\operatorname{mean}^{a}$ & \%RSD & mean & $\%$ RSD $^{b}$ & mean & $\%$ RSD & mean & $\%$ RSD & mean & $\%$ RSD & mean & $\%$ RSD \\
\hline $\mathrm{BZP}$ & 110.5 & 8.2 & 105 & 7.6 & 85.1 & 7.6 & 86.8 & 6 & 94 & 7.3 & 91.1 & 5.9 \\
\hline Cathinone & 75.1 & 11.3 & 99.6 & 9.6 & 97.5 & 12.7 & 84.2 & 7.4 & 73.2 & 12.4 & 83.9 & 7.2 \\
\hline Methcathinone & 99.3 & 12.4 & 93 & 7.4 & 74.5 & 13.3 & 83.3 & 6.5 & 73.9 & 12.9 & 77.5 & 6.4 \\
\hline Methylone & 82.4 & 10.8 & 86.1 & 7.2 & 84.9 & 11 & 88.4 & 6 & 70 & 10.7 & 76.1 & 5.9 \\
\hline Flephedrone & 77.5 & 10.2 & 74.8 & 4.2 & 82.6 & 10.1 & 82.8 & 4.1 & 64 & 9.8 & 61.9 & 4.1 \\
\hline Amphetamine & 92.4 & 10.5 & 85 & 7.8 & 83.9 & 10.2 & 90.2 & 6 & 77.5 & 9.8 & 76.7 & 5.9 \\
\hline MDA & 87.7 & 7.4 & 85.8 & 6.6 & 95.8 & 8.8 & 90.3 & 7.2 & 84 & 8.6 & 77.5 & 7.2 \\
\hline Methedrone & 94.1 & 11.9 & 94.8 & 5.5 & 80.8 & 11.4 & 82.8 & 4.8 & 76.1 & 11 & 78.5 & 4.7 \\
\hline Methamphetamine & 97.6 & 12.1 & 82.4 & 4.7 & 88.8 & 10.7 & 87.6 & 6.9 & 86.7 & 10.2 & 72.1 & 6.9 \\
\hline DMT & 64.2 & 8.7 & 90.3 & 11.7 & 125.3 & 14.1 & 99.4 & 9.5 & 80.4 & 13.9 & 89.7 & 9.3 \\
\hline MDMA & 92.2 & 11.6 & 88.5 & 6.6 & 85.3 & 10.6 & 82.6 & 7.7 & 78.6 & 10.3 & 73.1 & 7.6 \\
\hline 5-MeO-DMT & 52.9 & 12.9 & 60.6 & 12.7 & 127.4 & 16.2 & 106.1 & 11.5 & 67.3 & 15.9 & 64.3 & 11.3 \\
\hline Butylone & 98.9 & 12.4 & 90.5 & 5.5 & 80.8 & 12.1 & 80.9 & 4.5 & 79.8 & 11.8 & 73.2 & 4.4 \\
\hline AMT & 67.5 & 9.5 & 68.6 & 13.5 & 128.5 & 8.5 & 104.5 & 10.2 & 86.8 & 8.2 & 71.7 & 10 \\
\hline TMA & 85 & 9.1 & 84.9 & 6.9 & 81 & 9 & 89.5 & 7 & 68.8 & 8.7 & 76 & 7 \\
\hline Ethylamphetamine & 102.2 & 12.3 & 90.3 & 5 & 88.7 & 11.4 & 83.4 & 8.6 & 90.6 & 11 & 75.3 & 8.6 \\
\hline Mephedrone & 78.6 & 10.6 & 78 & 6.5 & 81.6 & 9.7 & 84.5 & 5.6 & 64.1 & 9.3 & 65.9 & 5.5 \\
\hline MDEA & 118.8 & 13.8 & 88.4 & 7.7 & 84.8 & 13.4 & 80.7 & 5.7 & 100.7 & 13 & 71.4 & 5.5 \\
\hline 4-MEC & 112.7 & 13.5 & 88.1 & 7.7 & 82.7 & 13.1 & 83.5 & 6.6 & 93.2 & 12.7 & 73.5 & 6.5 \\
\hline $\mathrm{mCPP}$ & 84.7 & 11.1 & 90.1 & 8.1 & 96.5 & 11.8 & 85.4 & 6.5 & 81.7 & 11.5 & 76.9 & 6.4 \\
\hline
\end{tabular}




\begin{tabular}{|c|r|r|r|r|r|r|r|r|r|r|r|r|}
\cline { 2 - 14 } \multicolumn{1}{c|}{} & \multicolumn{4}{|c|}{ Matrix Effects } & \multicolumn{4}{c|}{ Recovery } & \multicolumn{4}{c|}{ Process Efficiency } \\
\cline { 2 - 14 } \multicolumn{1}{c|}{ LOW } & \multicolumn{2}{|c|}{ HIGH } & \multicolumn{2}{|c|}{ LOW } & \multicolumn{2}{|c|}{ HIGH } & \multicolumn{3}{c|}{ LOW } & \multicolumn{2}{c|}{ HIGH } \\
\hline Compound & mean $^{\boldsymbol{a}}$ & \%RSD & mean & \%RSD $^{\mathbf{b}}$ & mean & \%RSD & mean & \%RSD & mean & \%RSD & mean & \%RSD \\
\hline MDPV & 109.9 & 14.5 & 106.7 & 8.5 & 80.1 & 15 & 81.4 & 6.9 & 88 & 14.6 & 86.9 & 6.8 \\
\hline 2C-B & 89.2 & 9.8 & 95 & 6 & 84.2 & 10.4 & 81.7 & 5.1 & 75.1 & 10.1 & 77.6 & 5 \\
\hline DBZP & 118.2 & 15.6 & 120.6 & 10.5 & 84.6 & 14.9 & 87.4 & 8.1 & 99.9 & 14.4 & 105.3 & 7.9 \\
\hline DOM & 92.5 & 11.6 & 72.4 & 12.8 & 88.3 & 11.3 & 84.7 & 10.5 & 81.8 & 10.9 & 61.3 & 10.4 \\
\hline 5-MeO-DiPT & 70.7 & 13.9 & 70.9 & 14.5 & 103.6 & 16.9 & 100.2 & 11.6 & 73.2 & 16.6 & 71 & 11.4 \\
\hline DOB & 70.4 & 10 & 85.6 & 7.7 & 96.7 & 10.2 & 90.1 & 5.9 & 68.1 & 9.9 & 77.1 & 5.8 \\
\hline TFMPP & 86.8 & 10.2 & 76.5 & 6.1 & 91.4 & 8.6 & 85.7 & 5.7 & 79.3 & 8.2 & 65.6 & 5.7 \\
\hline 2C-I & 88.4 & 9.8 & 88 & 8 & 88.4 & 10.8 & 79.7 & 6.1 & 78.2 & 10.5 & 70.2 & 6 \\
\hline 2C-E & 87.4 & 11.6 & 95.7 & 8.3 & 87.4 & 11.1 & 76 & 6.2 & 76.4 & 10.7 & 72.8 & 6.1 \\
\hline DOET & 93.6 & 11.7 & 79 & 7.4 & 80.3 & 11.3 & 80.5 & 5.7 & 75.2 & 10.9 & 63.6 & 5.6 \\
\hline 2C-T-4 & 92.2 & 11.3 & 111.1 & 9.5 & 71.8 & 12.7 & 69.5 & 9.9 & 66.2 & 12.4 & 77.2 & 9.8 \\
\hline 2C-T-7 & 106.7 & 12.1 & 123.8 & 10.2 & 68.6 & 13.5 & 67.3 & 8.2 & 73.2 & 13.2 & 83.3 & 8.1 \\
\hline
\end{tabular}

${ }^{a}$ Data in \%, see Equation 1 for details.

${ }^{b}$ Data in \%, see Equation 2 for details. 
Appendix 7: Processed Sample Stability at Two Concentrations

\begin{tabular}{|c|c|c|c|c|c|c|c|c|c|c|}
\hline \multirow[b]{2}{*}{ Drug } & \multicolumn{2}{|c|}{ LOW } & \multicolumn{3}{|c|}{ Based on Regression Line } & \multicolumn{2}{|c|}{ HIGH } & \multicolumn{3}{|c|}{ Based on Regression Line } \\
\hline & Slope & Intercept & $\begin{array}{c}\text { Initial } \\
(\mathbf{0} \text { h) }\end{array}$ & $\begin{array}{l}\text { Final } \\
(28 \text { h })\end{array}$ & $\Delta(\%)$ & Slope & Intercept & $\begin{array}{c}\text { Initial } \\
(2 \mathrm{~h})\end{array}$ & $\begin{array}{l}\text { Final } \\
(30 \text { h) }\end{array}$ & $\Delta(\%)$ \\
\hline BZP & -109 & 40404 & 40404 & 37357 & -7.5 & 963 & 611205 & 613130 & 640084 & 4.4 \\
\hline Cathinone & -68 & 19648 & 19648 & 17745 & -9.7 & -216 & 432246 & 431814 & 425765 & -1.4 \\
\hline Methcathinone & -85 & 32986 & 32986 & 30594 & -7.3 & -1605 & 1100493 & 1097282 & 1052334 & -4.1 \\
\hline Methylone & -160 & 52341 & 52341 & 47857 & -8.6 & -2126 & 1520949 & 1516697 & 1457172 & -3.9 \\
\hline Flephedrone & -97 & 35323 & 35323 & 32603 & -7.7 & -677 & 703464 & 702111 & 683162 & -2.7 \\
\hline Amphetamine & -88 & 17547 & 17547 & 15076 & -14.1 & 2926 & 396416 & 402268 & 484202 & 20.4 \\
\hline MDA & -176 & 41489 & 41489 & 36574 & -11.8 & -1090 & 633973 & 631793 & 601267 & -4.8 \\
\hline Methedrone & -116 & 40789 & 40789 & 37544 & -8 & -4361 & 900848 & 892125 & 770006 & -13.7 \\
\hline Methamphetamine & -95 & 26058 & 26058 & 23405 & -10.2 & -1979 & 510413 & 506456 & 451055 & -10.9 \\
\hline DMT & 177 & 7223 & 7223 & 12188 & 68.7 & 4125 & 579902 & 588152 & 703649 & 19.6 \\
\hline MDMA & -152 & 45195 & 45195 & 40935 & -9.4 & -7218 & 1323056 & 1308620 & 1106522 & -15.4 \\
\hline 5-MeO-DMT & 213 & 7119 & 7119 & 13091 & 83.9 & 7709 & 970115 & 985533 & 1201385 & 21.9 \\
\hline Butylone & -157 & 49644 & 49644 & 45254 & -8.8 & -4301 & 1230952 & 1222351 & 1101931 & -9.9 \\
\hline $\mathrm{AMT}$ & 301 & 6056 & 6056 & 14491 & 139.3 & 2102 & 42776 & 46979 & 105821 & 125.3 \\
\hline TMA & 294 & 23588 & 23588 & 31814 & 34.9 & -626 & 591243 & 589990 & 572450 & -3 \\
\hline Ethylamphetamine & -121 & 35386 & 35386 & 32012 & -9.5 & -2922 & 924730 & 918886 & 837070 & -8.9 \\
\hline Mephedrone & -111 & 42074 & 42074 & 38969 & -7.4 & -1015 & 1006374 & 1004344 & 975927 & -2.8 \\
\hline MDEA & -159 & 63807 & 63807 & 59349 & -7 & -4413 & 2638023 & 2629198 & 2505648 & -4.7 \\
\hline 4-MEC & -77 & 35130 & 35130 & 32968 & -6.2 & -2118 & 1550957 & 1546722 & 1487432 & -3.8 \\
\hline $\mathrm{mCPP}$ & -7 & 9123 & 9123 & 8925 & -2.2 & -26 & 322319 & 322268 & 321548 & -0.2 \\
\hline MDPV & -101 & 29138 & 29138 & 26307 & -9.7 & -3761 & 1674238 & 1666716 & 1561408 & -6.3 \\
\hline $2 \mathrm{C}-\mathrm{B}$ & 52 & 18695 & 18695 & 20154 & 7.8 & -594 & 397233 & 396045 & 379407 & -4.2 \\
\hline DBZP & -34 & 9617 & 9617 & 8654 & -10 & -2004 & 1019820 & 1015812 & 959697 & -5.5 \\
\hline
\end{tabular}




\begin{tabular}{|l|r|r|r|r|r|r|r|r|r|r|}
\hline & \multicolumn{2}{|c|}{ LOW } & \multicolumn{2}{c|}{ Based on Regression Line } & \multicolumn{2}{c|}{ HIGH } & \multicolumn{2}{c|}{ Based on Regression Line } \\
\hline \multirow{2}{*}{ Drug } & Slope & Intercept & $\begin{array}{c}\text { Initial } \\
\mathbf{( 0 ~ h )}\end{array}$ & $\begin{array}{c}\text { Final } \\
\mathbf{( 2 8} \mathbf{~ h})\end{array}$ & $\Delta \mathbf{( \% )}$ & Slope & Intercept & $\begin{array}{c}\text { Initial } \\
\mathbf{( 2 ~ h )}\end{array}$ & $\begin{array}{c}\text { Final } \\
(\mathbf{3 0} \mathbf{~})\end{array}$ & $\Delta \mathbf{( \% )}$ \\
\hline DOM & -317 & 125746 & 125746 & 116857 & -7.1 & -5532 & 3058967 & 3047903 & 2893013 & -5.1 \\
\hline 5-MeO-DiPT & 319 & 12644 & 12644 & 21575 & 70.6 & 19176 & 2280395 & 2318747 & 2855675 & 23.2 \\
\hline DOB & -48 & 32652 & 32652 & 31311 & -4.1 & -1342 & 965105 & 962421 & 924851 & -3.9 \\
\hline TFMPP & 5 & 21625 & 21625 & 21756 & 0.6 & -374 & 420297 & 419548 & 409064 & -2.5 \\
\hline 2C-I & 12 & 39936 & 39936 & 40270 & 0.8 & -898 & 1369695 & 1367898 & 1342740 & -1.8 \\
\hline 2C-E & -301 & 95824 & 95824 & 87387 & -8.8 & -3681 & 3256687 & 3249326 & 3146272 & -3.2 \\
\hline DOET & -366 & 168366 & 168366 & 158121 & -6.1 & -7521 & 4739575 & 4724532 & 4513933 & -4.5 \\
\hline 2C-T-4 & 30 & 48780 & 48780 & 49632 & 1.7 & -2993 & 2486121 & 2480135 & 2396325 & -3.4 \\
\hline 2C-T-7 & -18 & 40176 & 40176 & 39671 & -1.3 & 3206 & 2418269 & 2424682 & 2514458 & 3.7 \\
\hline
\end{tabular}


Appendix 8: Summary of Precision and Accuracy Data for at Four Concentrations

\begin{tabular}{|c|c|c|c|c|c|c|c|c|c|c|c|c|}
\hline \multirow[b]{2}{*}{ Analyte } & \multicolumn{4}{|c|}{ Repeatability (\%RSD) } & \multicolumn{4}{|c|}{ Intermediate Precision (\%RSD) } & \multicolumn{4}{|c|}{ Accuracy, Bias (\%) } \\
\hline & $\begin{array}{c}\text { LLO } \\
\mathbf{Q} \\
\end{array}$ & $\begin{array}{l}\text { LO } \\
\text { W } \\
\end{array}$ & $\begin{array}{c}\text { ME } \\
\text { D }\end{array}$ & $\begin{array}{c}\text { HIG } \\
\text { H }\end{array}$ & $\begin{array}{c}\text { LLO } \\
\text { Q }\end{array}$ & $\begin{array}{l}\text { LO } \\
\text { W }\end{array}$ & $\begin{array}{c}\text { ME } \\
\text { D }\end{array}$ & $\begin{array}{c}\text { HIG } \\
\text { H }\end{array}$ & $\begin{array}{c}\text { LLO } \\
\text { Q }\end{array}$ & $\begin{array}{l}\text { LO } \\
\text { W }\end{array}$ & $\begin{array}{c}\text { ME } \\
\text { D } \\
\end{array}$ & $\begin{array}{c}\text { HIG } \\
\text { H }\end{array}$ \\
\hline BZP & 3.4 & 4.2 & 4.3 & 6.6 & 4 & 5.4 & 5 & 6.6 & -7.7 & -1 & 2 & 0.2 \\
\hline Cathinone & 13.3 & 9.3 & 11.9 & 10.8 & 15.3 & 9.9 & 11.9 & 12.3 & -9.9 & -9.9 & -2.9 & 0.6 \\
\hline Methcathinone & 7 & 5.5 & 11 & 12.5 & 8.6 & 6.8 & 11 & 13.9 & -5.7 & -10 & -4.9 & 0.6 \\
\hline Methylone & 6.5 & 6 & 5.4 & 6.1 & 6.9 & 6.8 & 5.9 & 6.1 & -10.2 & -2.2 & 0.2 & -4.6 \\
\hline Flephedrone & 6.8 & 7.3 & 2.9 & 8.2 & 7.4 & 8 & 3.1 & 8.2 & -13.2 & -8 & -4.4 & -6.7 \\
\hline Amphetamine & 4.9 & 4.8 & 3.8 & 11.8 & 6.1 & 5.7 & 3.9 & 11.9 & -6.5 & -0.6 & 4.3 & 2.6 \\
\hline MDA & 5.2 & 5.4 & 12.7 & 11.9 & 6.5 & 6.3 & 12.8 & 11.7 & -6.7 & 2.3 & 0.8 & -6.2 \\
\hline Methedrone & 4.1 & 3.4 & 4.8 & 12.5 & 6.5 & 4.8 & 5.1 & 12.2 & -2.1 & -4.2 & -0.7 & -2.7 \\
\hline $\begin{array}{c}\text { Methamphetamin } \\
\text { e }\end{array}$ & 5.4 & 5.5 & 7.7 & 11.4 & 7.9 & 6.4 & 7.7 & 11.5 & -4.8 & -1.5 & 2 & -6.6 \\
\hline DMT & 3.4 & 4.4 & 4.2 & 4 & 4.9 & 5.4 & 4.5 & 4.1 & -3.5 & -1.7 & 5.1 & 27.5 \\
\hline MDMA & 5.4 & 5.8 & 4 & 9.7 & 5.9 & 6.3 & 4.4 & 9.7 & -6 & -0.4 & 3 & 1.9 \\
\hline 5-MeO-DMT & 3.6 & 4.2 & 3.8 & 3.2 & 5.1 & 5.2 & 4 & 3.3 & -7.3 & 2.6 & 18.5 & 60 \\
\hline Butylone & 4.2 & 4.3 & 5.2 & 13.6 & 6.2 & 5.3 & 5.4 & 13.6 & -6.6 & 0.3 & -0.2 & -5.3 \\
\hline AMT & 3 & 4.4 & 3.8 & 6.7 & 4.2 & 5.4 & 4.1 & 6.9 & 12.1 & -1.5 & 16.7 & -23.6 \\
\hline TMA & 3.2 & 4.2 & 5.1 & 6 & 4.5 & 5.1 & 5.5 & 6.2 & 4.9 & 4.2 & -12.9 & -14.9 \\
\hline $\begin{array}{c}\text { Ethylamphetamin } \\
\text { e }\end{array}$ & 9.2 & 7 & 6.8 & 6.1 & 10.6 & 7.8 & 7.1 & 6.2 & -0.2 & 0.1 & 0.7 & 5 \\
\hline Mephedrone & 4.7 & 5.6 & 3.2 & 8.5 & 5.3 & 6.3 & 3.6 & 8.5 & -9.5 & -5 & -2 & -3.7 \\
\hline MDEA & 9.3 & 7.1 & 13.1 & 5.4 & 11.9 & 7.9 & 13.1 & 6.4 & 0.6 & -3.9 & -1.8 & 0.6 \\
\hline 4-MEC & 4.3 & 6.6 & 13.8 & 11.3 & 6.5 & 7.5 & 13.8 & 12 & 3.1 & -6.9 & -2.9 & 2.8 \\
\hline $\mathrm{mCPP}$ & 3.6 & 8.8 & 13.6 & 12.1 & 6.7 & 10.6 & 13.6 & 12.1 & 9.6 & 0.9 & 0.2 & 8.8 \\
\hline MDPV & 8.7 & 8.7 & 12.4 & 7.8 & 10.4 & 9.1 & 12.4 & 8.8 & 8.3 & -5.1 & -4.8 & 5.8 \\
\hline $2 \mathrm{C}-\mathrm{B}$ & 14.6 & 5.7 & 7.2 & 7.6 & 15.5 & 6.7 & 7.3 & 7.7 & -9.9 & -3.5 & -5.3 & -2.1 \\
\hline DBZP & 2.8 & 3.7 & 4.4 & 4.9 & 3.9 & 4.6 & 4.7 & 5 & 20.3 & 16.6 & 1.2 & 4.8 \\
\hline DOM & 11.3 & 6.3 & 12.5 & 13.7 & 13.8 & 7.1 & 13 & 13.7 & -3.7 & -0.2 & -3.1 & -10.8 \\
\hline 5-MeO-DiPT & 3.5 & 4.2 & 4.4 & 4.9 & 5 & 5.2 & 4.7 & 5 & -6.1 & 3.2 & 0.6 & 4.6 \\
\hline DOB & 13.6 & 7.7 & 12.8 & 11.1 & 14.7 & 8.1 & 13 & 11.1 & -10.7 & 1.2 & -1.8 & -11.9 \\
\hline TFMPP & 2.1 & 3.8 & 4.4 & 7.2 & 4.4 & 4.6 & 4.6 & 7.4 & -8.5 & -2.9 & 0.8 & -0.5 \\
\hline $2 \mathrm{C}-\mathrm{I}$ & 19.1 & 9.9 & 12.3 & 11.9 & 19.5 & 10.4 & 12.6 & 11.9 & -13.3 & 2.8 & -3 & -9.5 \\
\hline $2 \mathrm{C}-\mathrm{E}$ & 12.5 & 7 & 5.7 & 15 & 12.7 & 7.3 & 6 & 14.9 & -6.3 & -3.6 & -2.1 & -0.4 \\
\hline DOET & 3.6 & 4 & 5.6 & 6.7 & 5.1 & 4.9 & 6 & 6.8 & -7.4 & 9.1 & -21.2 & -22.8 \\
\hline $2 \mathrm{C}-\mathrm{T}-4$ & 17.1 & 10.9 & 11.8 & 14.2 & 17.3 & 11.4 & 13.6 & 14.2 & 1.9 & -2.9 & -12.9 & -4.1 \\
\hline $2 \mathrm{C}-\mathrm{T}-7$ & 18 & 10.1 & 11.2 & 9.2 & 18.4 & 10.5 & 12.5 & 9.5 & 1.2 & -5 & -11.1 & -3.2 \\
\hline
\end{tabular}


Appendix 9: Blind Spiked Sample Analysis by ELISA

\begin{tabular}{|c|c|c|c|c|c|c|c|c|c|c|c|c|c|c|c|c|}
\hline \multirow[b]{2}{*}{ Sample } & \multicolumn{2}{|c|}{ Immunalysis } & \multicolumn{8}{|c|}{ Neogen } & \multicolumn{2}{|c|}{ Randox } & \multicolumn{4}{|c|}{ OraSure } \\
\hline & Amp & Meth & Amp & $\begin{array}{c}\text { AMP } \\
\text { Specific }\end{array}$ & $\begin{array}{l}\text { Amp } \\
\text { Ultra }\end{array}$ & BZP & Ketamine & MPD & $\begin{array}{c}\text { Meth/ } \\
\text { MDMA }\end{array}$ & MPT & MDPV & $\begin{array}{l}\text { Meph/ } \\
\text { Mcath }\end{array}$ & PCP & Cotinine & $\begin{array}{c}\text { Amp } \\
\text { Specific }\end{array}$ & Meth \\
\hline Sample 01 & - & - & - & - & - & - & - & - & - & - & - & + & - & + & - & - \\
\hline Sample 02 & - & - & - & - & - & - & - & - & - & - & - & + & - & + & - & - \\
\hline Sample 03 & - & + & + & - & + & - & - & - & \pm & - & \pm & \pm & - & + & - & + \\
\hline Sample 04 & - & + & + & - & + & - & - & - & \pm & - & \pm & - & - & + & - & + \\
\hline Sample 05 & - & - & - & - & - & - & - & - & - & - & - & - & - & + & - & - \\
\hline Sample 06 & - & + & + & - & + & - & - & - & + & - & - & + & - & + & - & + \\
\hline Sample 07 & - & + & + & - & + & - & - & - & + & - & - & + & - & + & - & + \\
\hline Sample 08 & - & + & + & - & + & - & - & - & + & \pm & \pm & - & - & + & - & + \\
\hline Sample 09 & - & + & + & - & + & \pm & - & - & + & \pm & - & - & - & + & - & + \\
\hline Sample 10 & - & - & - & - & - & - & - & - & - & - & - & + & - & + & - & + \\
\hline Sample 11 & + & - & + & + & + & - & - & - & - & - & - & - & - & + & + & - \\
\hline Sample 12 & - & - & - & - & - & - & - & - & - & - & - & + & - & + & - & \pm \\
\hline Sample 13 & - & - & - & - & - & - & - & - & - & - & - & - & - & + & - & - \\
\hline Sample 14 & - & - & - & - & - & - & - & - & - & - & + & + & - & + & - & + \\
\hline Sample 15 & + & + & + & + & + & - & - & - & \pm & - & \pm & + & - & + & + & + \\
\hline Sample 16 & - & - & - & - & - & - & - & - & - & - & - & - & - & + & - & - \\
\hline Sample 17 & - & - & - & - & - & - & - & - & - & - & - & - & - & + & - & - \\
\hline Sample 18 & - & - & - & - & - & - & - & - & - & - & - & - & - & + & - & - \\
\hline Sample 19 & - & - & - & - & - & - & - & - & - & - & - & - & - & + & - & - \\
\hline Sample 20 & - & - & - & - & - & - & - & - & - & - & - & - & - & + & - & - \\
\hline Sample 21 & - & - & - & - & - & - & - & - & - & - & - & + & - & + & - & - \\
\hline Sample 22 & - & - & - & - & - & - & - & - & - & - & - & + & - & + & - & - \\
\hline
\end{tabular}


Appendix 10: PBSO Sample Analysis by ELISA

\begin{tabular}{|c|c|c|c|c|c|c|c|c|c|c|c|c|c|c|c|c|}
\hline \multirow[b]{2}{*}{ Sample } & \multicolumn{2}{|c|}{ Immunalysis } & \multicolumn{8}{|c|}{ Neogen } & \multicolumn{2}{|c|}{ Randox } & \multicolumn{4}{|c|}{ OraSure } \\
\hline & Amp & Meth & Amp & $\begin{array}{c}\text { AMP } \\
\text { Specific }\end{array}$ & $\begin{array}{l}\text { Amp } \\
\text { Ultra }\end{array}$ & BZP & Ketamine & MPD & $\begin{array}{c}\text { Meth/ } \\
\text { MDMA }\end{array}$ & MPT & MDPV & $\begin{array}{l}\text { Meph/ } \\
\text { Mcath }\end{array}$ & PCP & Cotinine & $\begin{array}{c}\text { Amp } \\
\text { Specific }\end{array}$ & Meth \\
\hline 07-001 & - & - & - & - & - & - & - & - & - & - & - & - & - & - & - & - \\
\hline 11-001 & - & - & - & - & - & - & - & - & - & - & - & - & - & - & - & - \\
\hline 11-002 & - & - & - & - & - & - & - & - & - & - & - & - & - & + & - & - \\
\hline 12-001 & - & - & - & - & - & - & - & - & - & - & - & - & - & + & - & - \\
\hline $12-002$ & - & - & - & - & - & - & - & - & - & - & - & - & - & + & - & - \\
\hline
\end{tabular}


VITA

MADELEINE JEAN SWORTWOOD

1987

Born, Columbus, Ohio

2007 - $2008 \quad$ Undergraduate Researcher

Johnson Group, Analytical Lab

Duquesne University

Pittsburgh, PA

2008-2009 Intern

Food and Drug Administration

Forensic Chemistry Center

Cincinnati, $\mathrm{OH}$

2009

B.A., Biochemistry

Duquesne University

Pittsburgh, PA

2009-2011 Teaching Assistant

Survey of Forensic Science Lab

Florida International University

Miami, FL

2012 - Present Toxicologist I

Miami-Dade Medical Examiner

Toxicology Lab

Miami, FL

PROFESSIONAL MEMBERSHIPS

2010 - PresentAmerican Chemical Society, Student Member

2011 - PresentSociety of Forensic Toxicologists, Student Member

2011 - PresentAmerican Academy of Forensic Sciences, Student Member 


\section{PUBLICATIONS AND PRESENTATIONS}

Swortwood, M. J. and DeCaprio, A. P. (September 2011). Determination of Cathinone Derivatives and Other Designer Drugs in Serum by Comprehensive LC-Triple Quadrupole-MS/MS Analysis. Poster presented at the joint meeting of Society of Forensic Toxicologists and The International Association of Forensic Toxicologists, San Francisco, California.

Swortwood, M. J. and DeCaprio, A. P. (April 2012). Targeted LC-QQQ-MS Screening of Cathinone Derivatives and Other Designer Drugs in Serum. Webinar presented for Forensics eSeminar Series, Agilent Technologies.

Swortwood, M. J., Boland, D. M., and DeCaprio, A. P. (July 2012). Determination of Designer Drugs in Post-Mortem Blood by LC-QQQ-MS/MS Analysis. Oral presentation at the meeting of the Society of Forensic Toxicologists, Boston, Massachusetts.

Swortwood, M. J., Boland, D. M., and DeCaprio, A. P. (September 2012). Determination of Designer Drugs in Post-Mortem Blood by LC-MS/MS Analysis. Oral presentation at the meeting of the Australia-New Zealand Forensic Science Society, Hobart, Tasmania.

Swortwood, M. J. and DeCaprio, A. P. (September 2012). Designer Drug Analysis in The United States. Oral presentation at the meeting of the Forensic and Clinical Toxicology Association, Hobart, Tasmania.

Swortwood, M. J., Hearn, W. L., and DeCaprio, A. P. (February 2013). Cross-Reactivity of Cathinone Derivatives and Other Designer Drugs in Commercial Enzyme-Linked Immunosorbent Assays. Oral presentation at the meeting of the American Academy of Forensic Sciences, Washington. DC.

Swortwood, M. J., Boland, D. M., and DeCaprio, A. P. (February 2013). Determination of 32 Cathinone Derivatives and Other Designer Drugs in Serum by Comprehensive LCQQQ-MS/MS Analysis. Analytical and Bioanalytical Chemistry, 405 (4):1383-1397.

Swortwood, M. J., Hearn, W. L., and DeCaprio, A. P. (March 2013). Cross-Reactivity of Designer Drugs, Including Cathinone Derivatives, in Commercial Enzyme-Linked Immunosorbent Assays. Accepted to Drug Testing and Analysis. 